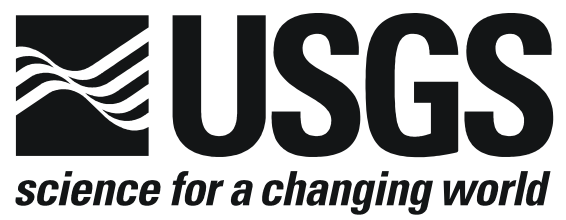

\title{
Magnetotelluric Survey to Locate the Archean/Proterozoic Suture Zone North of Wells, Nevada
}

By Jackie M. Williams and Brian D. Rodriguez

Open-File Report 2006-1119

U.S. DEPARTMENT OF THE INTERIOR

U.S. GEOLOGICAL SURVEY 


\section{U.S. Department of the Interior Gale A. Norton, Secretary \\ U.S. Geological Survey P. Patrick Leahy, Acting Director}

U.S. Geological Survey, Reston, Virginia 2006

Revised and reprinted: 2006

For product and ordering information:

World Wide Web: http://www.usgs.gov/pubprod

Telephone: 1-888-ASK-USGS

For more information on the USGS - the Federal source for science about the Earth, its natural and living resources, natural hazards, and the environment:

World Wide Web: http://www.usgs.gov

Telephone: 1-888-ASK-USGS

Any use of trade, product, or firm names is for descriptive purposes only and does not imply endorsement by the U.S. Government.

Although this report is in the public domain, permission must be secured from the individual copyright owners to reproduce any copyrighted materials contained within this report. 


\section{Contents}

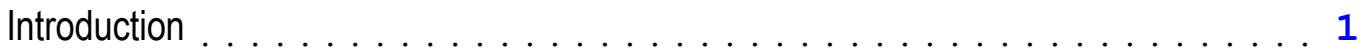

Electrical Rock Properties . . . . . . . . . . . . . . . . . . . . . . 1

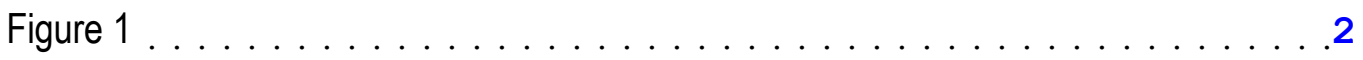

Magnetotelluric Method . . . . . . . . . . . . . . . . . .3

Magnetotelluric Survey $\ldots \ldots \ldots \ldots \ldots \ldots \ldots \ldots \ldots$

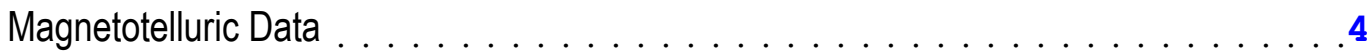

References . .........................

Appendix 1 Magnetotelluric Data Plots . . . . . . . . . . . . . . . . . . . . . 10 


\section{Introduction}

It is important to know whether major mining districts in the Northern Nevada Gold Province are underlain by rocks of the Archean Wyoming craton, which are known to contain orogenic gold deposits (Hausel and Hull, 1990), or by accreted rocks of the Paleoproterozoic Mojave province (Whitmeyer and Karlstrom, 2004). It is also important to know the location and orientation of the Archean/Proterozoic suture zone between these provinces as well as major basement structures within these terranes because they may influence subsequent patterns of sedimentation, deformation, magmatism, and hydrothermal activity (Crafford and Grauch, 2002; Grauch and others, 2003). The Archean was the main gold-mineralization period, and Archean lode-gold deposits were formed at mid-crustal depths along major shear zones (Cameron, 1988).

The nature of the crystalline basement below the Northern Nevada Gold Province and the location of major faults within it are relevant to Rodinian reconstructions, crustal development, and ore deposit models (e.g., Hofstra and Cline, 2000; Grauch and others, 2003). According to Whitmeyer and Karlstrom (2004), the Archean cratons of the northwestern United States and Canada had stabilized as continental lithosphere by $2.5 \mathrm{Ga}$, and were rifted and assembled into a large continental mass by $1.8 \mathrm{Ga}$, to which the 1.73-1.68 Ga Mohave province was accreted by $1.65 \mathrm{Ga}$. The Archean/Proterozoic suture zone has a west-southwest strike where it is exposed (Reed, 1993) at the eastern Utah and southwestern Wyoming border (Cheyenne Belt) where it is characterized by an up to 7-km-thick mylonite zone (Smithson and Boyd, 1998). In the Great Basin, the strike of the Archean/Proterozoic suture zone is poorly constrained because it is largely concealed below a Neoproterozoic-Paleozoic miogeocline and basin fill. East-west and southwest-northeast strikes for the Archean/Proterozoic suture zone have been inferred based on $\mathrm{Sr}, \mathrm{Nd}$, and $\mathrm{Pb}$ isotopic compositions of granitoid intrusions (Tosdal and others, 2000). To better constrain the location and strike of the Archean/Proterozoic suture zone below cover, three regional north-south magnetotelluric (MT) sounding profiles were acquired in western Utah and northeastern Nevada (Williams and Rodriguez, 2003; 2004; 2005), and one east-west MT sounding profile (fig. 1) MT sounding profile was acquired in northeastern Nevada. Resistivity modeling of the MT data can be used to investigate buried structures or sutures that may have influenced subsequent regional fluid flow and localized mineralization. The purpose of this report is to release the MT sounding data collected along the east-west profile in northeastern Nevada; no interpretation of the data is included.

\section{Electrical Rock Properties}

Electromagnetic geophysical methods detect variations in the electrical properties of rocks - in particular, electrical resistivity, or its inverse, electrical conductivity. Electrical resistivity can be correlated with geologic units on the surface and at depth using lithologic logs to provide a three-dimensional (3-D) picture of subsurface geology. In the upper crust the resistivity of geologic units is largely dependent upon their fluid content, pore-volume porosity, interconnected fracture porosity, and conductive mineral content (Keller, 1989). While there is not a one-to-one relationship between lithology and resistivity, there are general correlations that can be made using typical values, even though values can be found at other localities that may fall outside of the ranges 


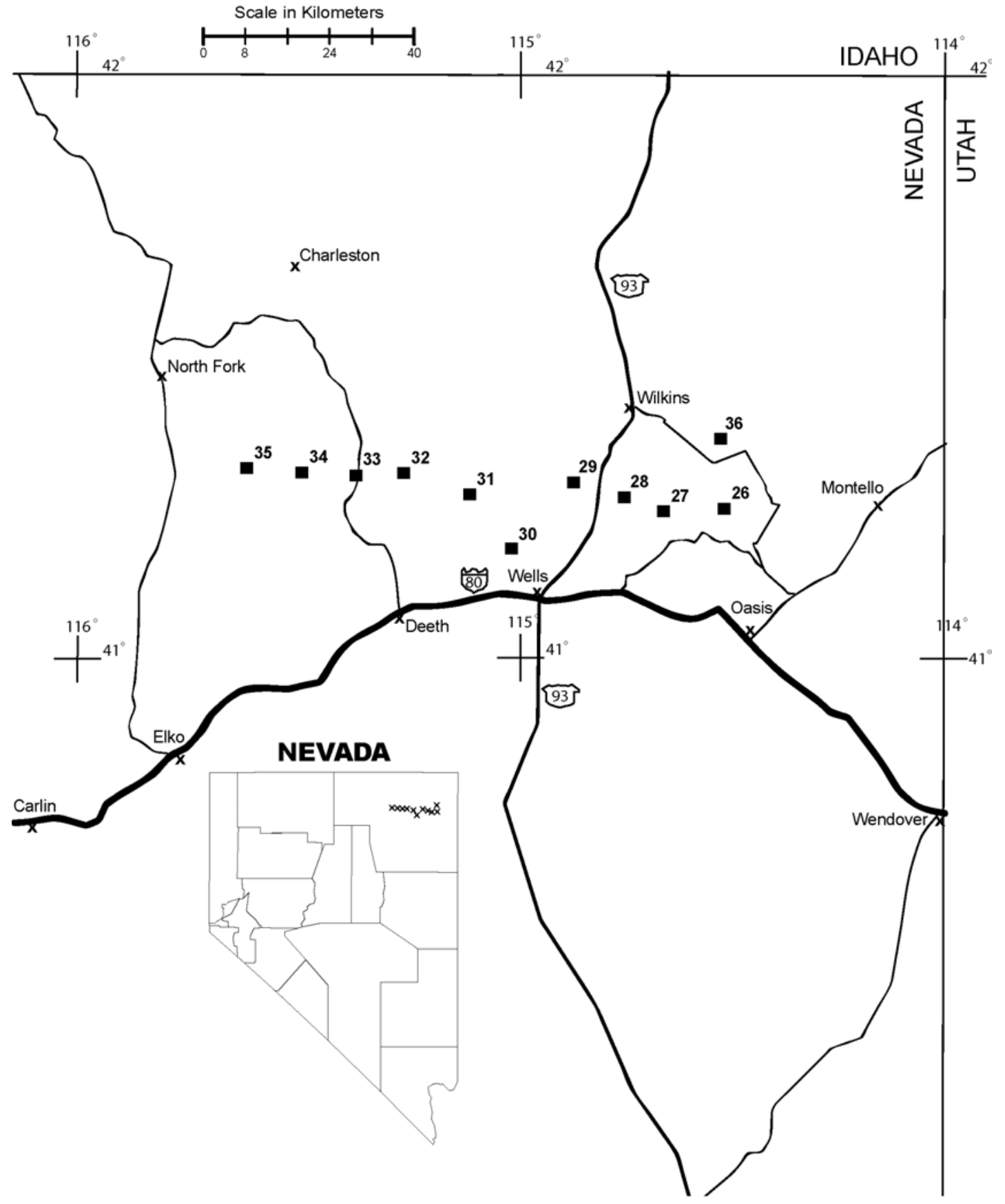

Figure 1. Magnetotelluric (MT) profile index map in north eastern Nevada. MT stations acquired in July 2005 are labeled 26-36. Base map modified from Nevada Bureau of Mines and Geology Topographic Map of Nevada, scale 1:1,000,000 (1972). 
presented below (Palacky, 1987). Fluids within the pore spaces and fracture openings, especially if saline, can reduce resistivities in what would otherwise be a resistive rock matrix. Resistivity can also be lowered by the presence of electrically conductive clay minerals, graphitic carbon, and metallic mineralization. It is common, for example, for altered volcanic rocks to contain replacement minerals that have resistivities ten times lower than those of the surrounding rocks (Nelson and Anderson, 1992). Fine-grained sediments, such as clay-rich alluvium, marine shales, and other mudstones, are normally conductive from a few ohm-m to a few tens of ohm-m (Keller, 1987; Palacky, 1987). Metamorphic rocks (non-graphitic) and unaltered, unfractured igneous rocks are normally moderately to highly resistive (a few hundreds to thousands of ohm-m). Carbonate rocks can have similarly high resistivities depending on their fluid content, porosity, and impurities (Keller, 1987; Palacky, 1987). Fault zones may be moderately conductive (tens of ohm-m) when comprised of rocks fractured enough to have hosted fluid transport and consequent mineralogical alteration (Eberhart-Phillips and others, 1995). Higher subsurface temperatures cause higher ionic mobility that reduces rock resistivities (Keller, 1987; Palacky, 1987). Tables of electrical resistivity for a variety of rocks, minerals and geological environments may be found in Keller (1987) and Palacky (1987).

\section{Magnetotelluric Method}

The MT method is a passive surface electromagnetic geophysical technique that measures variations in the Earth's natural electromagnetic fields to investigate the electrical resistivity structure of the subsurface from depths of tens of meters to tens of kilometers (Vozoff, 1991). Worldwide lightning activity at frequencies of 10,000 to $1 \mathrm{Hertz}(\mathrm{Hz})$ and geomagnetic micro-pulsations at frequencies of 1 to $0.001 \mathrm{~Hz}$ provide the majority of natural signal used by the MT method. The natural electromagnetic wave propagates vertically in the earth due to the large resistivity contrast between the air and the earth causing a vertical refraction of the electromagnetic wave transmitted into the Earth (Vozoff, 1972).

The natural electric and magnetic fields are recorded in two orthogonal, horizontal directions at the Earth's surface (the vertical magnetic field is also recorded). The resulting time-series signals are used to derive tensor apparent resistivities and phases by first converting them to complex cross-spectra using Fourier transform techniques. Least squares, cross-spectral analysis (Bendat and Piersol, 1971) are used to solve for a tensor transfer function. Prior to conversion to apparent resistivity and phase, the tensor is normally rotated into principal directions that usually correspond to the direction of maximum and minimum apparent resistivity. For a two-dimensional (2-D) Earth, in which Earth's resistivity structure varies with depth and in one lateral direction, the MT fields can be decoupled into transverse-electric (TE) and transverse-magnetic (TM) modes; 2-D resistivity modeling is generally computed to fit both modes. When the geology satisfies the 2-D assumption, the MT data for the TE mode represents electric fields oriented parallel to geologic strike, and the data for the TM mode represents electric fields oriented perpendicular to strike. The MT method is well suited for studying complicated geological environments because the electric and magnetic fields are sensitive to vertical and horizontal variations in resistivity. The method is capable of establishing whether the electromagnetic fields are responding to subsurface rock bodies 
of effectively 1, 2, or 3 dimensions. An introduction to the MT method and references for a more advanced understanding are contained in Dobrin and Savit (1988) and Vozoff (1991).

\section{Magnetotelluric Survey}

Eleven MT soundings were collected in July 2005 along a 90-km-long profile in northeastern Nevada (fig. 1) starting just west of Toano Well No. 2, northeast of Wells, Nevada, near the Pequop Siding railroad stop, then continuing westerly and ending just northeast of Contact Ranch. The profile location was selected to cross the Archean/Proterozoic suture zone on the basis of hypothesized projections from MT data to the southeast (Williams and Rodriguez, 2004) and regional interpretations of geologic mapping (Reed, 1993).

Station locations were chosen for proximity to roads and to avoid electrical noise such as power lines. All data at the stations were collected with a portable Electromagnetic Instruments, Inc. (EMI), MT-1 system (EMI, Inc., 1996). Horizontal electric fields were recorded using copper sulfate porous pots placed in an L-shaped, three-electrode array with dipole lengths of 30 meters $(\mathrm{m})$. The orthogonal, horizontal magnetic fields in the direction of the electric-field measurement array were sensed using high magnetic permeability, mu-metal-cored induction coils. Frequencies were sampled from 0.009 to $70 \mathrm{~Hz}$, using single-station recordings of the orthogonal, horizontal components of the electric and magnetic fields and the vertical magnetic field.

The following table lists the $11 \mathrm{MT}$ station locations. Remote reference stations were not used because stations were located remotely from man-made noise sources. Coordinates are referenced to the 1866 Clarke spheroid and North American 1927 Western United States datum. Longitude and latitude format is degrees:minutes:seconds. Universal Transverse Mercator (UTM) units and station elevations are in meters. The accuracy of the north and east component is $\pm 5 \mathrm{~m}$ and is $\pm 10 \mathrm{~m}$ for the elevation. $\mathrm{X}$ direction is in degrees clockwise from True North.

\begin{tabular}{cclllll} 
& \multicolumn{7}{c}{ Table 1 } \\
Station & X Dir. & Longitude & Latitude & North(m) & East(m) & Elevation \\
\hline $\mathbf{3 5}$ & 270 & $-115: 37: 03$ & $41: 19: 31$ & $4,575,574$ & $11,615,704$ & 1724 \\
$\mathbf{3 4}$ & 180 & $-115: 29: 34$ & $41: 19: 06$ & $4,574,981$ & $11,626,160$ & 1908 \\
$\mathbf{3 3}$ & 90 & $-115: 22: 15$ & $41: 18: 49$ & $4,574,636$ & $11,636,356$ & 2094 \\
$\mathbf{3 2}$ & 0 & $-115: 15: 46$ & $41: 19: 01$ & $4,575,175$ & $11,645,417$ & 1735 \\
$\mathbf{3 1}$ & 90 & $-115: 06: 47$ & $41: 16: 49$ & $4,571,384$ & $11,658,025$ & 1739 \\
$\mathbf{3 0}$ & 180 & $-115: 01: 17$ & $41: 11: 16$ & $4,561,283$ & $11,665,936$ & 1716 \\
$\mathbf{2 9}$ & 180 & $-114: 52: 53$ & $41: 18: 06$ & $4,574,203$ & $11,677,371$ & 1866 \\
$\mathbf{2 8}$ & 90 & $-114: 46: 02$ & $41: 16: 33$ & $4,571,553$ & $11,687,006$ & 1962 \\
$\mathbf{2 7}$ & 270 & $-114: 40: 42$ & $41: 15: 09$ & $4,569,181$ & $11,694,513$ & 1899 \\
$\mathbf{2 6}$ & 180 & $-114: 32: 28$ & $41: 15: 23$ & $4,570,132$ & $11,705,926$ & 1783 \\
$\mathbf{3 6}$ & 270 & $-114: 32: 55$ & $41: 22: 33$ & $4,583,177$ & $11,704,999$ & 1709 \\
\hline
\end{tabular}

\section{Magnetotelluric Data}

The recorded time-series data were converted to the frequency domain and processed to determine both the impedance tensor, which is used to derive apparent 
resistivities, and phase tensor at each site. Rotation of the impedance tensor to maximum and minimum directions allowed for decoupling into the TE and TM modes.

Although remote reference techniques were not used in the study, cross-power files were sorted to select optimal signal-to-noise time-series data sets (see Appendix 1).

The effects of near-surface resistivity anomalies can give rise to "static shifts" in the data (Sternberg and others, 1988) that can be modeled with two-dimensional forward modeling in the near surface. Static shifts were significant at stations 33, 29, 28, 27, and 36. Cultural features can affect the response of the MT system. Fences, pipelines, communication lines, moving vehicles and trains, and other manmade sources of electromagnetic noise can contaminate the responses.

The figures in Appendix 1 represent the field-processed MT data for each station after the time-series data were converted to the frequency domain, and after the tensor-transfer function was rotated into principal directions as described in the "Magnetotelluric Method" section of this report.

For each station, nine separate plots are given:

1. Apparent Resistivity ( $\mathrm{x}$ and o symbols are $\mathrm{xy}$ and $\mathrm{yx}$ components)

2. Impedance Phase ( $\mathrm{x}$ and o symbols are $\mathrm{xy}$ and $\mathrm{yx}$ components)

3. Impedance Skew

4. Multiple Coherency ( $\mathrm{x}$ and o symbols are $\mathrm{xy}$ and $\mathrm{yx}$ components)

5. Impedance Polar Plots

6. Tipper Magnitude

7. Tipper Strike

8. HzHx (x symbol) and HzHy (o symbol) Coherency

Error bars (],[) on the Apparent Resistivity, Impedance Phase, Skew, Tipper Magnitude, and Tipper Strike plots represent probable errors within one standard deviation of the sample variance (Gamble and others, 1979).

Apparent resistivity is the ratio of the electric field strength magnitude over the magnetic field strength magnitude for a given frequency. The impedance phase is proportional to the slope of the apparent-resistivity curve on a log-log plot, relative to a baseline at -45 degrees (Vozoff, 1991). A measure of the dimensionality for MT data is provided by the impedance skew of the impedance tensor (Vozoff, 1972). If the effective, measured resistivity response to the geology beneath an MT station is truly one- or two-dimensional, then the skew will be zero. Both instrument and environmental sources of noise contribute to non-zero skew values but are typically small (about 0.1 ) for relatively low-noise-level recordings. Higher skews (more than 0.2) indicate either the resistivity response to 3-D geology or higher levels of noise.

In the study area, noise from a number of small power lines and small moving vehicles was negligible at distances of $0.4 \mathrm{~km}$ and farther from the noise source. Power-line amplitude levels were measured at each site and were typically less than 20 percent of the maximum recordable signals. Noise from larger power lines, power generators, pipelines, and trains was negligible at distances more than $5 \mathrm{~km}$. Local lightning, wind, and rainstorms also can degrade data quality, but these were avoided by not recording during active thunderstorm periods. Burying the magnetic induction coils and keeping the electric dipole wires flat on the ground helped to minimize wind noise. 
Predicted values of the electric field can be computed from the measured values of the magnetic field (Vozoff, 1991). The coherence of the predicted electric field with the measured electric field is a measure of the signal-to-noise ratio provided in the multiple coherency plots. Values are normalized between 0 and 1 , where values at 0.5 signify signal levels equal to noise levels. For this data set, coherencies generally were at an acceptable level, except at times in the frequency "dead band" (0.01 to $5 \mathrm{~Hz}$ ) (Dobrin and Savit, 1988).

The figures in Appendix 1 represent the field-processed MT data at each station, and include some data scatter and poor signal-to-noise ratios. The only effort aimed at removing noisy data points was to visually inspect and select the best signal-to-noise field data to combine into the final data plots.

The impedance polar plots provide a measure of the MT data dimensionality (Reddy and others, 1977). For 1-D resistivity structures, the principal impedance (off-diagonal elements) polar diagram (dashed line) is a circle. For 2-D or 3-D resistivity structures, the principal impedance polar diagram (dashed line) elongates either parallel to or perpendicular to strike direction. Over resistors, the principal impedance polar diagram elongates perpendicular to strike direction, while over conductors, the principal impedance polar diagram elongates parallel to strike direction. For 2-D resistivity structures, the additional impedance polar diagram (solid line) attains the shape of a symmetric clover leaf. For 3-D resistivity structures, the additional impedance polar diagram (solid line) elongates in one direction, and its amplitude is comparable to that of the principal impedance polar diagram (dashed line), although high noise levels can produce the same effect on the polar diagram. A 3-D analysis of polar plots at each frequency should also take into account the corresponding coherence and skew values along with their associated error levels. The polar plots computed for our data show station 35 was moderately 3-D below $0.05 \mathrm{~Hz}$. Stations 33 and 32, were weakly 3-D below $0.05 \mathrm{~Hz}$. Station 31 was moderately 3-D below $0.1 \mathrm{~Hz}$. Station 29 was weakly 3-D below $0.2 \mathrm{~Hz}$. Because of noise, station 27 is difficult to interpret but is possibly 3-D below $1 \mathrm{~Hz}$. Station 36 was moderately 3-D below $0.2 \mathrm{~Hz}$. Station 28 was 3-D over all frequencies.

The tipper can be calculated from the vertical component of the magnetic field. The tipper magnitude is a measure of the tipping of the magnetic field out of the horizontal plane (Vozoff, 1991). The magnitude is zero for the 1-D case, typically increases between 0.1 to 0.5 , and rarely is as great as 1 as it responds to vertical and subvertical structures. The tipper strike typically is used to help resolve the 90 -degree ambiguity in the impedance rotation angle. The tipper magnitude of these stations typically ranged between 0.1 and 0.6 over the lower frequencies, indicating some vertical structure at depth. The HzHx and HzHy coherency is a measure of the signal-to-noise ratio of the vertical magnetic field with respect to each of the orthogonal, horizontal magnetic field directions. Values are normalized between 0 and 1 , where values of 0.5 signify signal levels equal to noise levels. These three components of magnetic-field coherence provide a check on the quality of the measured values in the tipper magnitude and tipper strike plots. 


\section{References}

Bendat, J.S., and Piersol, A.G., 1971, Random data-analysis and measurement procedures: New York, Wiley Interscience, 407 p.

Cameron, E.M., 1988, Archean gold: relation to granulite formation and redox zoning in the crust: Geology, v. 16, p. 109-112.

Crafford, A.E.J., and Grauch, V.J.S., 2002, Geologic and geophysical evidence for the influence of deep crustal structures on Paleozoic tectonics and the alignment of world class gold deposits, north-central Nevada, USA: Ore Geology Reviews, vol. 21, p. 157-184.

Dobrin, M.D., and Savit, C.H., 1988, Introduction to Geophysical Prospecting (4th ed.): New York, McGraw-Hill, 867 p.

Eberhart-Phillips, Donna, Stanley, W.D., Rodriguez, B.D., and Lutter, W.J., 1995, Surface seismic and electrical methods to detect fluids related to faulting: Journal of Geophysical Research, v. 100, no. B7, p. 12,919-12,936.

EMI, Inc., 1996, MT-1 magnetotelluric system operation manual, version 3.2: Richmond, Calif., Electromagnetic Instruments, Inc., 220 p.

Gamble, T.D., Goubau, W.M., and Clarke, J., 1979, Error analysis for remote reference magnetotellurics: Geophysics, v. 44, no. 5, p. 959-968.

Grauch, V.J.S, Rodriguez, B.D., and Wooden, J.L., 2003, Geophysical and isotopic constraints on crustal structure related to mineral trends in north-central Nevada and implications for tectonic history: Economic Geology and the Bulletin of the Society of Economic Geologists, v. 98, no. 2, p. 269-286.

Hausel, W.D. and Hull, J., 1990, Guide to gold mineralization and Archean geology of the South Pass greenstone belt, Wind River Range, Wyoming, in Roberts, S., ed.: Geologic Field Tours of Western Wyoming and Parts of Adjacent Idaho, Montana and Utah, Public Information Circular, Geological Survey of Wyoming, vol. 29, p. 179-191.

Hofstra, A.H. and Cline, J.S., 2000, Characteristics and models for Carlin-type gold deposits, Chapter 5: in Hagemann, S.G. and Brown, P.E., eds., Gold in 2000, Reviews in Economic Geology, v. 13, p. 163-220.

Keller, G.V., 1987, Rock and mineral properties, in Nabighian, M.N., ed., Electromagnetic Methods in Applied Geophysics Theory: Tulsa, Okla., Society of Exploration Geophysicists, v. 1, p. 13-51. 
Keller, G.V., 1989, Electrical properties, in Carmichael, R.S., ed., Practical Handbook of Physical Properties of Rocks and Minerals: Boca Raton, Fla., CRC Press, p. 359-427.

Nelson, P.H., and Anderson, L.A., 1992, Physical properties of ash flow tuff from Yucca Mountain, Nevada: Journal of Geophysical Research, v. 97, no. B5, p. 6,823-6,841.

Palacky, G.J., 1987, Resistivity characteristics of geologic targets, in Nabighian, M.N., ed., Electromagnetic Methods in Applied Geophysics Theory: Tulsa, Okla., Society of Exploration Geophysicists, v. 1, p. 53-129.

Reddy, I.K., Rankin, David, and Phillips, R.J., 1977, Three-dimensional modelling in magnetotelluric and magnetic variational sounding: Geophysical Journal of the Royal Astronomical Society, v. 51, p. 313-325.

Reed, J.C., 1993, Precambrian rocks of the conterminous United States, in The Geology of North America: Geological Society of America, v. C-2, plate 1.

Smithson, S B., and Boyd, N.K., 1998, Geophysical constraints on the deep structure of the Cheyenne belt, Southeastern Wyoming, in Karlstrom, K.E., ed.: Lithospheric structure and evolution of the Rocky Mountains, Part I, Rocky Mountain Geology, vol. 33, no. 2, p. 279-292.

Sternberg, B.K., Washburne, J.C., and Pellerin, Louise, 1988, Correction for the static shift in magnetotellurics using transient electromagnetic soundings: Geophysics, v. 53, p. 1,459-1,468.

Tosdal, R.M., Wooden, J.L, and Kistler, R.W., 2000, Geometry of the Neoproterozoic continental break-up, and implications for location of Nevadan mineral belts, in Geology and Ore Deposits 2000: The Great Basin and Beyond, Symposium Proceedings: Cluer, J.K., Price, J.G., Struhsacker, R.F., Hardyman, R.F., and Morris, C.L., eds., Geological Society of Nevada, Reno, Nevada, v. I, p. 451-466.

Vozoff, Keeva, 1972, The magnetotelluric method in the exploration of sedimentary basins: Geophysics, v. 37, p. 98-141.

Vozoff, Keeva, 1991, The magnetotelluric method, in Nabighian, M.N., Electromagnetic Methods in Applied Geophysics: Tulsa, Oklahoma, Society of Exploration Geophysicists, v. 2, pt. B, p. 641-711.

Whitmeyer, S.J., and Karlstrom, K., 2004, Progressive Proterozoic growth of southern Laurentia by magmatic stabilization of lithosphere: Geological Society of America Abstracts with Programs, Denver, Co., vol. 36, no. 5, p. 404. 
Williams, J.M., and Rodriguez, B.D., 2003, Magnetotelluric data release for locating the Archean/Proterozoic suture zone, east central Tooele County, Utah: U.S. Geological Survey Open-File Report 03-495, 119 p. (http://pubs.usgs.gov/of/2003/ofr-03-495/)

Williams, J.M., and Rodriguez, B.D., 2004, Magnetotelluric survey to locate the Archean/Proterozoic suture zone in northeastern Nevada: U.S. Geological Survey Open-File Report 2004-1215, 212 p. (http://pubs.usgs.gov/of/2004/1215)

Williams, J.M., and Rodriguez, B.D., 2005, Magnetotelluric survey to locate the Archean/Proterozoic suture zone in north-central Elko County, Nevada: U.S. Geological Survey Open-File Report 2005-1255, 184 p. (http://pubs.usgs.gov/of/2005/1255) 


\section{Appendix 1 Magnetotelluric Data Plots}

There are nine separate plots for each station:

1. Apparent Resistivity for the unrotated xy (x symbol) and yx (o symbol) modes

2. Impedance Phase for the unrotated $x y(x$ symbol) and yx (o symbol) modes

3. Impedance Skew for the impedance tensor

4. Multiple Coherency for the xy (x symbol) and minimum (o symbol) modes of the electric field

5. Impedance Polar Plots (at 12 selected frequencies)

6. Tipper Magnitude for the vertical magnetic field

7. Tipper Strike for the vertical magnetic field

8. HzHx (x symbol) and HzHy (o symbol) Coherency

Refer to the "Magnetotelluric Data" section in this report for an explanation of these plots. 
Double Mt., NV 100k

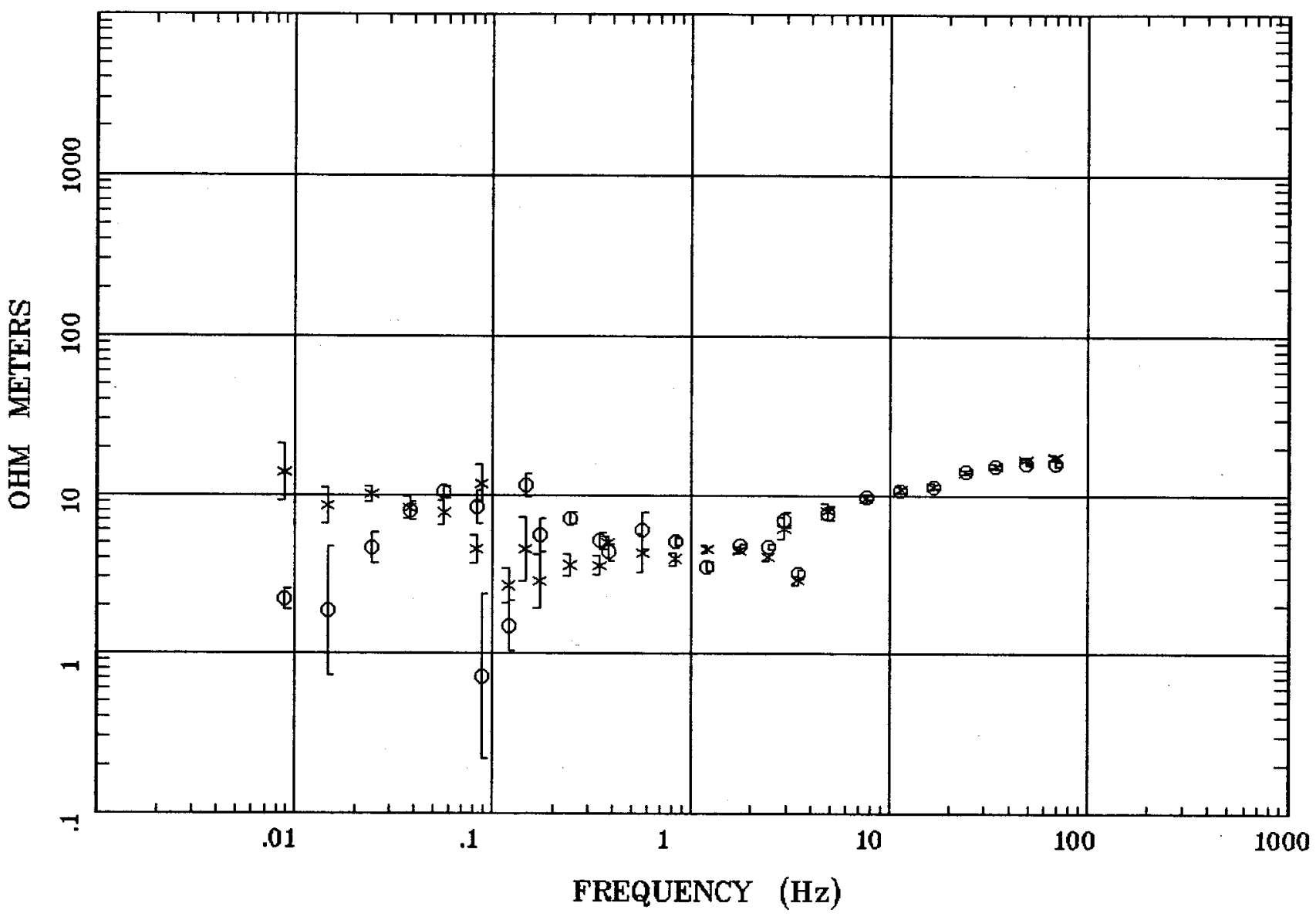

Client:

Remote: none

Acquired: $15: 4$ Jul 12,2005

Survey Co:USGS
Rotation:

Filename: ap35m.avg

Channels: Ch1 Ch2 Ch3 Ch4 Ch5 Ch3 Ch4 Plotted: '08:46 Jul 19, 2005

< EMI - ElectroMagnetic Instruments > 
Station 35

IMPEDANCE PHASE

Double Mt., NV 100k

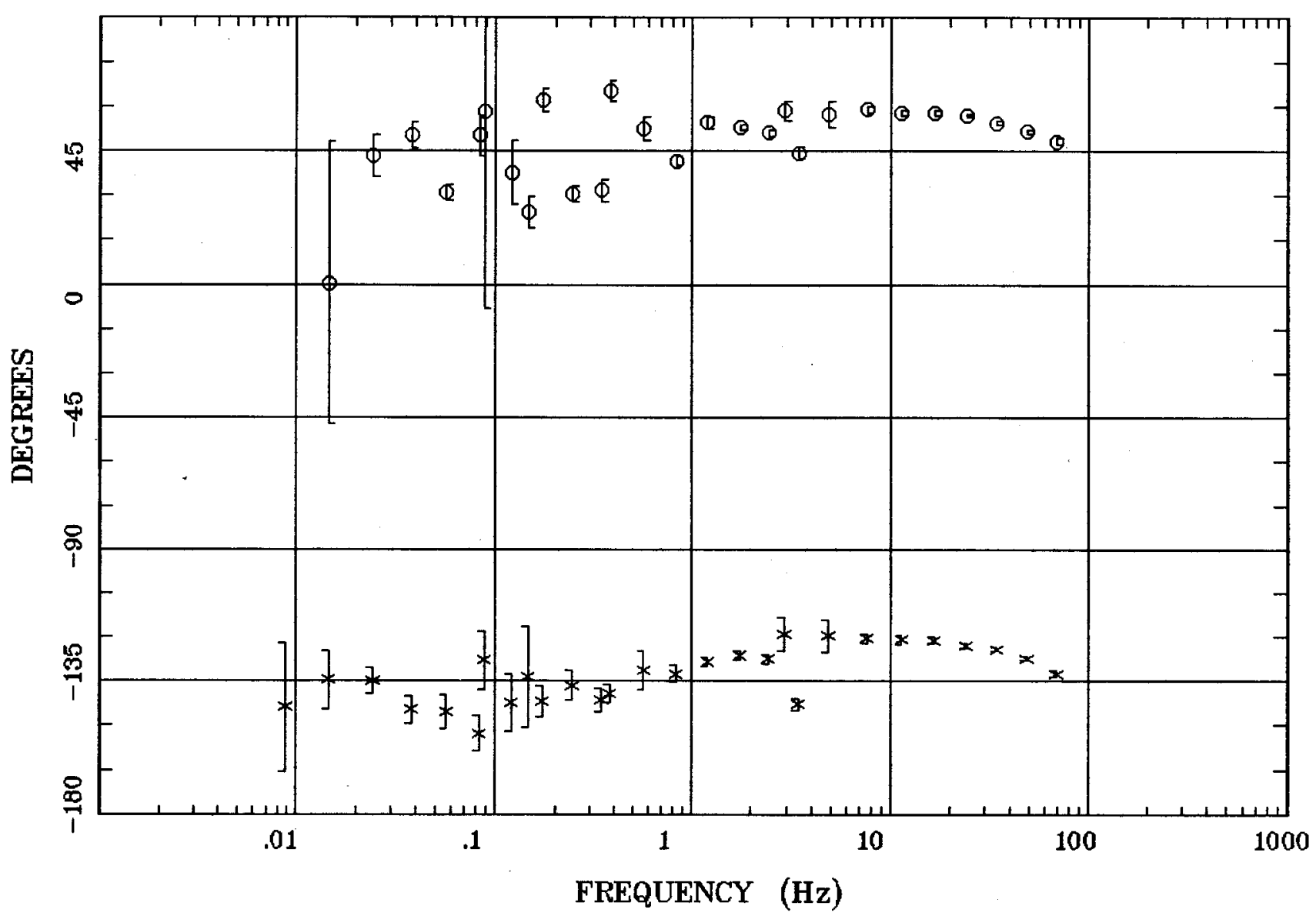

Client:

Remote: none

Acquired: 15:4 Jul 12, 2005 Survey Co:USGS
Rotation:

Filename: ap35m.avg

Channels: Ch1 Ch2 Ch3 Ch4 Ch5 Ch3 Ch4 Plotted: 08:46 Jul 19, 2005

$<$ EMI - ElectroMagnetic Instruments 
IMPEDANCE SKEW

Double Mt., NV 100k

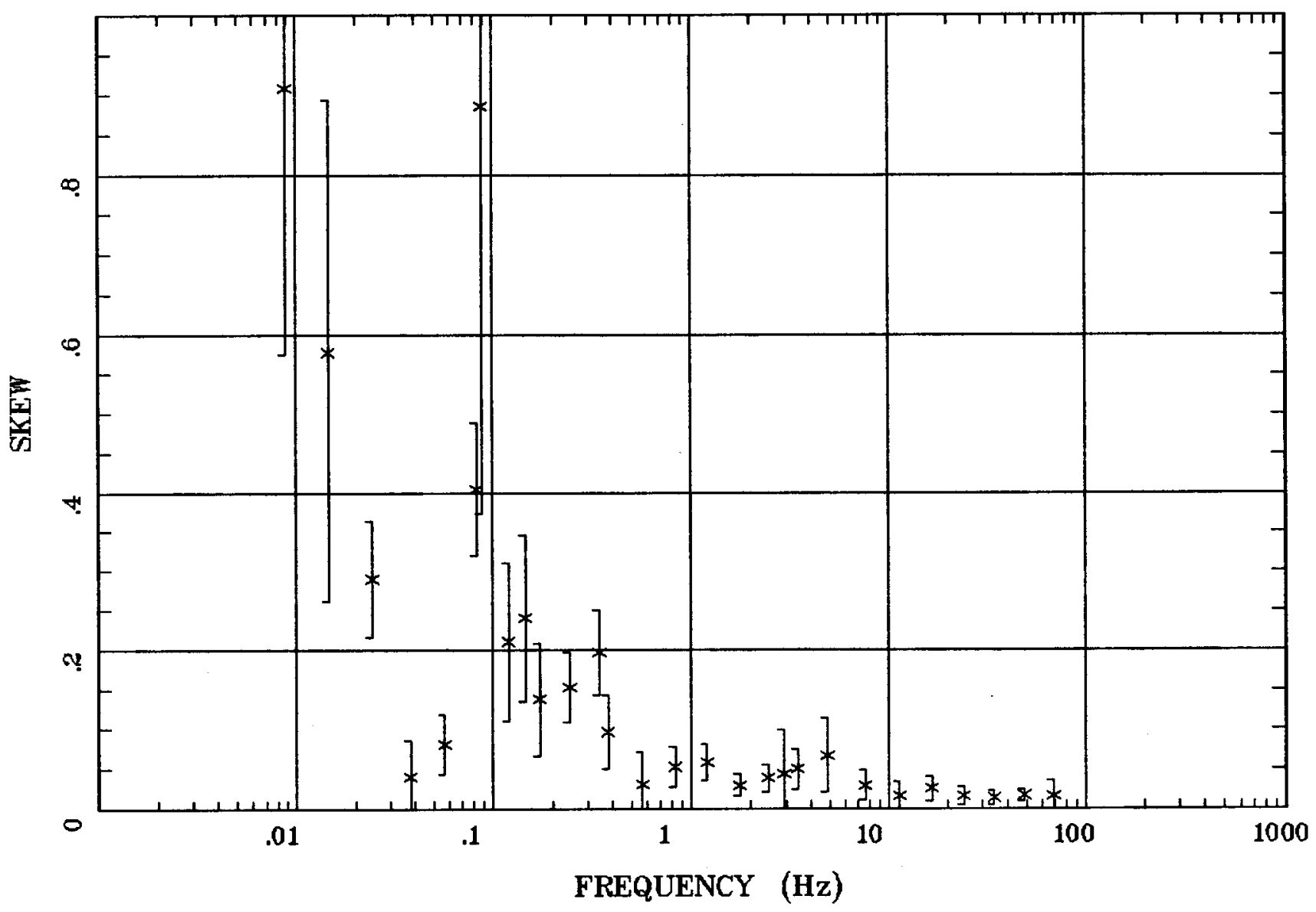

Client:

Remote: none

Acquired: 15:4 Jul 12, 2005 Survey Co:USGS
Rotation:

Filename: ap35m.avg

Channels: Ch1 Ch2 Ch3 Ch4 Ch5 Ch3 Ch4

Plotted: 08:46 Jul 19, 2005

$<$ EMI - ElectroMagnetic Instruments > 


\section{E MULT Coh.}

Double Mt., NV 100k

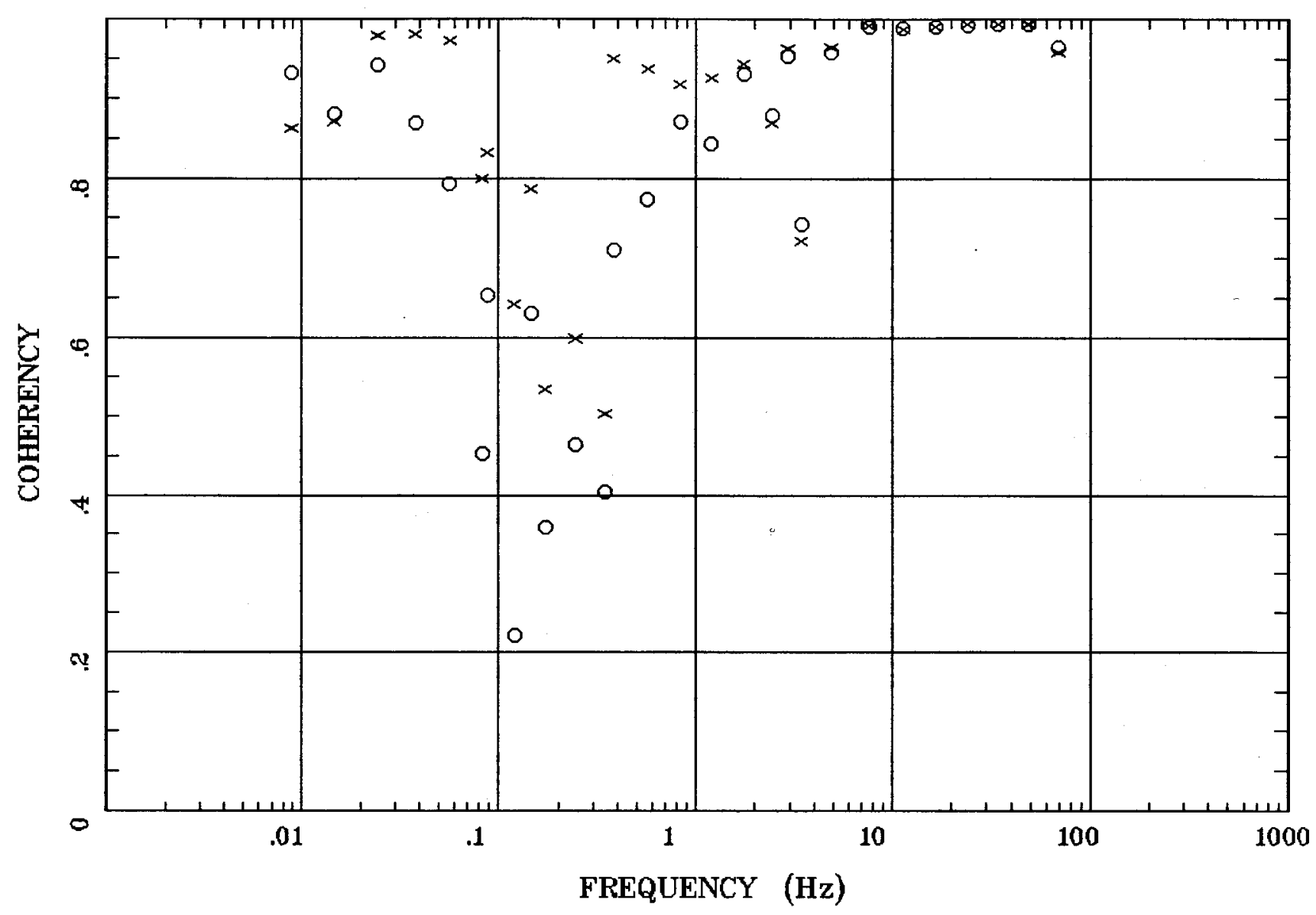

Client:

Remote: none Acquired: 15:4 Jul 12, 2005 Survey Co:USGS
Rotation:

Filename: ap35m.avg

Channels: Ch1 Ch2 Ch3 Ch4 Ch5 Ch3 Ch4 Plotted: 08:46 Jul 19, 2005

$<$ EMI - ElectroMagnetic Instruments 


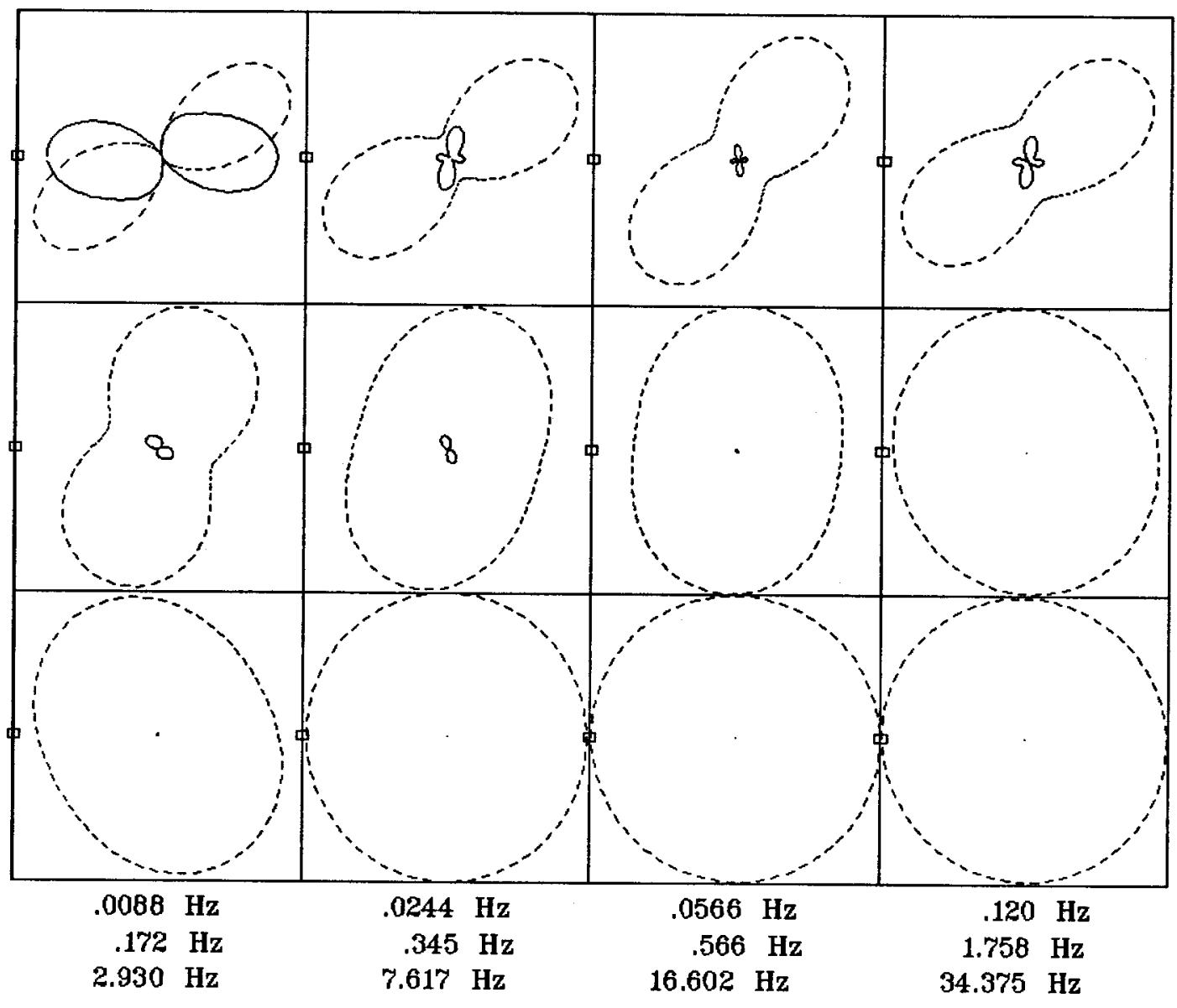

Client:

Remote: none

Acquired: 15:4 Jul 12, 2005

Survey Co:USGS
Rotation:

Filename: ap35m.avg

Channels: Ch1 Ch2 Ch3 Ch4 Ch5 Ch3 Ch4 Plotted: 08:46 Jul 19, 2005

$<$ EMI - ElectroMagnetic Instruments > 


\section{Station 35}

TIPPER MAGNITUDE

Double Mt., NV 100k

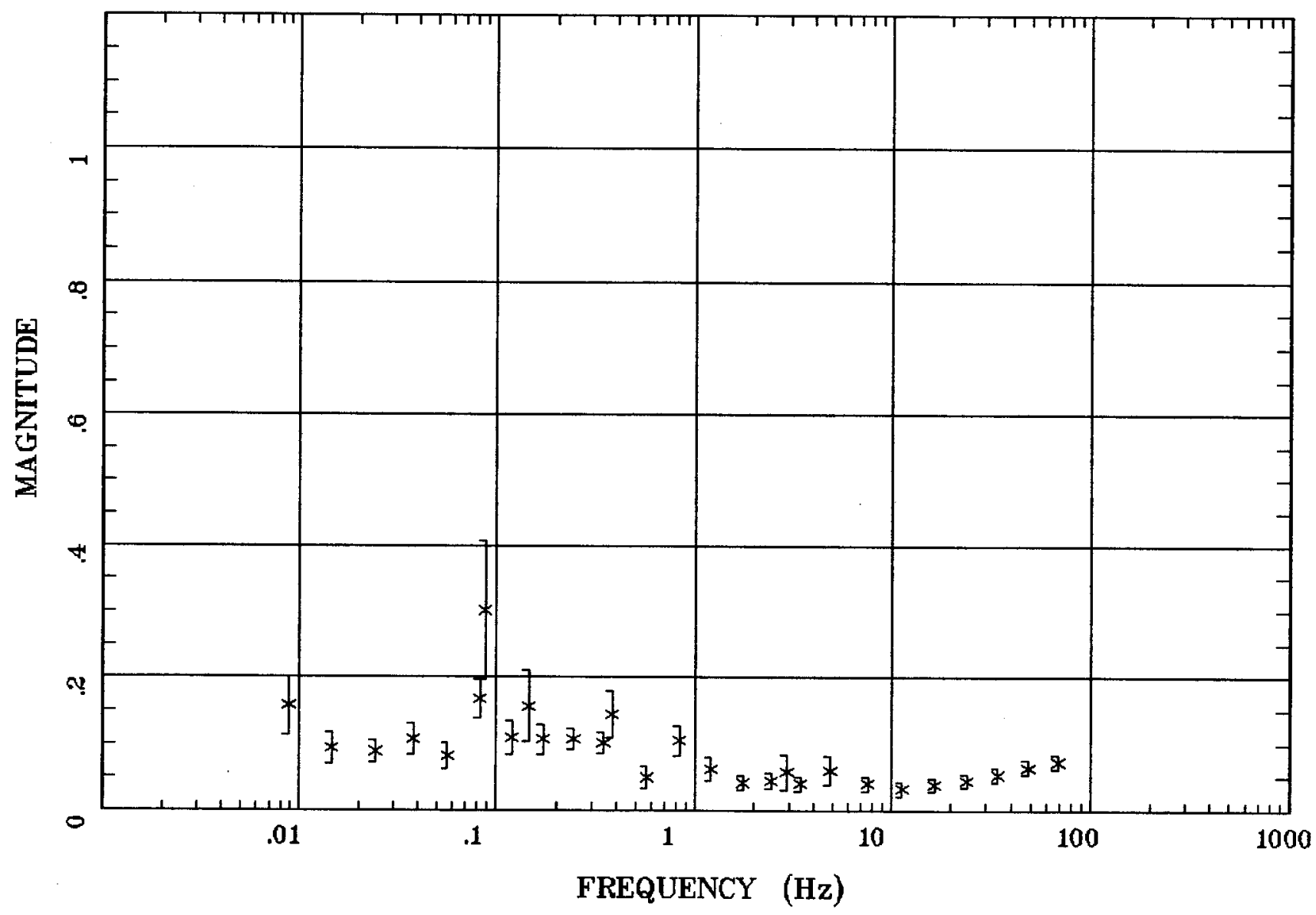

Client:

Remote: none

Acquired: 15:4 Jul 12, 2005 Survey Co:USGS
Rotation:

Filename: ap $35 \mathrm{~m}$.avg

Channels: Ch1 Ch2 Ch3 Ch4 Ch5 Ch3 Ch4

Plotted: 08:46 Jul 19, 2005

$<$ EMI - ElectroMagnetic Instruments > 


\section{Station 35}

TIPPER STRIKE

Double Mt., NV 100k

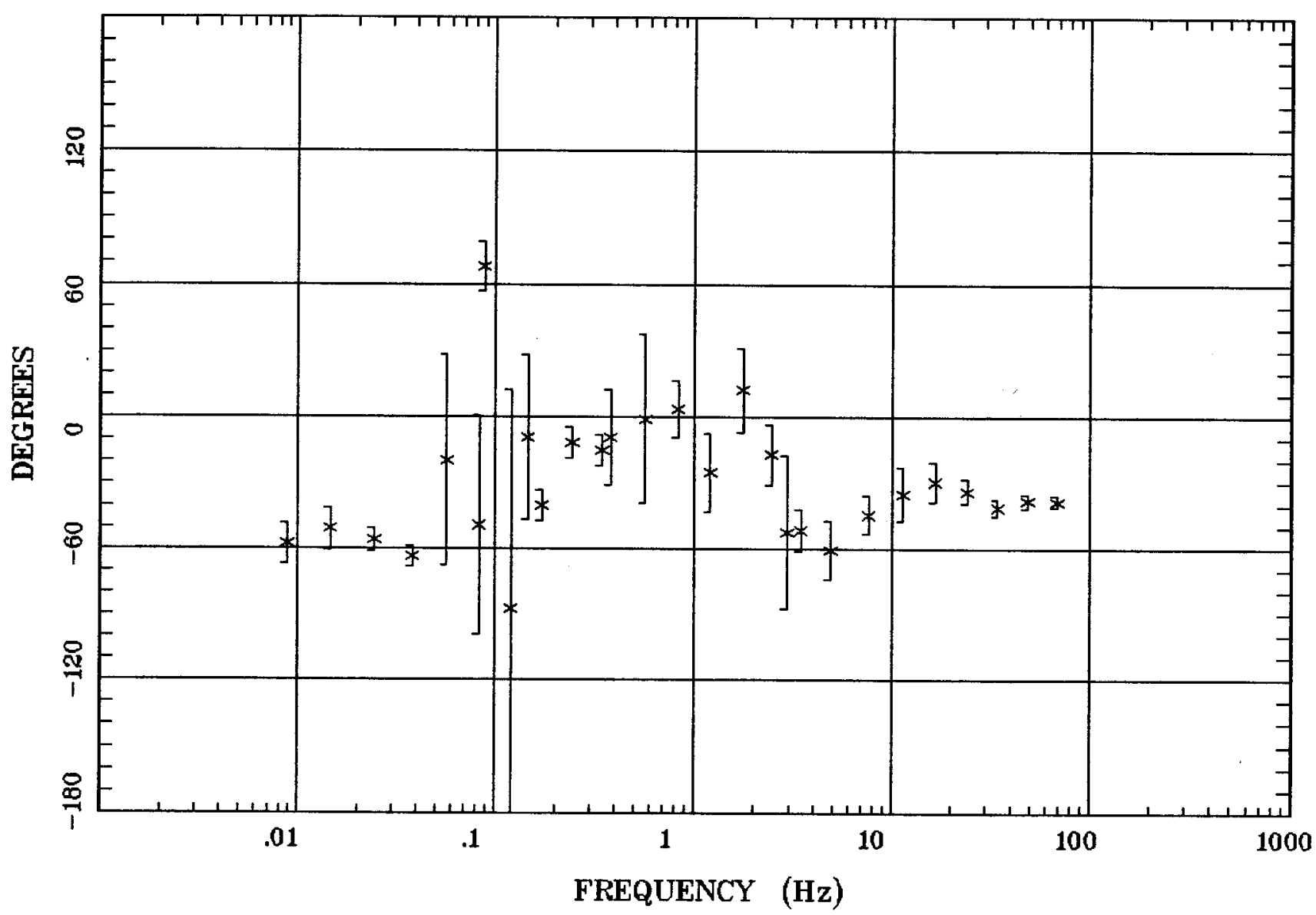

Client:

Remote: none

Acquired: 15:4 Jul 12, 2005

Survey Co:USGS
Rotation:

Filename: ap35m.avg

Channels: Ch1 Ch2 Ch3 Ch4 Ch5 Ch3 Ch4 Plotted: 08:46 Jul 19, 2005

< EMI - ElectroMagnetic Instruments > 
HzHx.x Coh HzHy.o

Double Mt., NV 100k

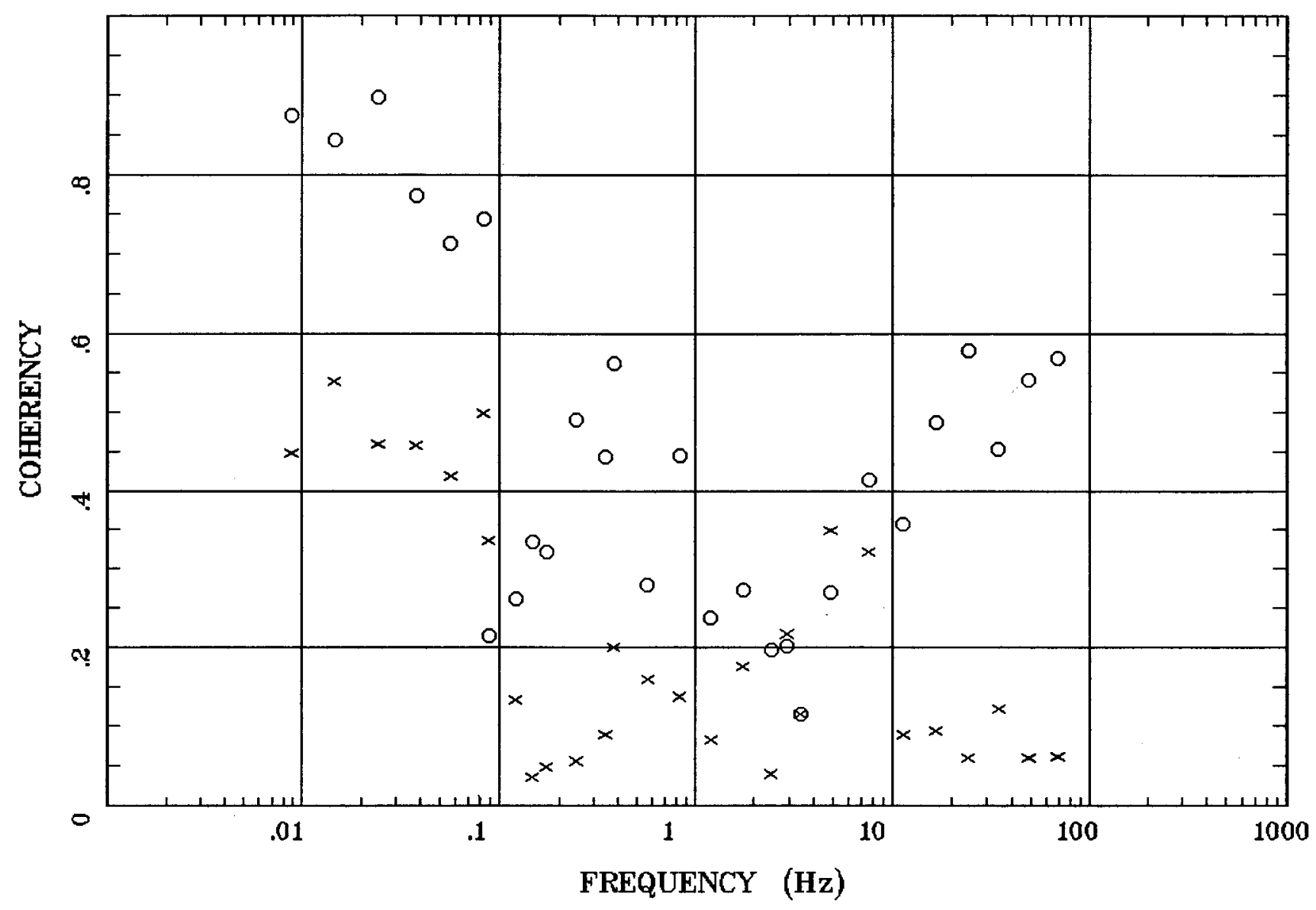

Client:

Remote: none

Acquired: 15:4 Jul 12, 2005 Survey Co:USGS
Rotation:

Filename: ap35m.avg

Channels: Ch1 Ch2 Ch3 Ch4 Ch5 Ch3 Ch4 Plotted: 08:46 Jul 19, 2005

$<$ EMI - ElectroMagnetic Instruments 
Station 34

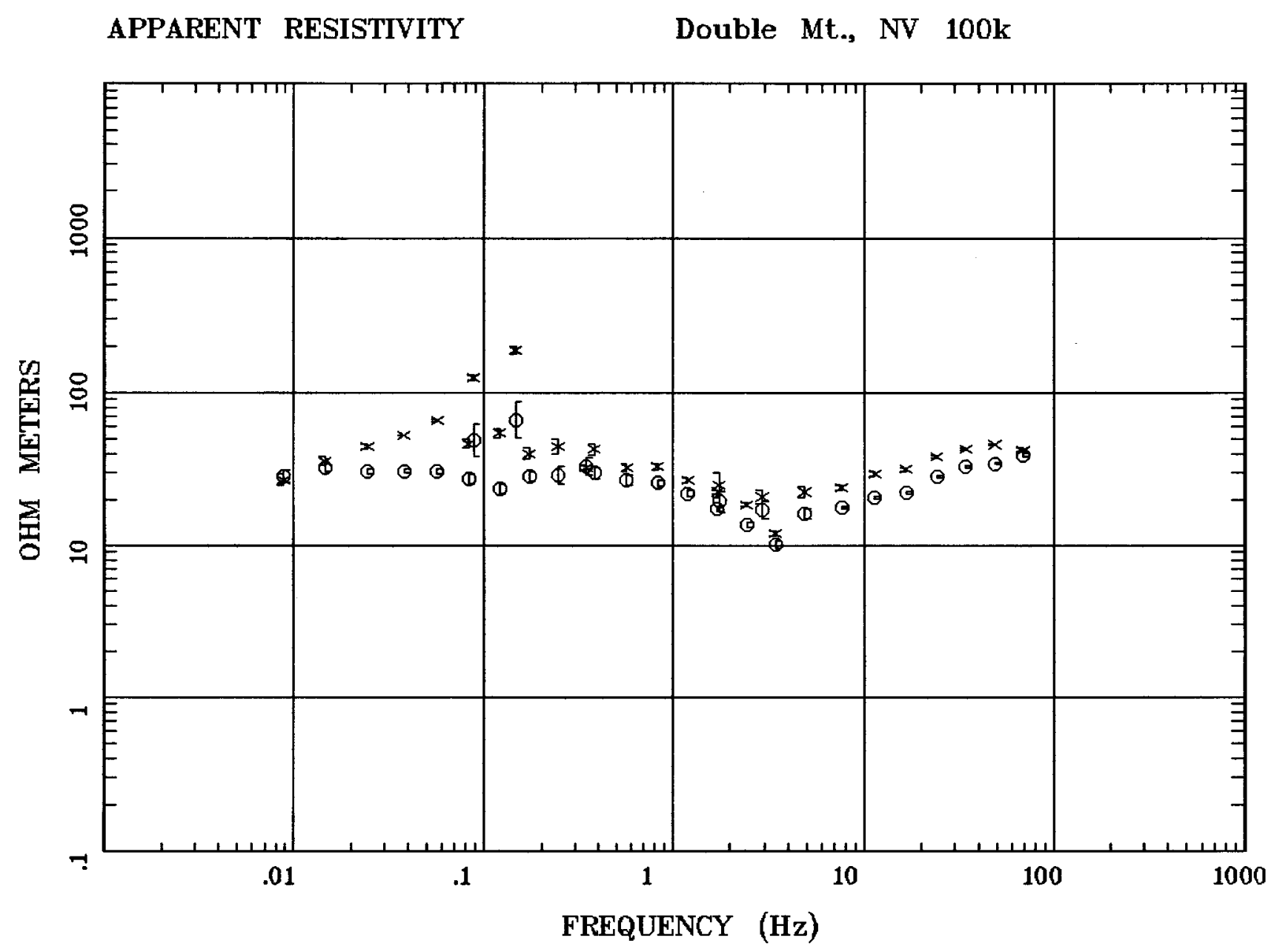

Client:

Remote: none

Acquired: 11:0 Jul 12, 2005

Survey Co:USGS
Rotation:

Filename: ap34mall.avg

Channels: Ch1 Ch2 Ch3 Ch4 Ch5 Ch3 Ch4 Plotted: 14:27 Jul 20, 2005

< EMI - ElectroMagnetic Instruments > 
Station 34

IMPEDANCE PHASE

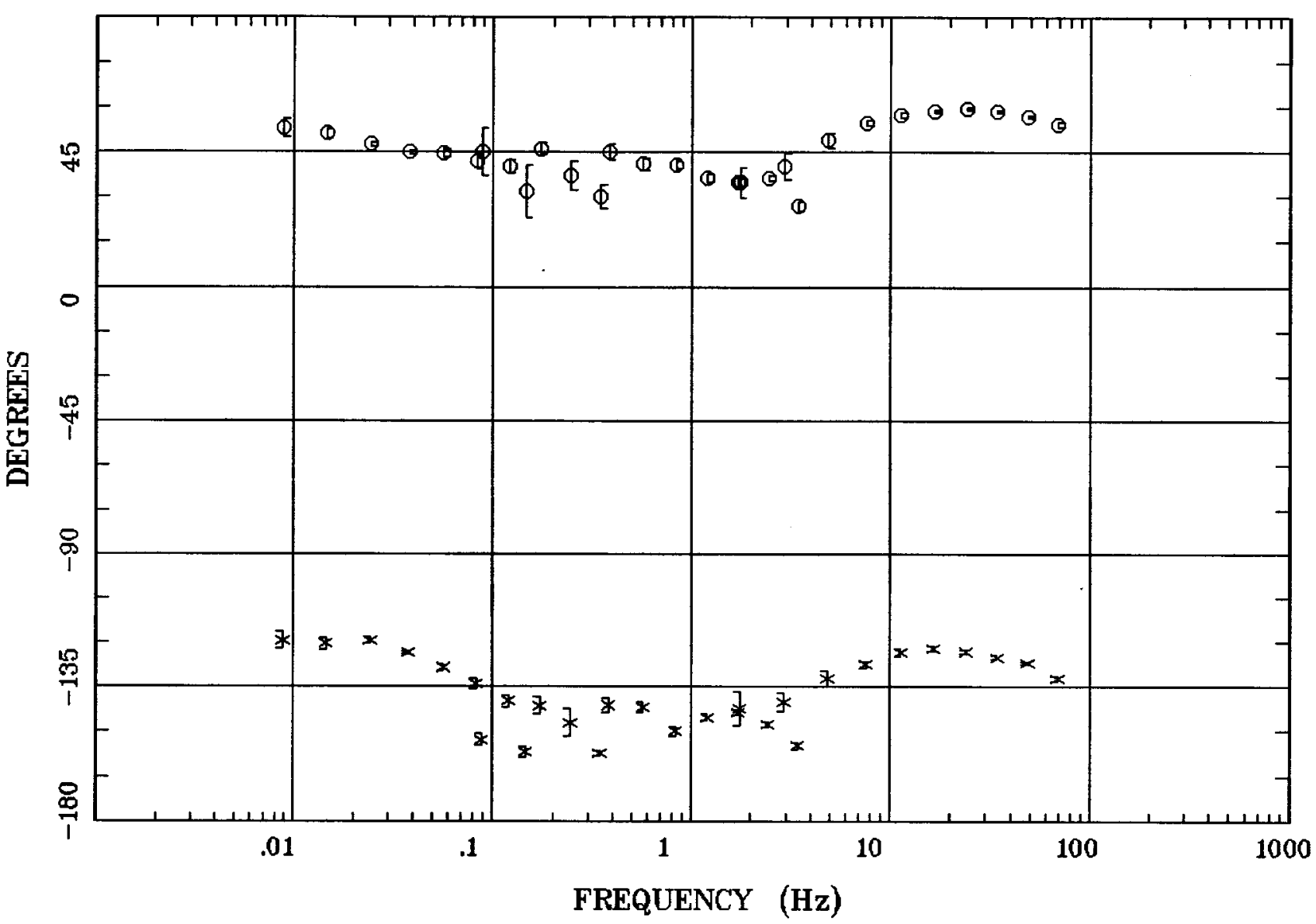

Client:

Remote: none

Acquired: 11:0 Jul 12, 2005

Survey Co:USGS
Double Mt., NV 100k

Rotation:

Filename: ap34mall.avg

Channels: Ch1 Ch2 Ch3 Ch4 Ch5 Ch3 Ch4

Plotted: 14:27 Jul 20, 2005

< EMI - ElectroMagnetic Instruments > 
Station 34

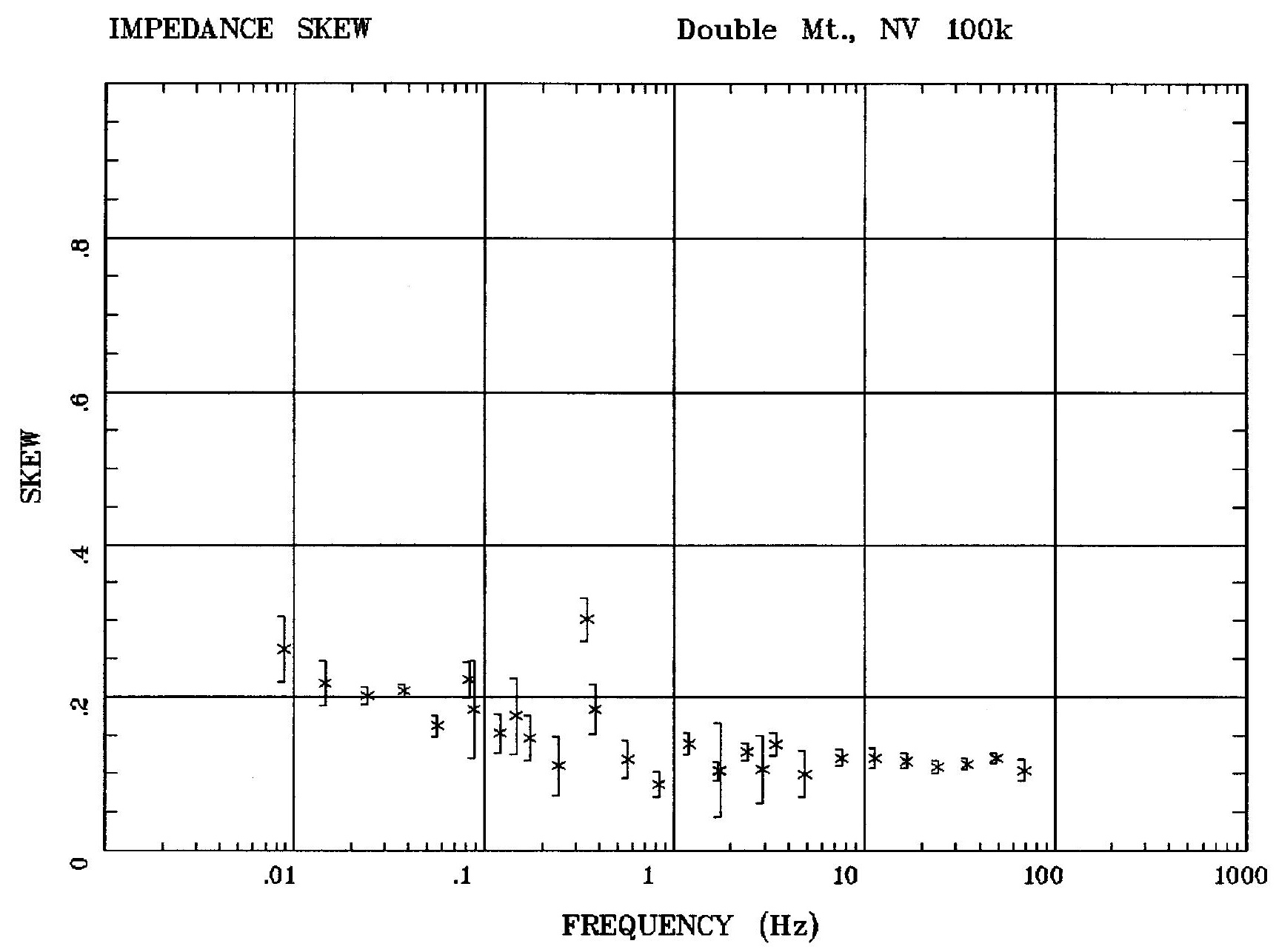

Client:

Remote: none

Acquired: 11:0 Jul 12, 2005

Survey Ca:USGS
Rotation:

Filename: ap34mall.avg

Channels: Ch1 Ch2 Ch3 Ch4 Ch5 Ch3 Ch4

Plotted: 14:27 Jul 20, 2005

< EMI - ElectroMagnetic Instruments > 
Station 34

E MULT Coh.

Double Mt., NV 100k

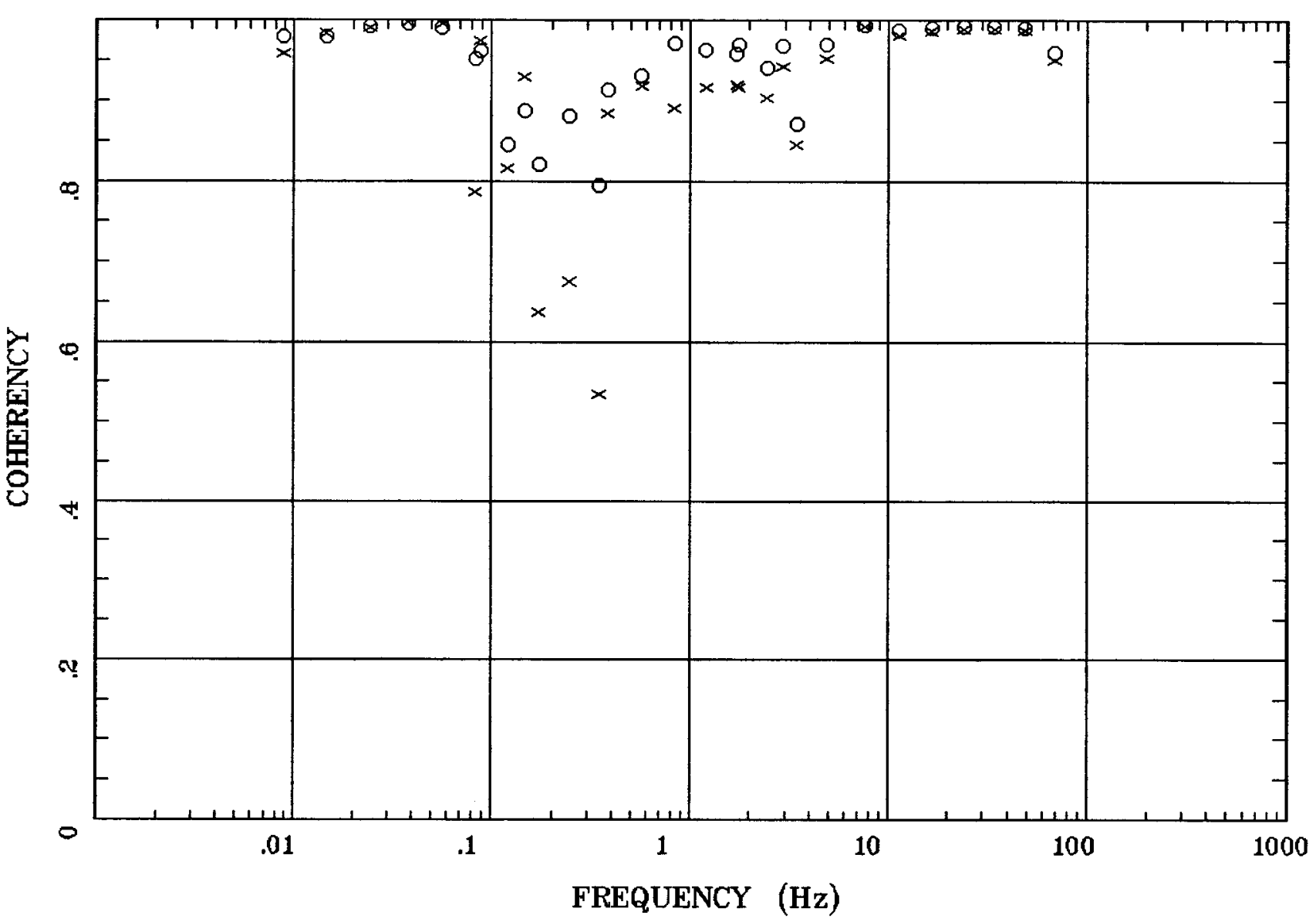

Client:

Rotation:

Remote: none

Acquired: 11:0 Jul 12, 2005

Survey Co:USGS
Filename: ap34mall.avg

Channels: Ch1 Ch2 Ch3 Ch4 Ch5 Ch3 Ch4

Plotted: 14:27 Jul 20, 2005

< EMI - ElectroMagnetic Instruments > 
Double Mt., NV 100k

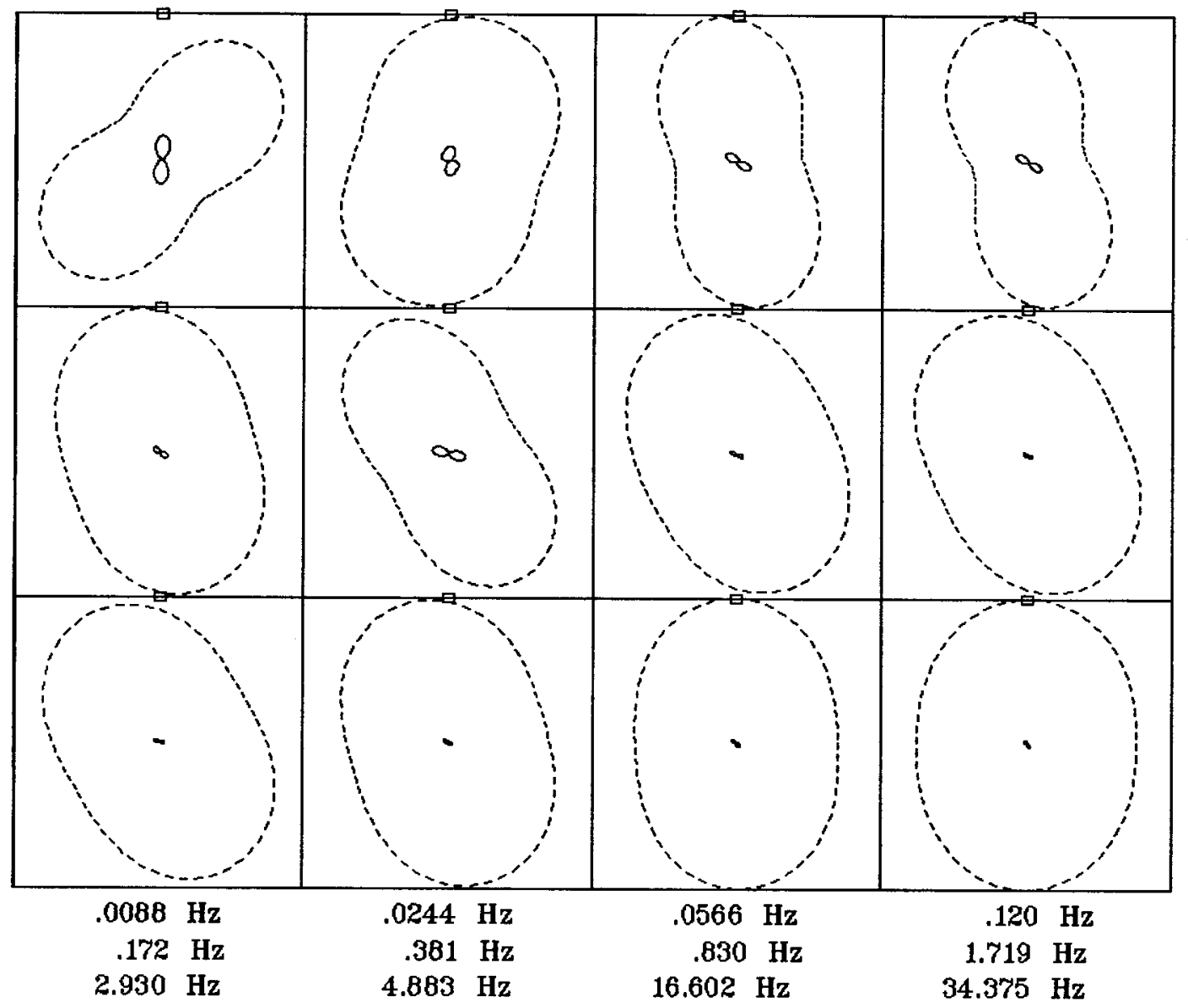

Client:

Remote: none

Acquired: 11:0 Jul 12, 2005 Survey Co:USGS
Rotation:

Filename: ap34mall.avg

Channels: Ch1 Ch2 Ch3 Ch4 Ch5 Ch3 Ch4 Plotted: 14:27 Jul 20, 2005

< EMI - ElectroMagnetic Instruments 
Station 34

TIPPER MAGNITUDE

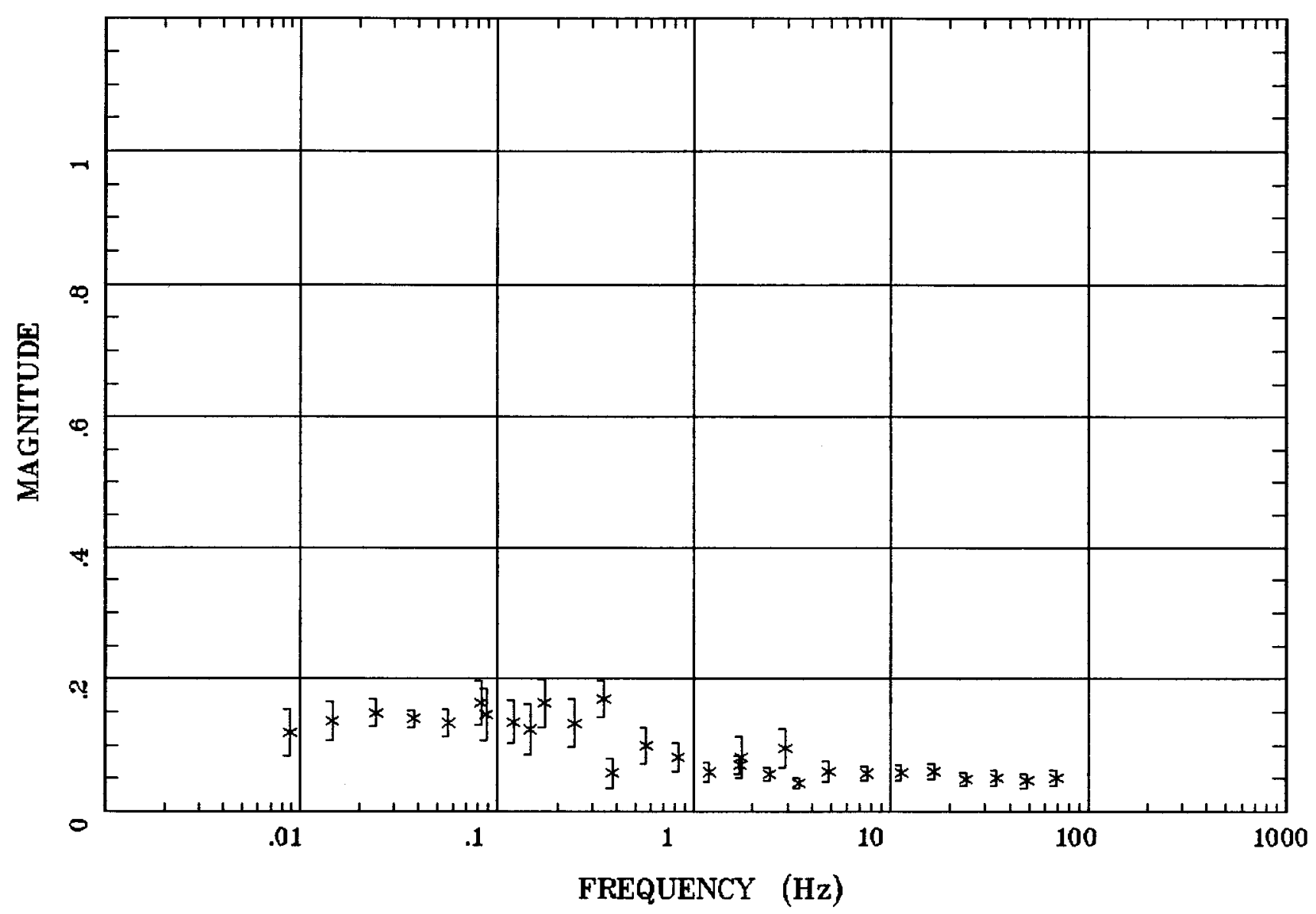

Client:

Remote: none

Acquired: 11:0 Jul 12, 2005

Survey Co:USGS
Rotation:

Filename: ap34mall.avg

Channels: Ch1 Ch2 Ch3 Ch4 Ch5 Ch3 Ch4

Plotted: 14:27 Jul 20, 2005

$<$ EMI - ElectroMagnetic Instruments 
TIPPER STRIKE

Double Mt., NV 100k

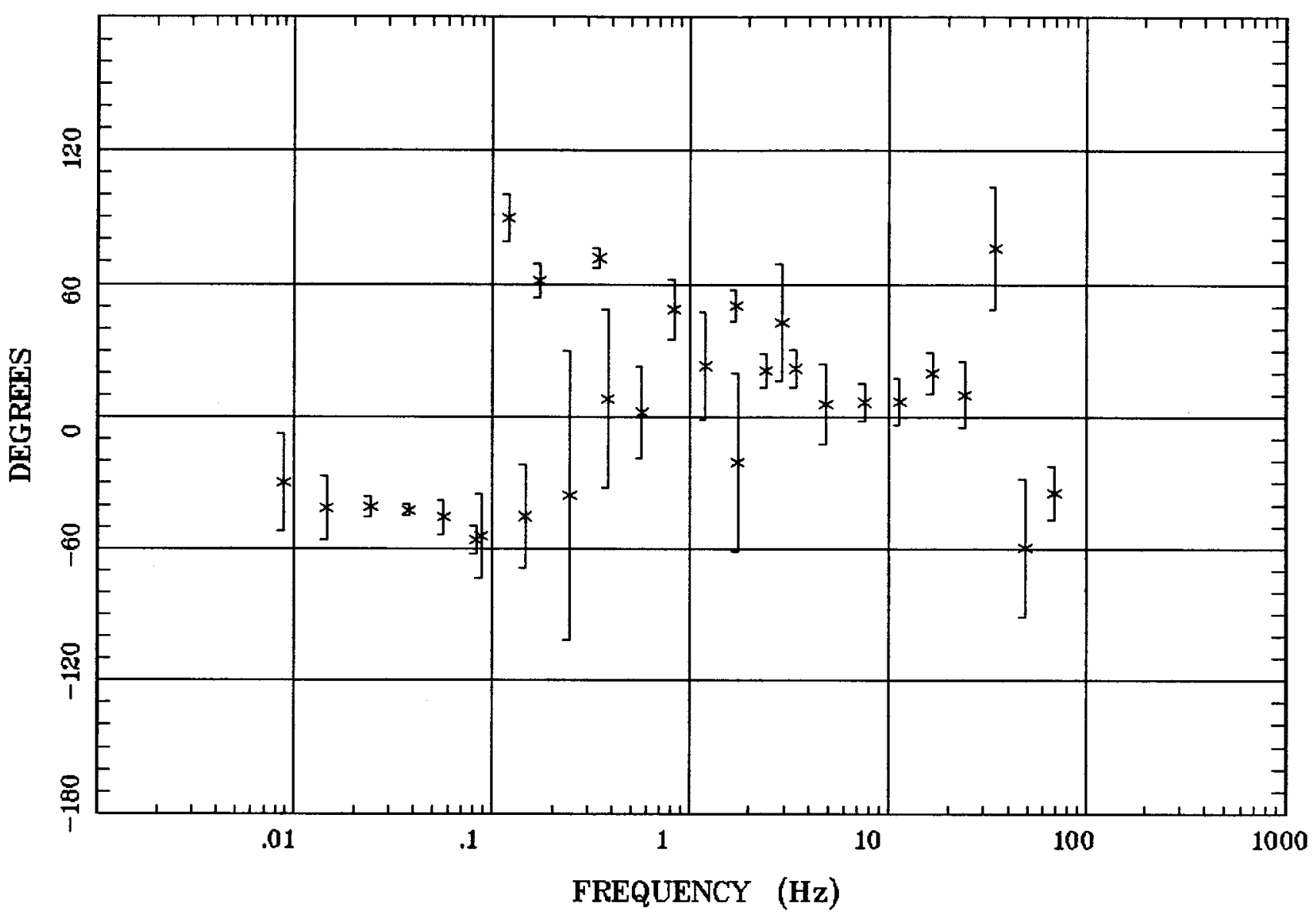

Client:

Remote: none Acquired: 11:0 Jul 12, 2005 Survey Co:USGS
Rotation:

Filename: ap34mall.avg

Channels: Ch1 Ch2 Ch3 Ch4 Ch5 Ch3 Ch4 Plotted: 14:27 Jul 20, 2005

< EMI - ElectroMagnetic Instruments 


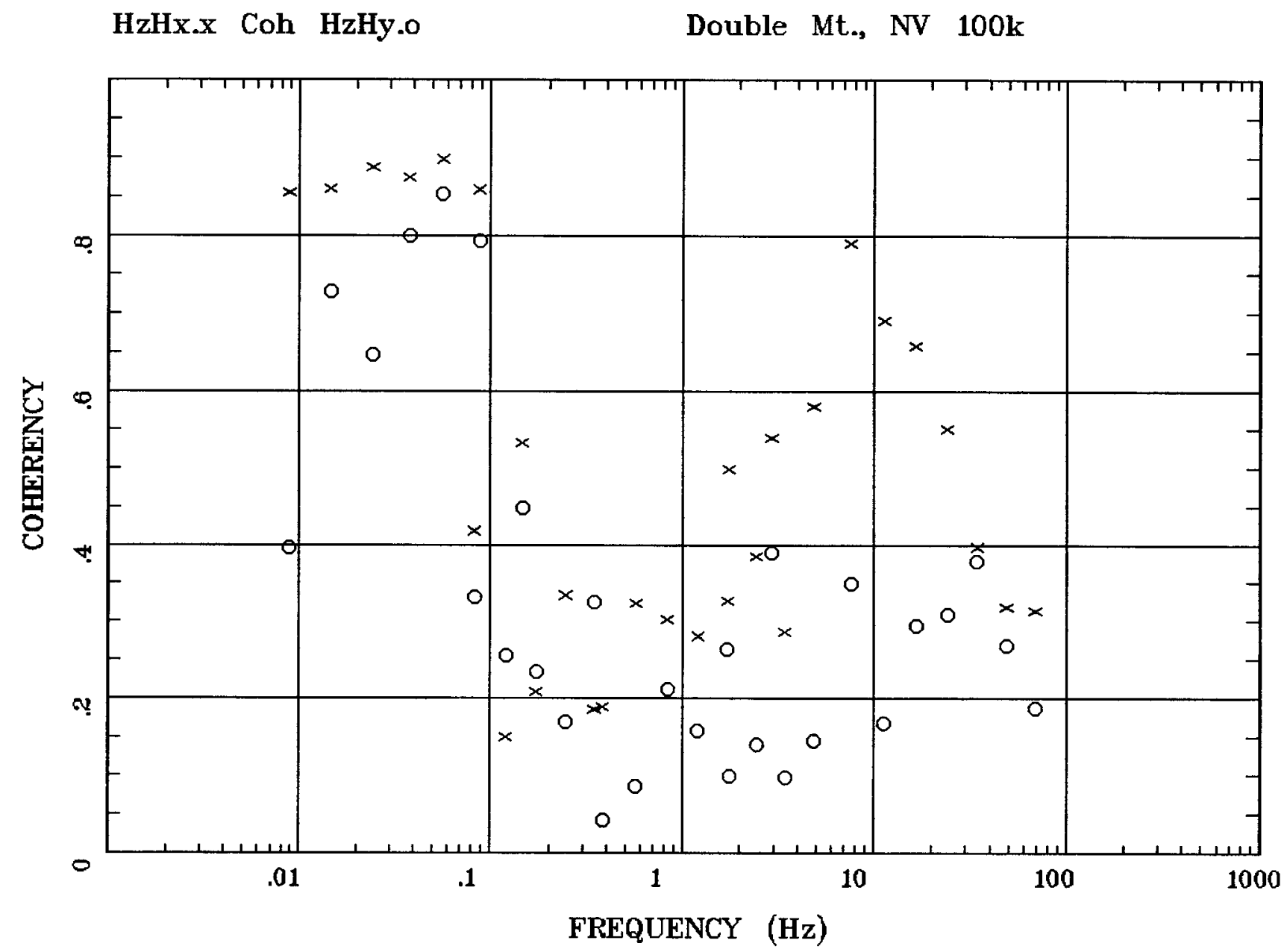

Client:

Remote: none

Acquired: 11:0 Jul 12, 2005

Survey Co:USGS

Rotation:

Filename: ap34mall.avg

Channels: Ch1 Ch2 Ch3 Ch4 Ch5 Ch3 Ch4

Plotted: 14:27 Jul 20, 2005

< EMI - ElectroMagnetic Instruments > 
APPARENT RESISTIVITY

Double Mt., NV 100k

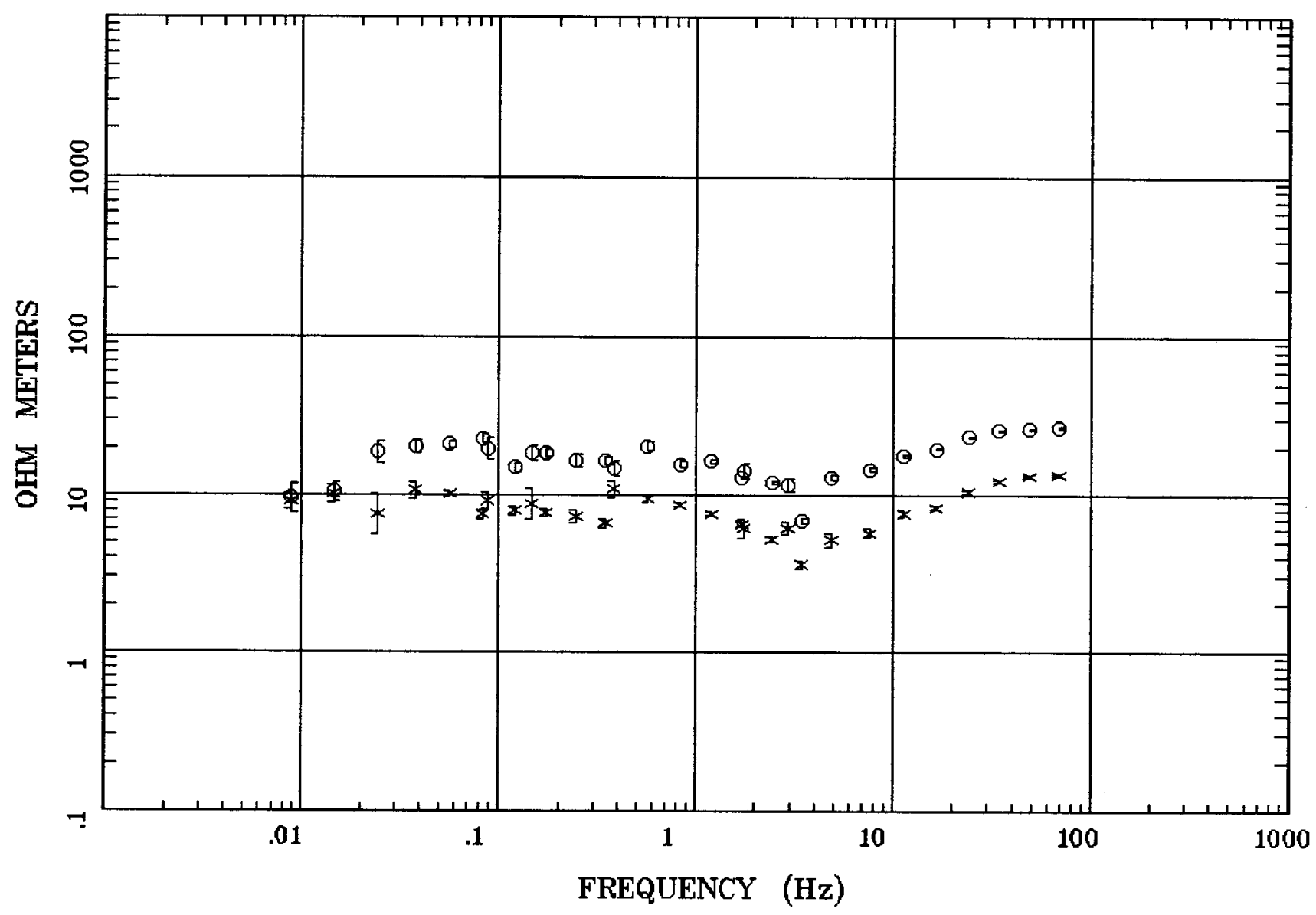

Client:

Remote: none

Acquired: 15:0 Jul 11, 2005 Survey Co:USGS
Rotation:

Filename: ap33mall.avg

Channels: Ch1 Ch2 Ch3 Ch4 Ch5 Ch3 Ch4 Plotted: 14:27 Jul 20, 2005

< EMI - ElectroMagnetic Instruments 
Station 33

IMPEDANCE PHASE

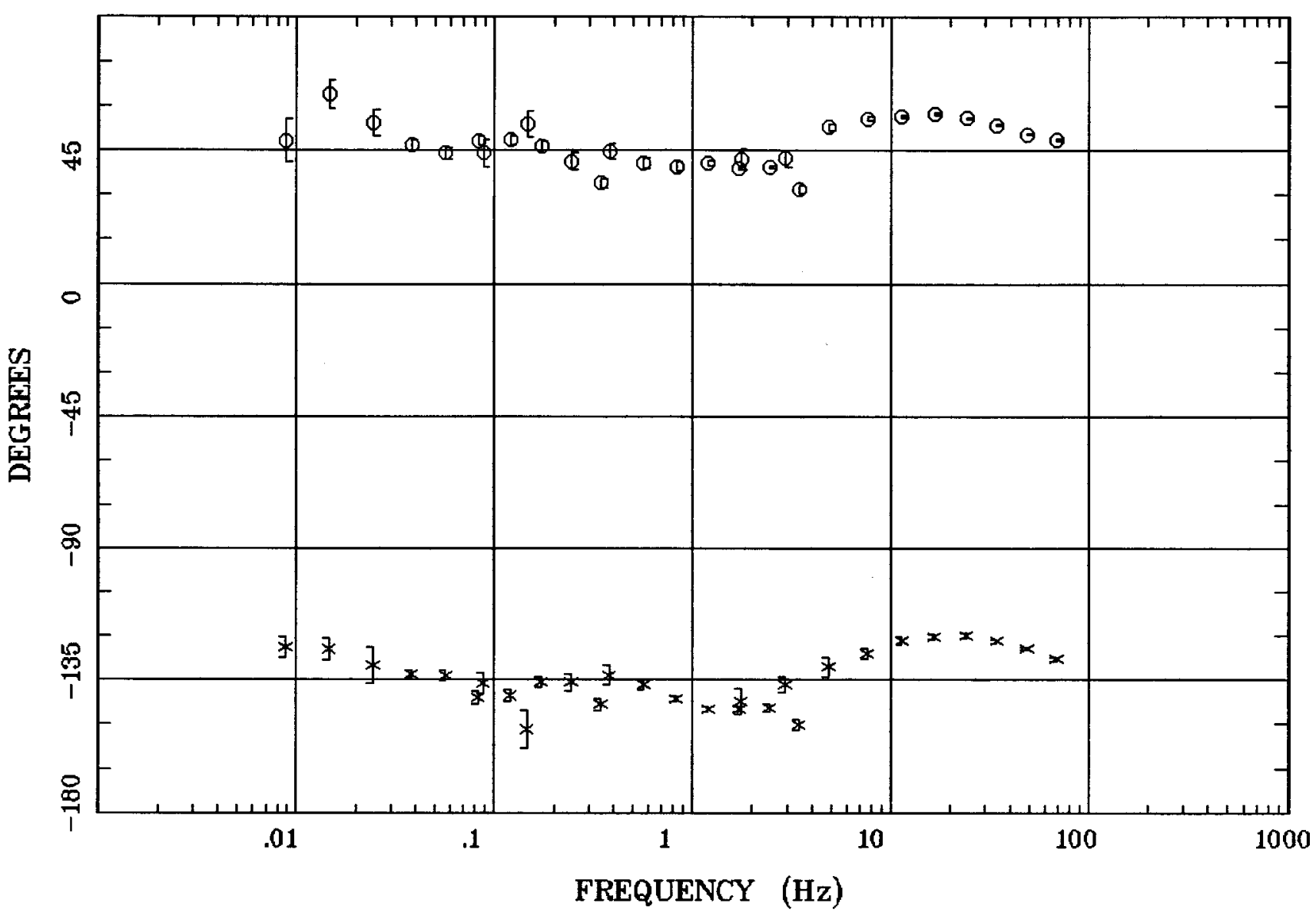

Client:

Remote: none

Acquired: 15:0 Jul 11, 2005 Survey Co:USGS
Rotation:

Filename: ap33mall.avg

Channels: Ch1 Ch2 Ch3 Ch4 Ch5 Ch3 Ch4

Plotted: 14:27 Jul 20, 2005

< EMI - ElectroMagnetic Instruments > 
Double Mt., NV 100k

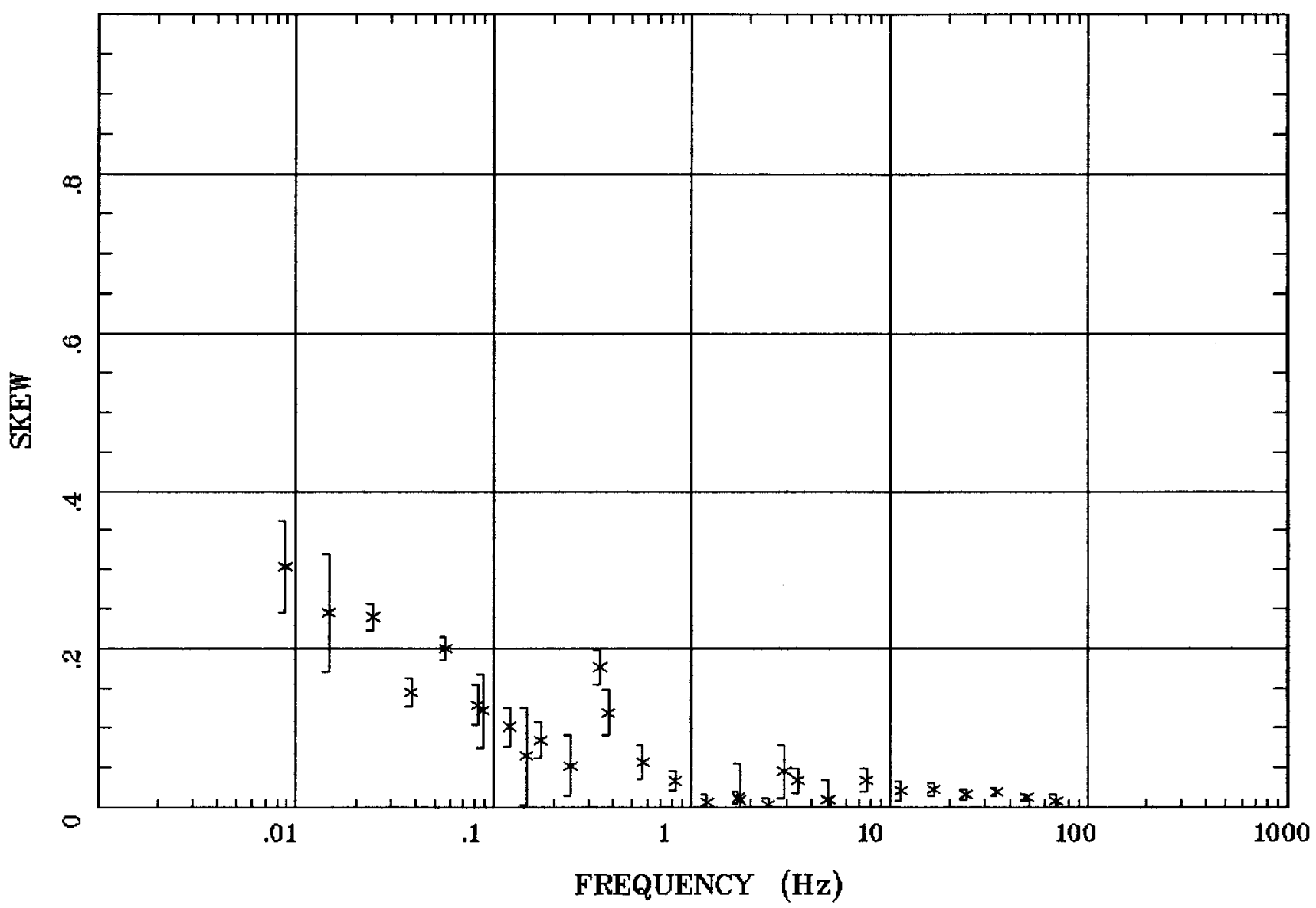

Client:

Remote: none

Acquired: 15:0 Jul 11, 2005

Survey Co:USGS
Rotation:

Filename: ap33mall.avg

Channels: Ch1 Ch2 Ch3 Ch4 Ch5 Ch3 Ch4 Plotted: 14:27 Jul 20, 2005

< EMI - ElectroMagnetic Instruments > 
E MULT Coh.

Double Mt., NV 100k

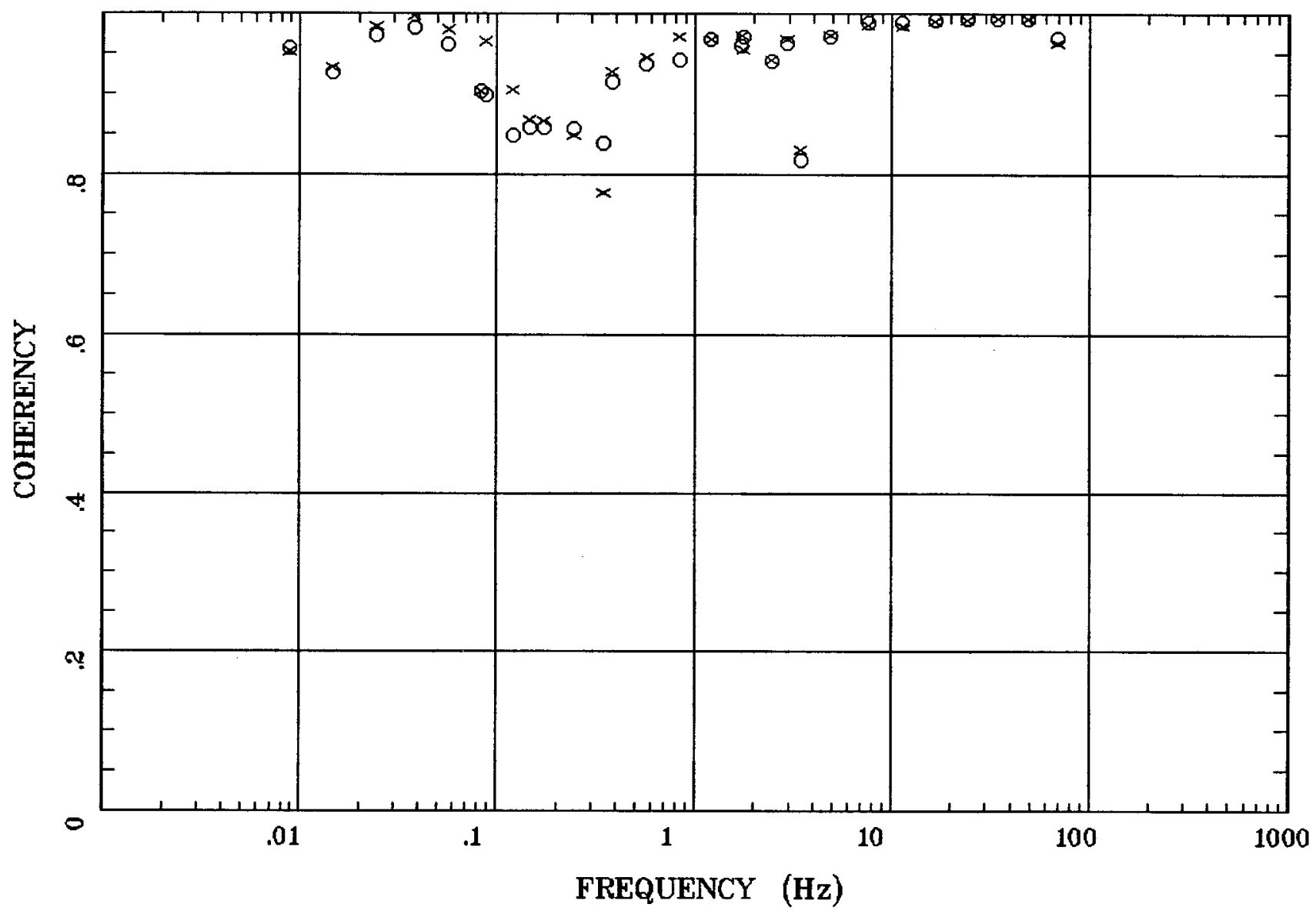

Client:

Remote: none Acquired: 15:0 Jul 11, 2005 Survey Co:USGS
Rotation:

Filename: ap33mall.avg

Channels: Ch1 Ch2 Ch3 Ch4 Ch5 Ch3 Ch4

Plotted: 14:27 Jul 20, 2005

< EMI - ElectroMagnetic Instruments > 
Station 33

POLAR PLOTS

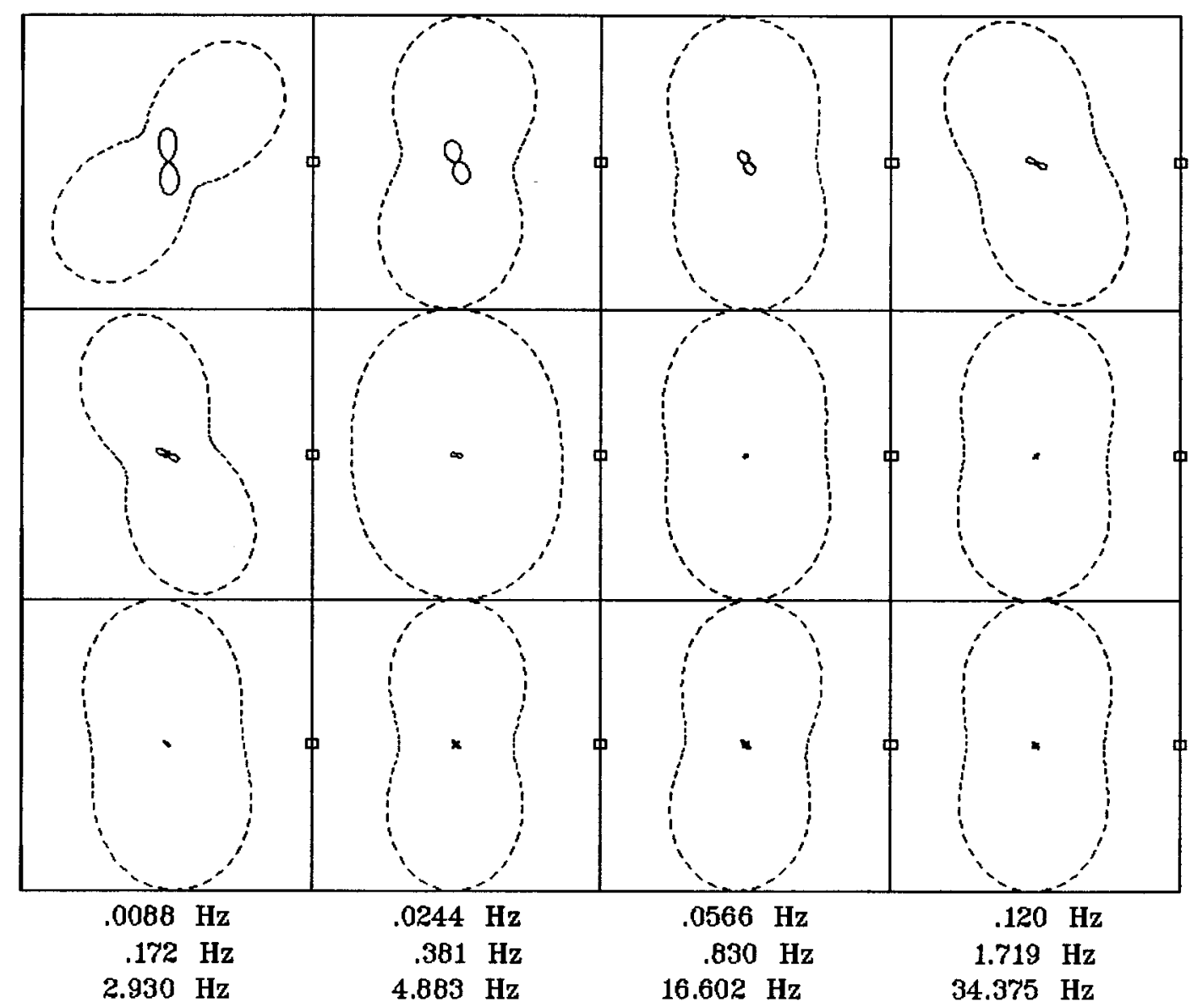

Client:

Remote: none

Acquired: 15:0 Jul 11, 2005

Survey Co:USGS
Double Mt., NV 100k

\section{Rotation:}

Filename: ap33mall.avg

Channels: Ch1 Ch2 Ch3 Ch4 Ch5 Ch3 Ch4

Plotted: 14:27 Jul 20, 2005

< EMI - ElectroMagnetic Instruments > 
TIPPER MAGNITUDE

Double Mt., NV 100k

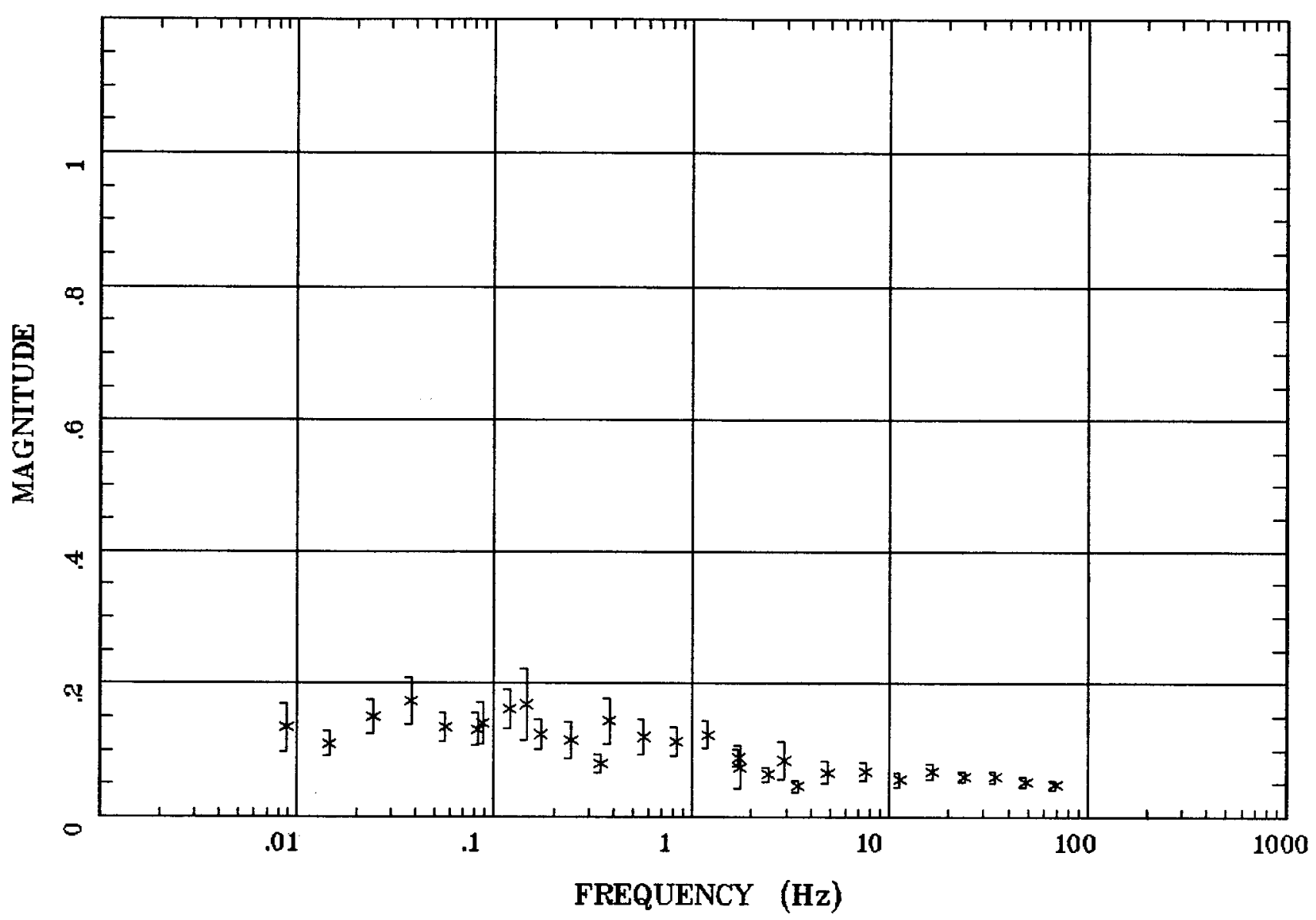

Client:

Remote: none

Acquired: 15:0 Jul 11, 2005 Survey Co:USGS
Rotation:

Filename: ap33mall.avg

Channels: Ch1 Ch2 Ch3 Ch4 Ch5 Ch3 Ch4

Plotted: 14:27 Jul 20, 2005

$<$ EMI - ElectroMagnetic Instruments > 
Station 33

TIPPER STRIKE

Double Mt., NV 100k

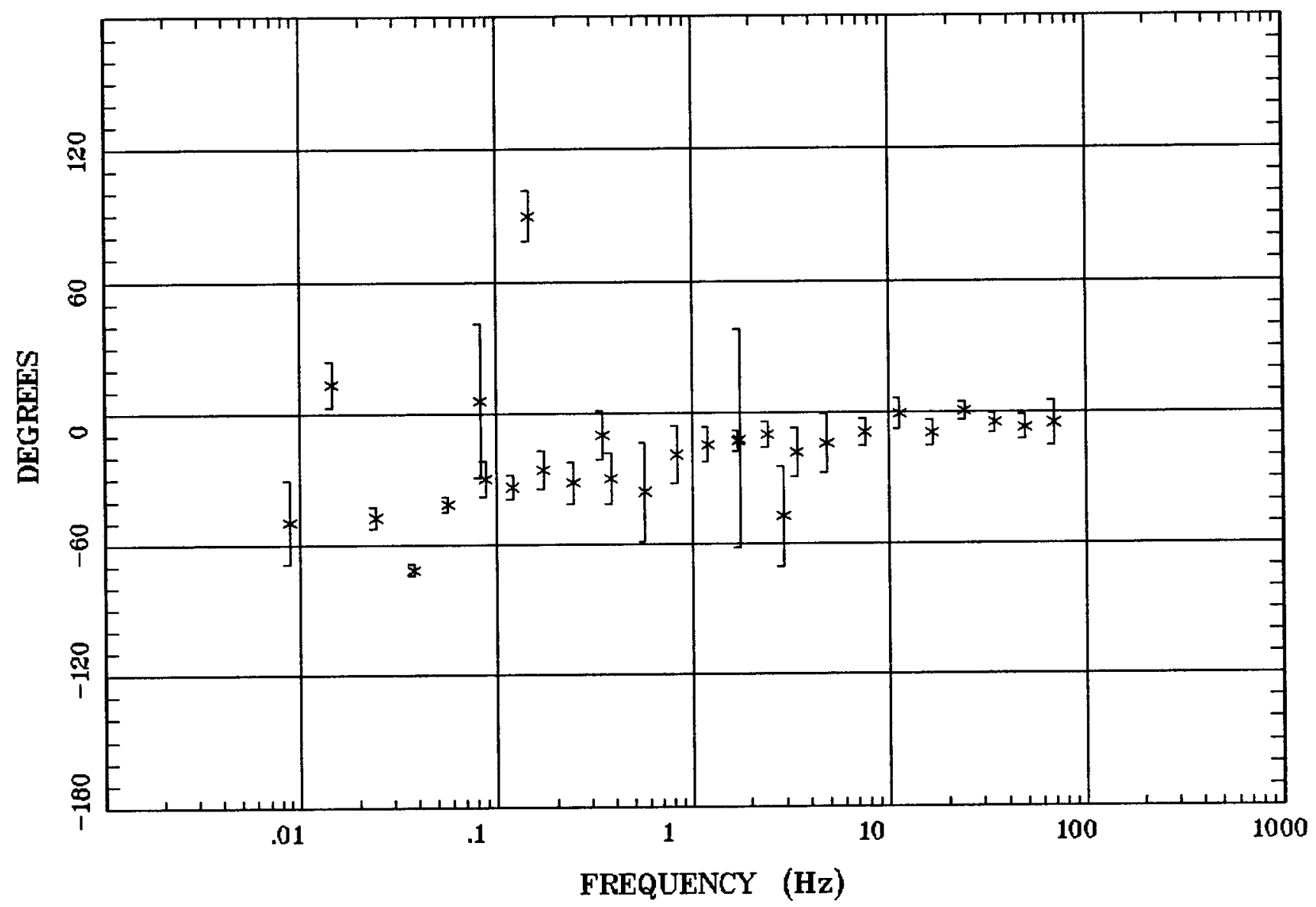

Client:

Remote: none

Acquired: 15:0 Jul 11, 2005 Survey Co:USGS
Rotation:

Filename: ap33mall.avg

Channels: Ch1 Ch2 Ch3 Ch4 Ch5 Ch3 Ch4

Plotted: 14:27 Jul 20, 2005

< EMI - ElectroMagnetic Instruments > 
HzHx.x Coh HzHy.o

Double Mt., NV 100k

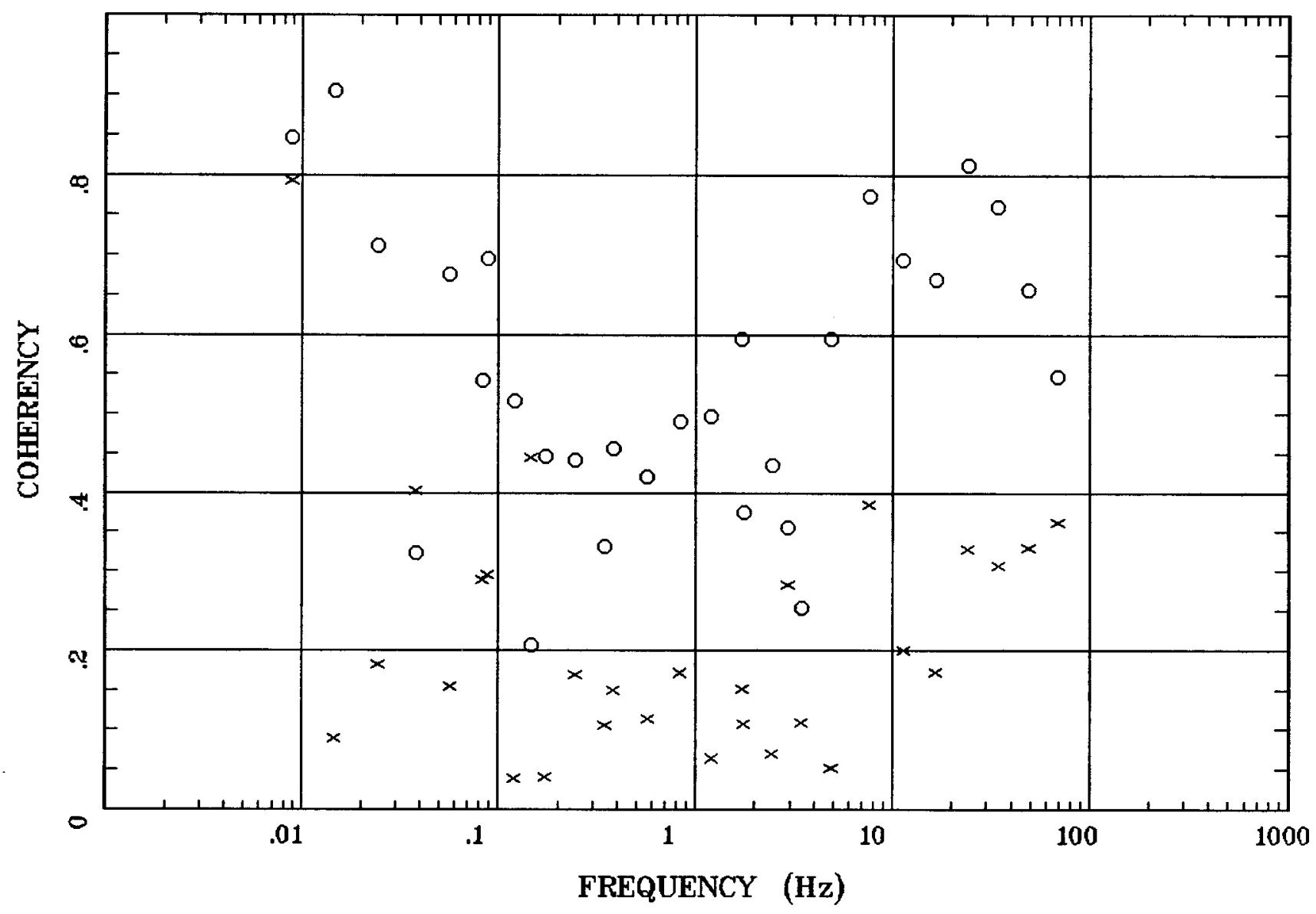

Client:

Remote: none

Acquired: 15:0 Jul 11, 2005

Survey Co:USGS
Ratation:

Filename: ap33mall.avg

Channels: Ch1 Ch2 Ch3 Ch4 Ch5 Ch3 Ch4

Plotted: 14:27 Jul 20, 2005

< EMI - ElectroMagnetic Instruments > 
APPARENT RESISTIVITY

Double Mt., NV 100k

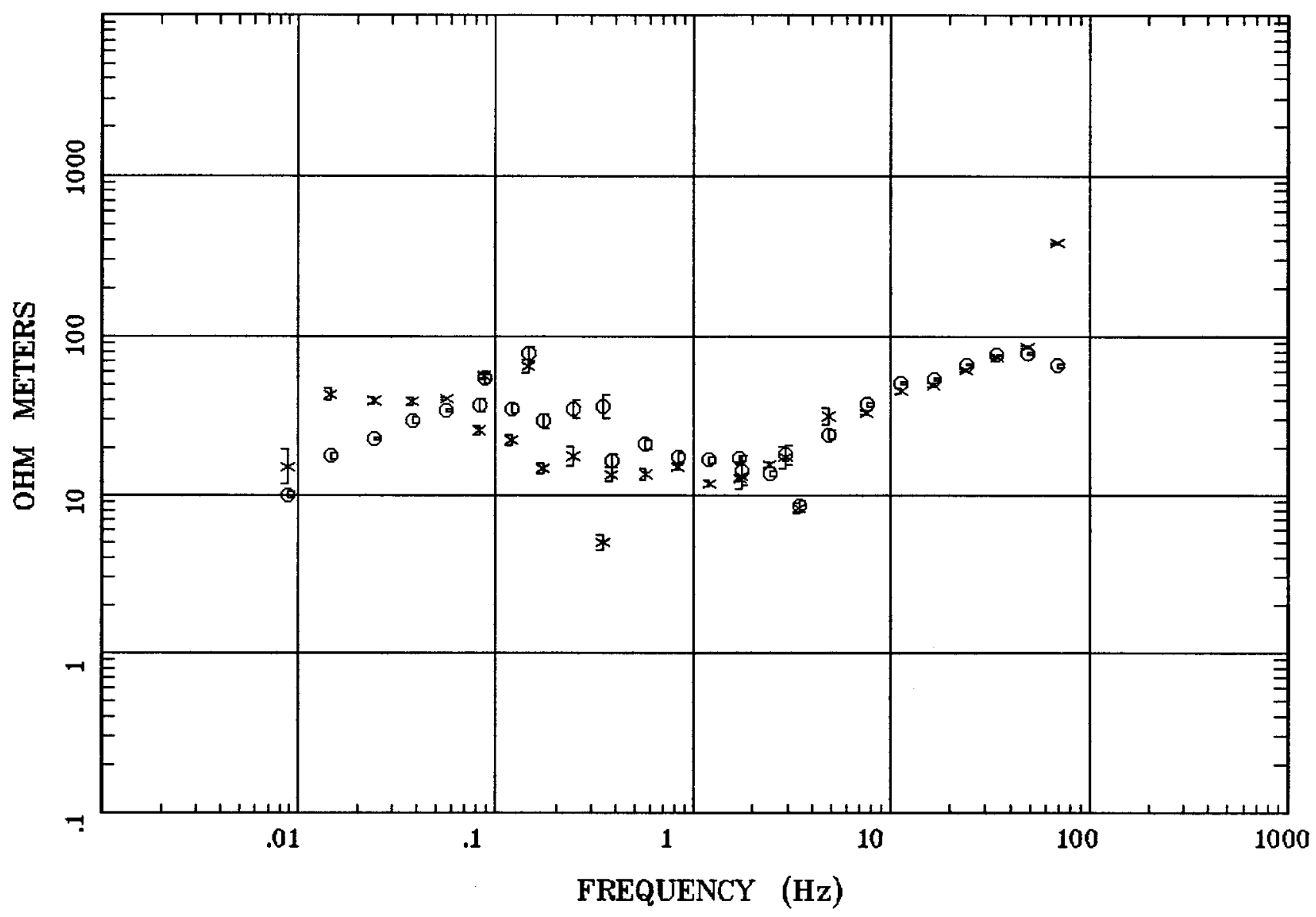

Client:

Remote: none

Acquired: 10:0 Jul 11, 2005 Survey Co:USGS
Rotation:

Filename: ap32mall.avg

Channels: Ch1 Ch2 Ch3 Ch4 Ch5 Ch3 Ch4

Plotted: 14:26 Jul 20, 2005

$<$ EMI - ElectroMagnetic Instruments 
Double Mt., NV 100k

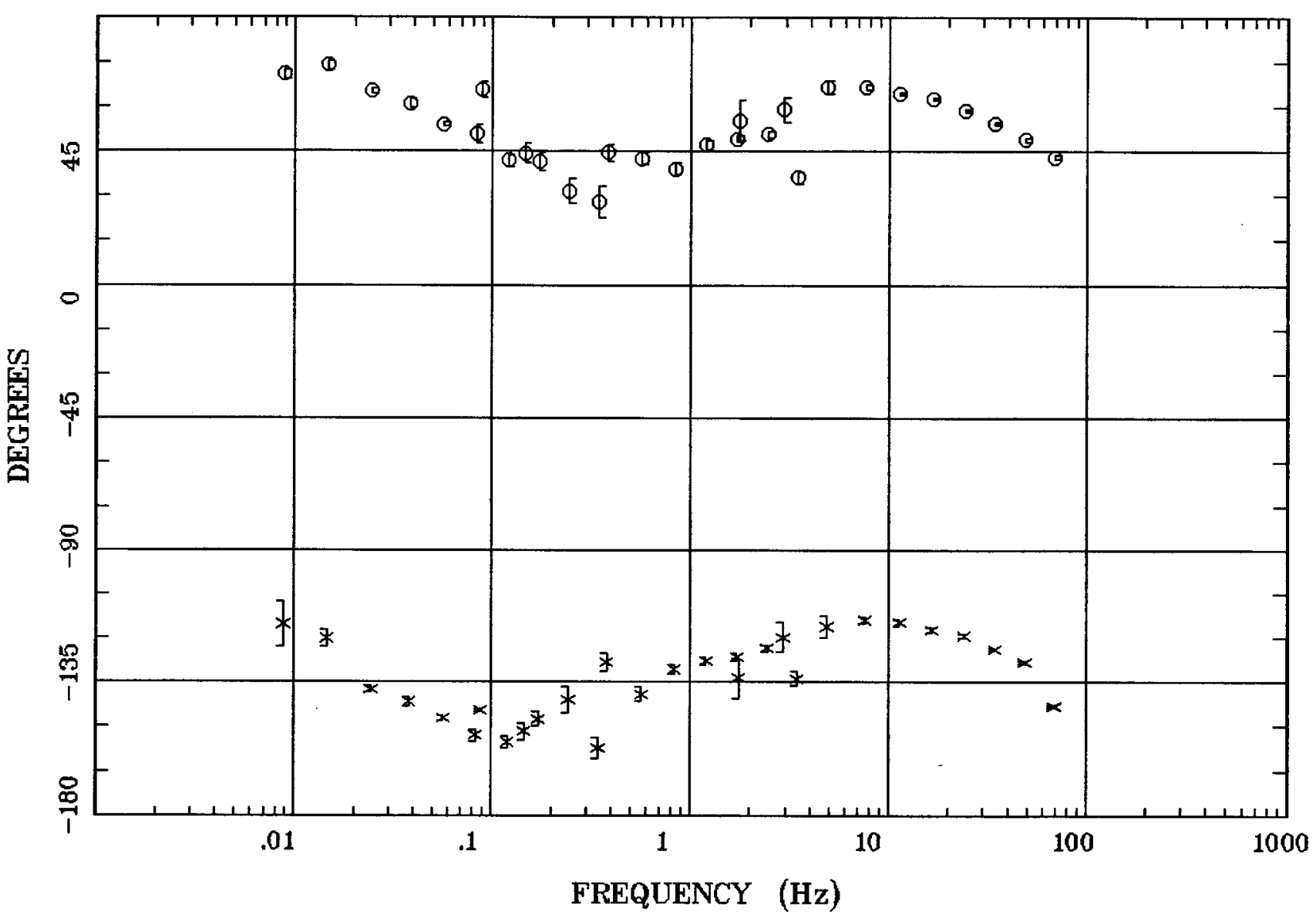

Client:

Remote: none

Acquired: 10:0 Jul 11, 2005 Survey Co:USGS
Rotation:

Filename: ap32mall.avg

Channels: Ch1 Ch2 Ch3 Ch4 Ch5 Ch3 Ch4

Plotted: 14:26 Jul 20, 2005

< EMI - ElectroMagnetic Instruments 
Double Mt., NV 100k

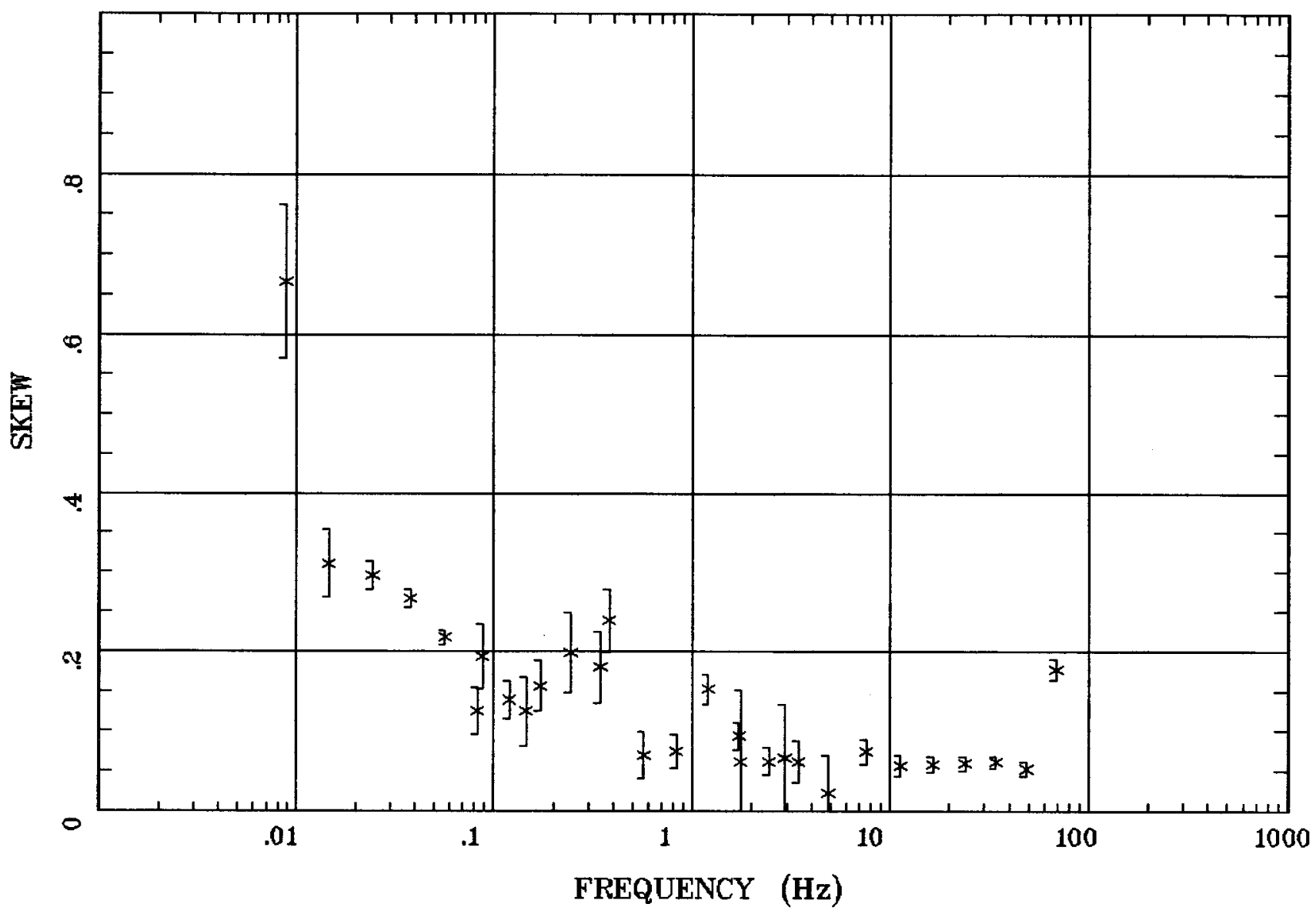

Client:

Remote: none Acquired: 10:0 Jul 11, 2005 Survey Co:USGS
Rotation:

Filename: ap32mall.avg

Channels: Ch1 Ch2 Ch3 Ch4 Ch5 Ch3 Ch4

Plotted: 14:26 Jul 20, 2005

< EMI - ElectroMagnetic Instruments > 
E MULT Coh.

Double Mt., NV 100k

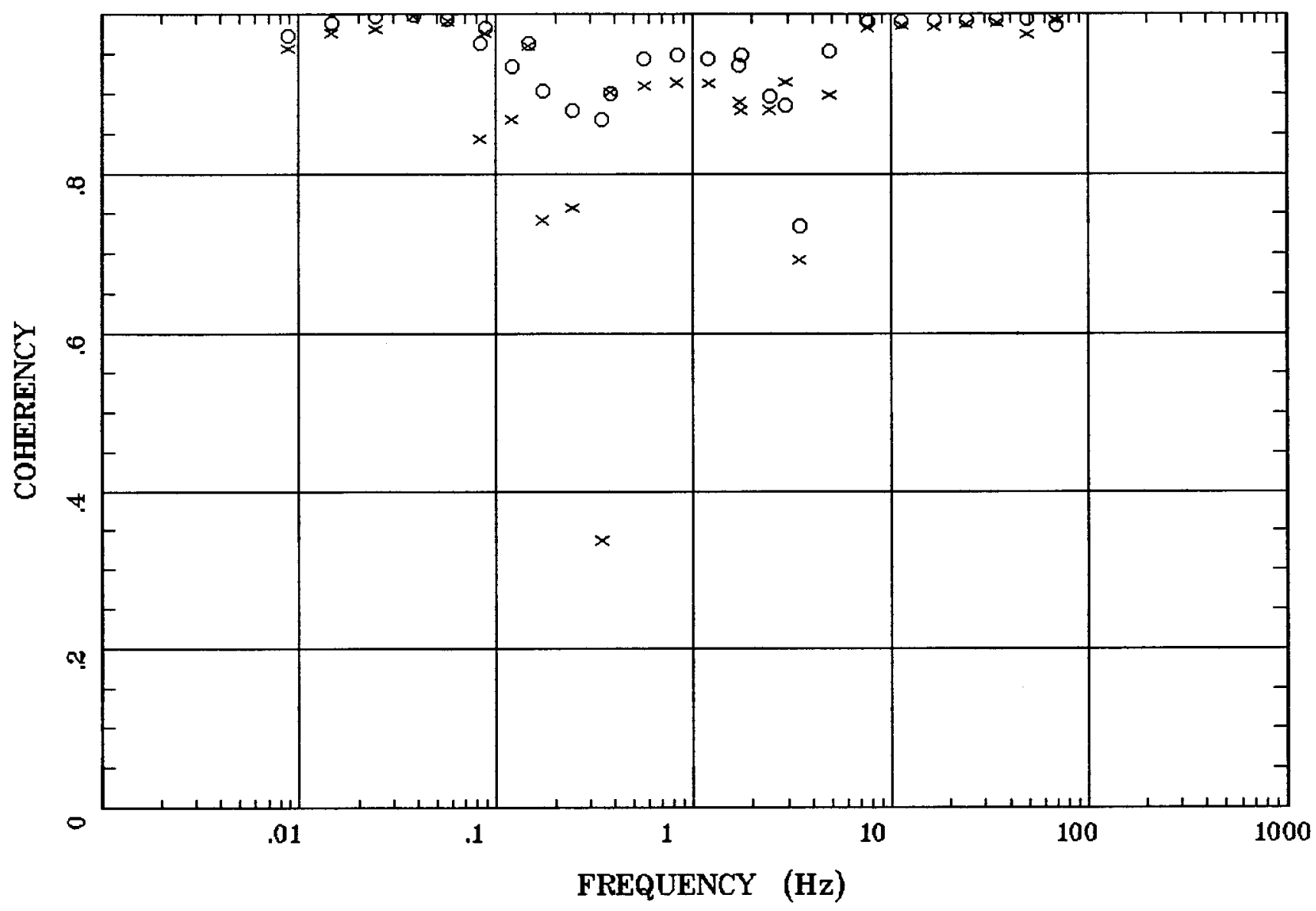

Client:

Remote: none

Acquired: 10:0 Jul 11, 2005

Survey Co:USGS
Rotation:

Filename: ap32mall.avg

Channels: Ch1 Ch2 Ch3 Ch4 Ch5 Ch3 Ch4

Plotted: 14:26 Jul 20, 2005

$<$ EMI - ElectroMagnetic Instruments > 
POLAR PLOTS

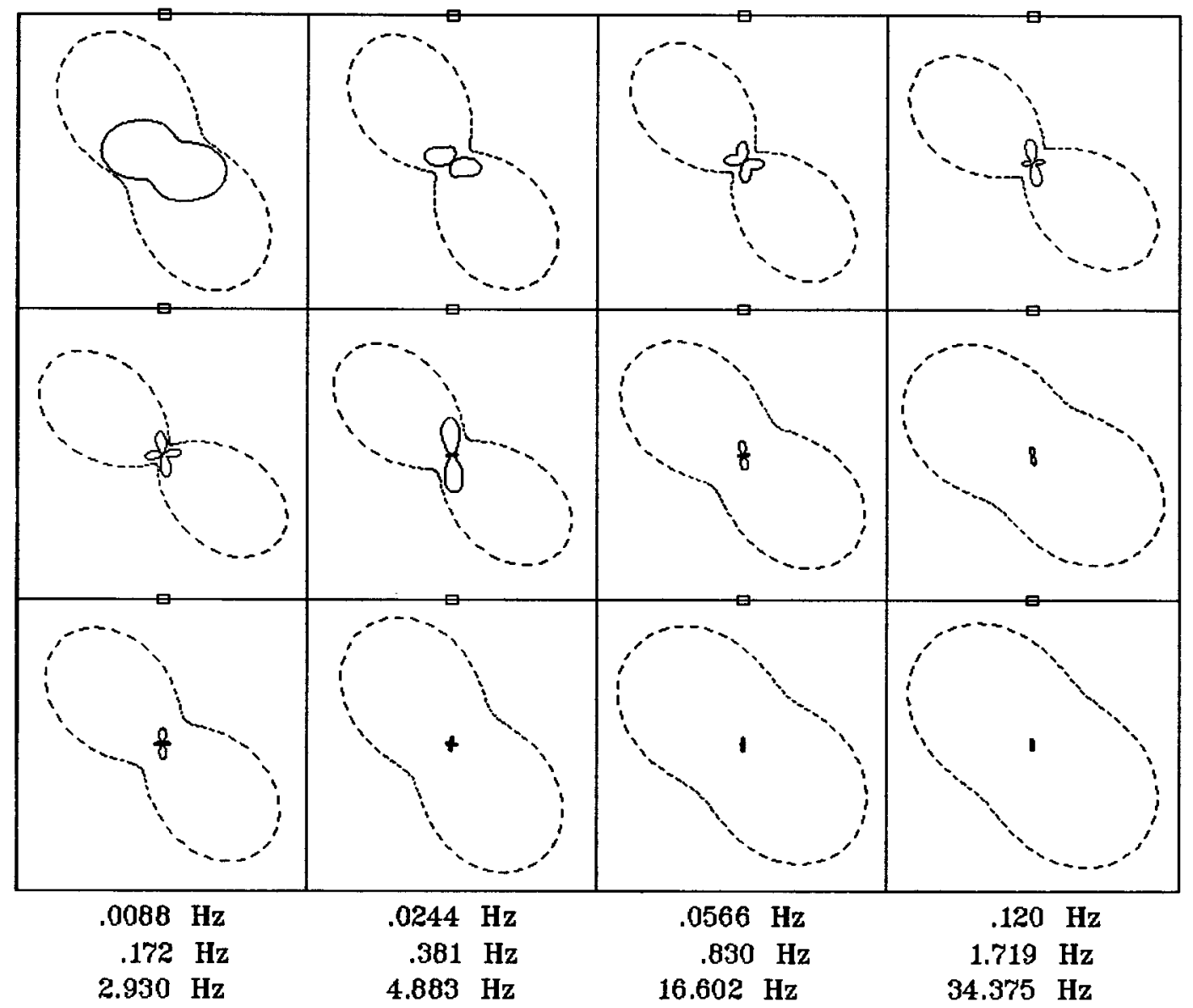

Client:

Remote: none

Acquired: 10:0 Jul 11, 2005

Survey Co:USGS
Double Mt., NV 100k

Rotation:

Filename: ap32mall.avg

Channels: Ch1 Ch2 Ch3 Ch4 Ch5 Ch3 Ch4

Plotted: 14:26 Jul 20, 2005

< EMI - ElectroMagnetic Instruments 
TIPPER MAGNITUDE

Double Mt., NV $100 \mathrm{k}$

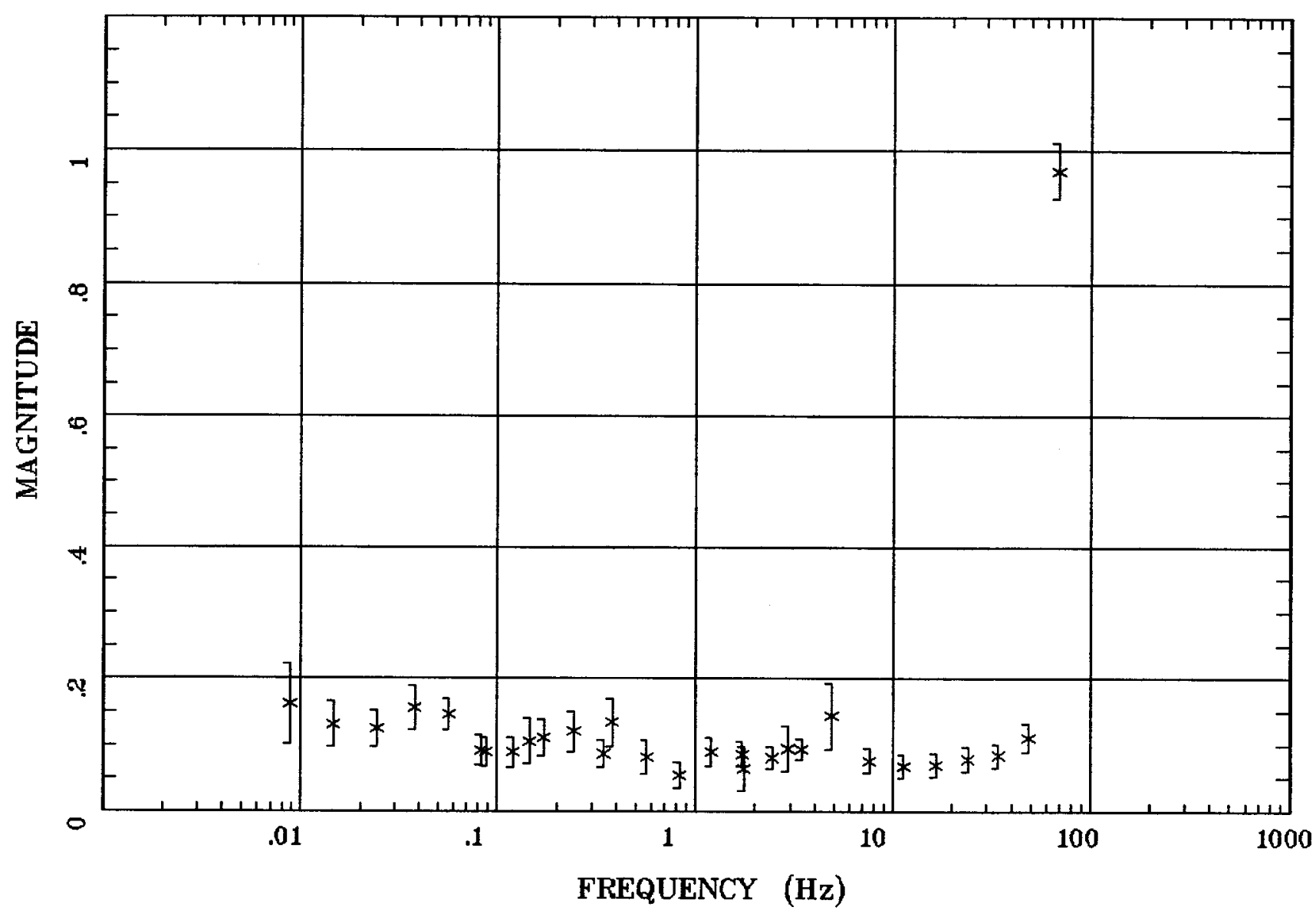

Client:

Remote: none

Acquired: 10:0 Jul 11, 2005 Survey Co:USGS
Rotation:

Filename: ap32mall.avg

Channels: Ch1 Ch2 Ch3 Ch4 Ch5 Ch3 Ch4

Plotted: 14:26 Jul 20, 2005

$<$ EMI - ElectroMagnetic Instruments 
TIPPER STRIKE

Double Mt., NV 100k

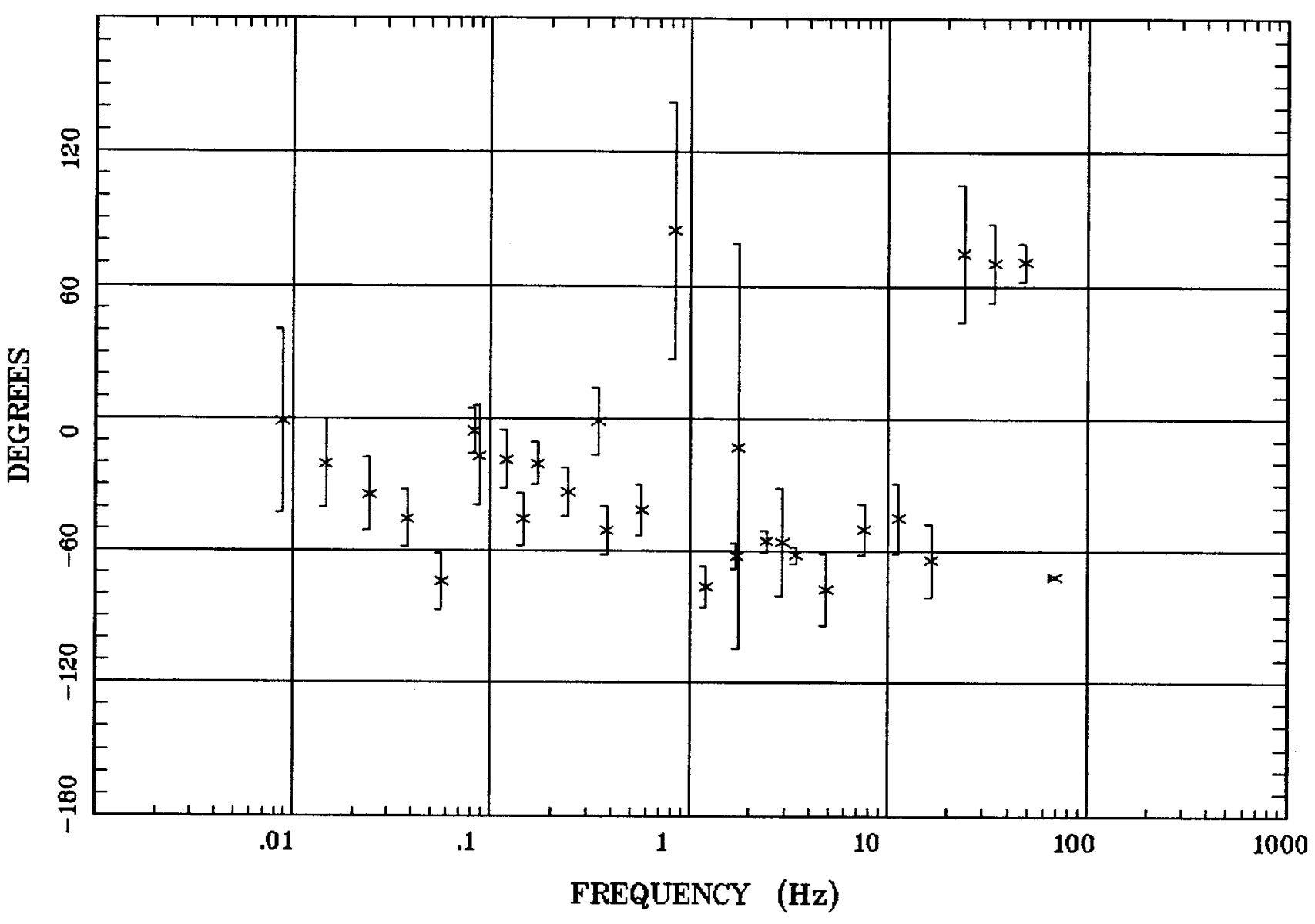

Client:

Remote: none

Acquired: 10:0 Jul 11, 2005 Survey Co:USGS
Rotation:

Filename: ap32mall.avg

Channels: Ch1 Ch2 Ch3 Ch4 Ch5 Ch3 Ch4 Plotted: 14:26 Jul 20, 2005

$<$ EMI - ElectroMagnetic Instruments > 
HzHx.x Coh HzHy.o

Double Mt., NV 100k

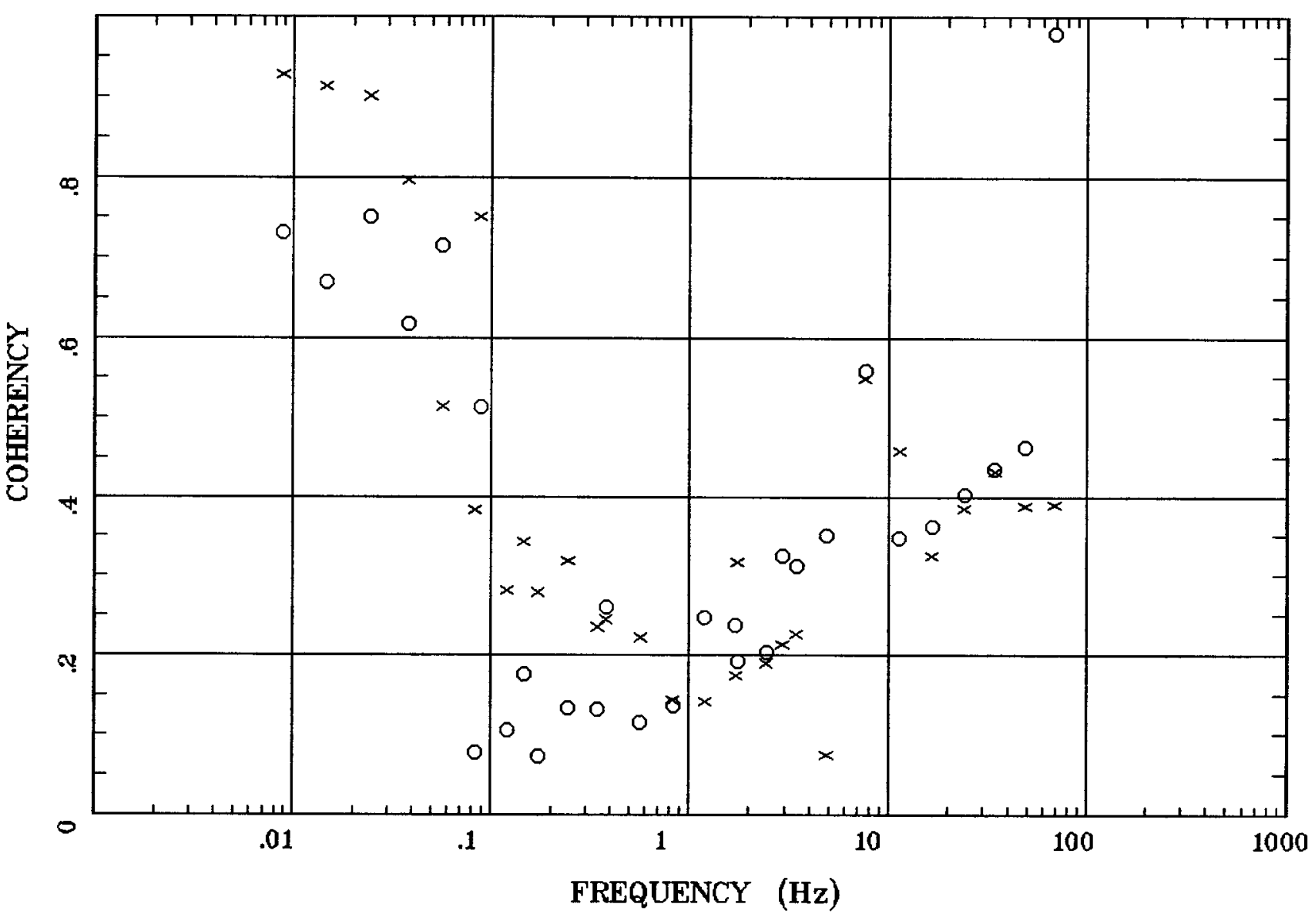

Client:

Remote: none

Acquired: 10:0 Jul 11, 2005 Survey Co:USGS
Rotation:

Filename: ap32mall.avg

Channels: Ch1 Ch2 Ch3 Ch4 Ch5 Ch3 Ch4 Platted: 14:26 Jul 20, 2005

< EMI - ElectroMagnetic Instruments > 


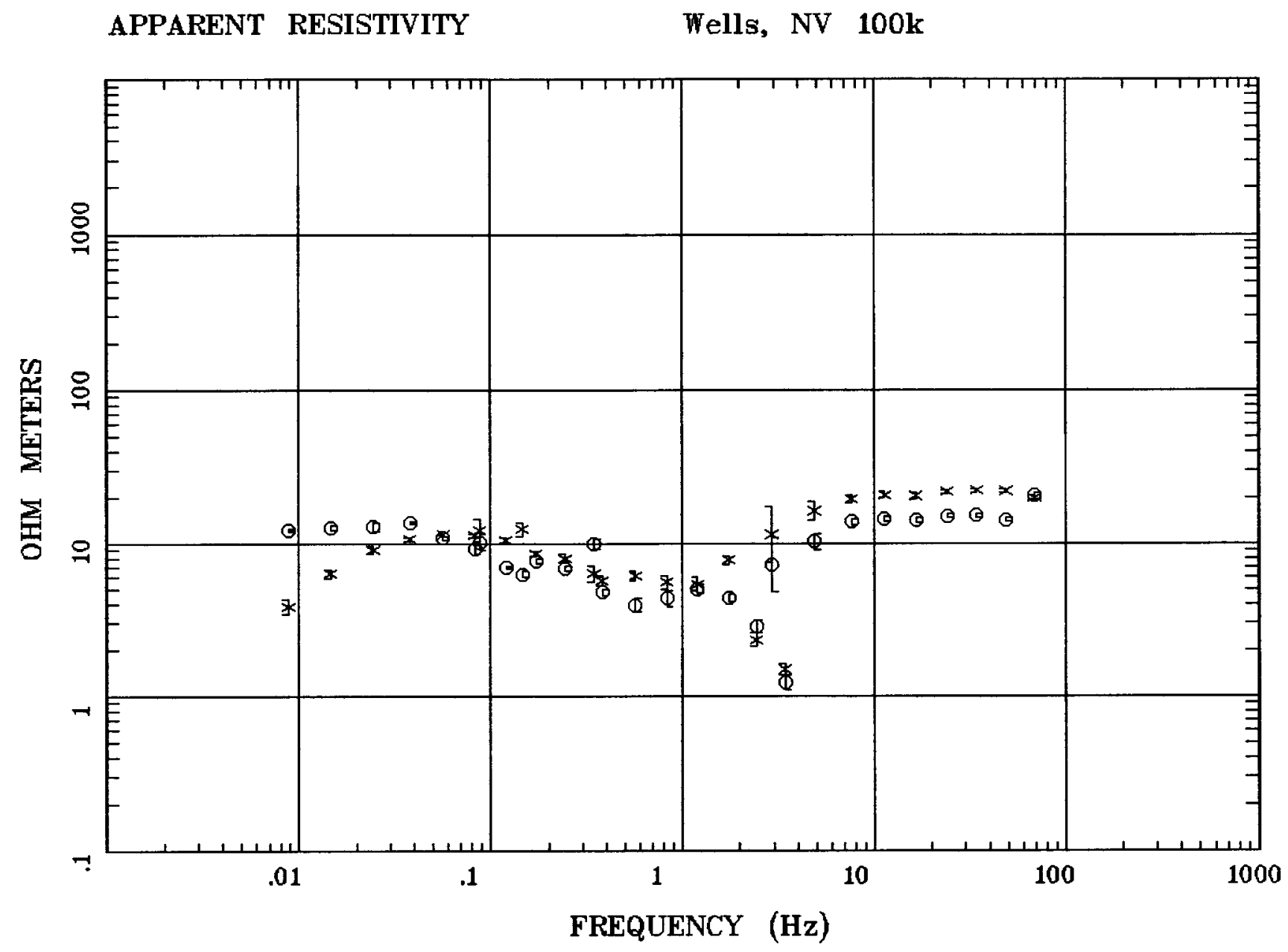

Client:

Remote: none

Acquired: 09:5 Jul 10, 2005 Survey Co:USGS
Rotation:

Filename: ap31m.avg

Channels: Ch1 Ch2 Ch3 Ch4 Ch5 Ch3 Ch4 Plotted: 15:22 Jul 20, 2005

$<$ EMI - ElectroMagnetic Instruments 
Station 31

IMPEDANCE PHASE

Wells, NV 100k

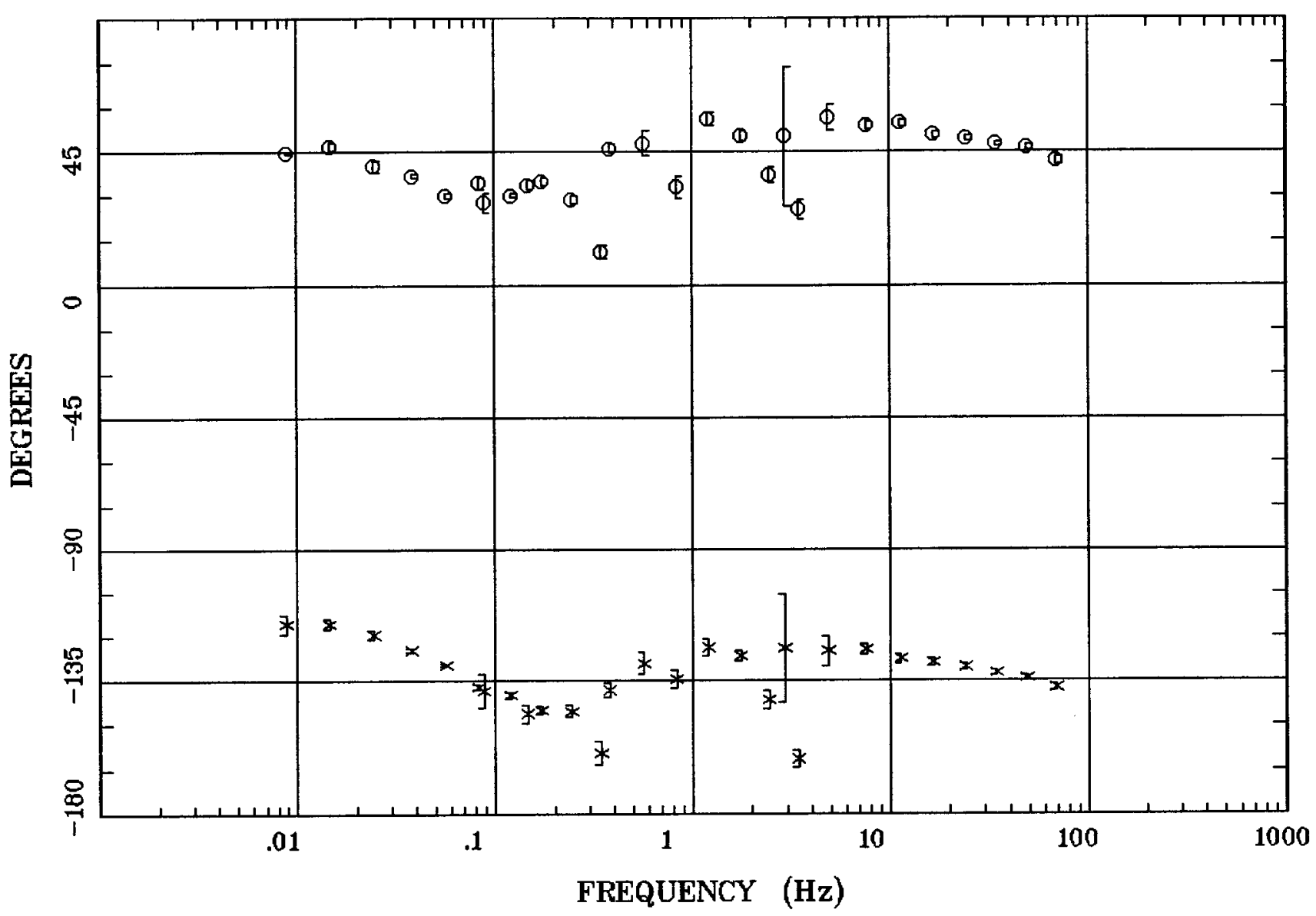

Client:

Remote: none

Acquired: 09:5 Jul 10, 2005

Survey Co:USGS

\section{Rotation:}

Filename: ap31mavg

Channels: Ch1 Ch2 Ch3 Ch4 Ch5 Ch3 Ch4 Plotted: 15:22 Jul 20, 2005

< EMI - ElectroMagnetic Instruments > 
Wells, NV 100k

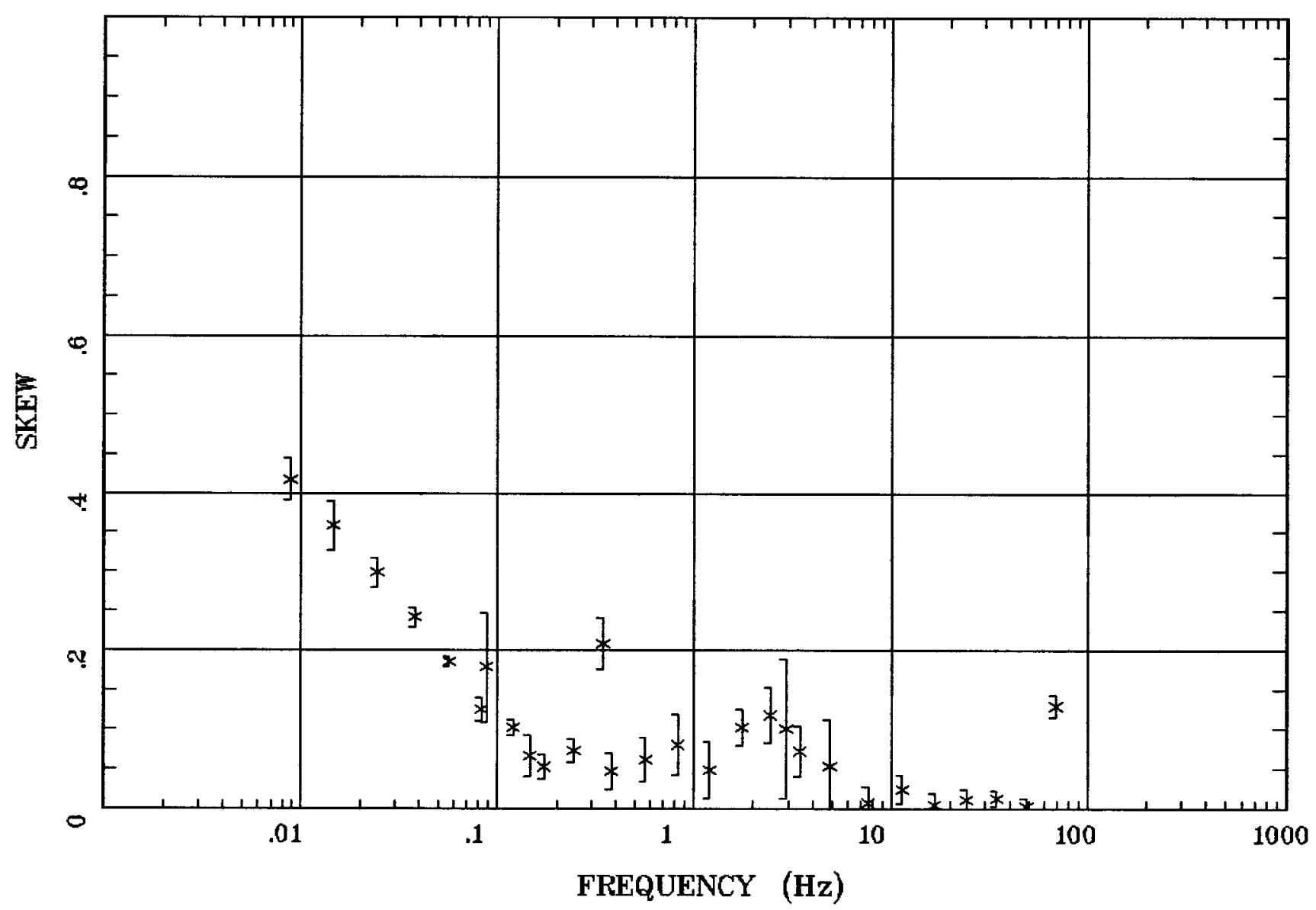

Client:

Remote: none

Acquired: 09:5 Jul 10, 2005

Survey Co:USGS
Rotation:

Filename: ap31m.avg

Channels: Ch1 Ch2 Ch3 Ch4 Ch5 Ch3 Ch4

Plotted: 15:22 Jul 20, 2005

$<$ EMI - ElectroMagnetic Instruments > 
E MULT Coh. Wells, NV 100k

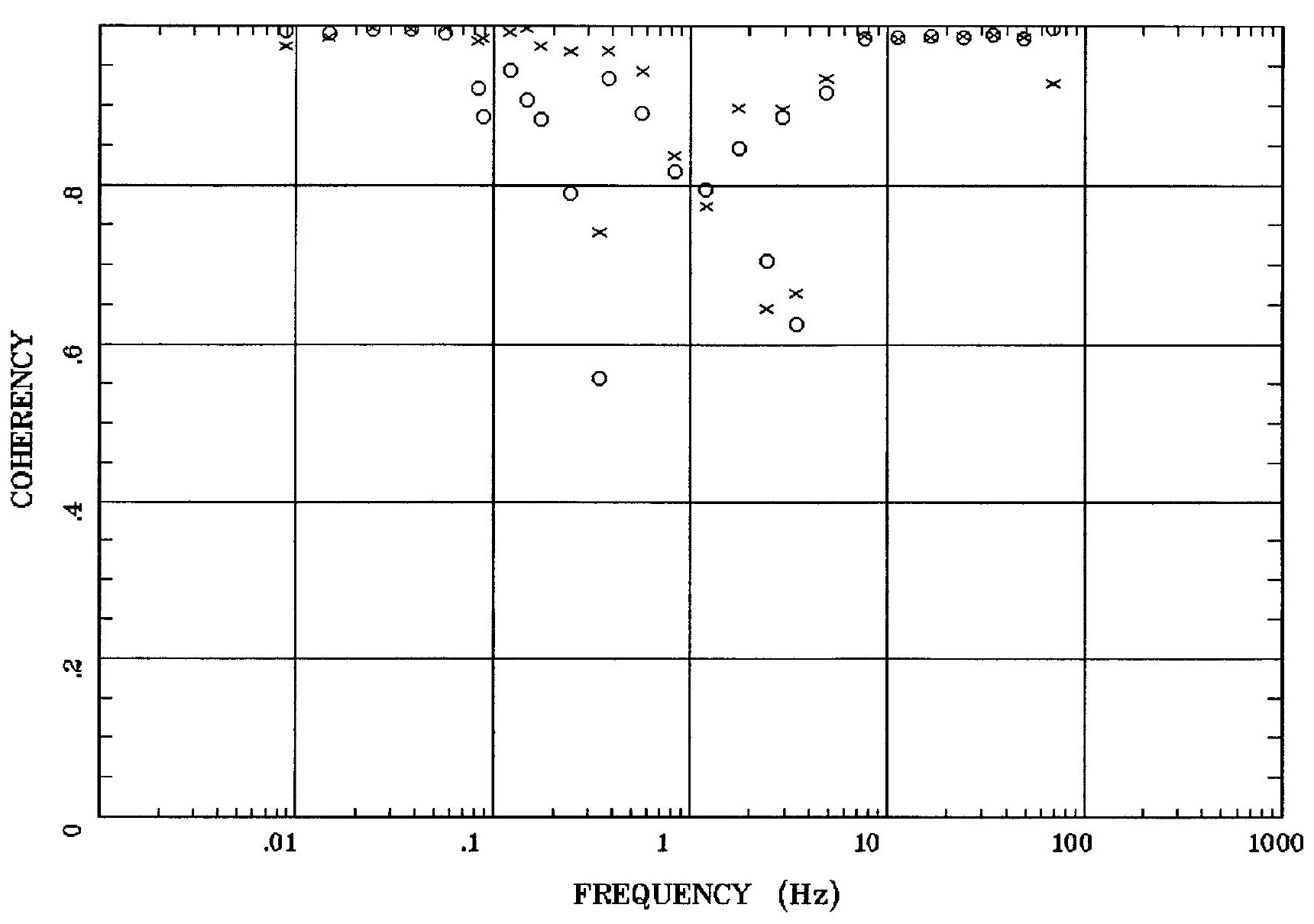

Client:

Remote: none

Acquired: 09:5 Jul 10, 2005

Survey Co:USGS
Rotation:

Filename: ap $31 \mathrm{~m}$ avg

Channels: Ch1 Ch2 Ch3 Ch4 Ch5 Ch3 Ch4 Plotted: 15:22 Jul 20, 2005

< EMI - ElectroMagnetic Instruments > 


\section{Station 31}

\section{POLAR PLOTS}

Wells, NV 100k

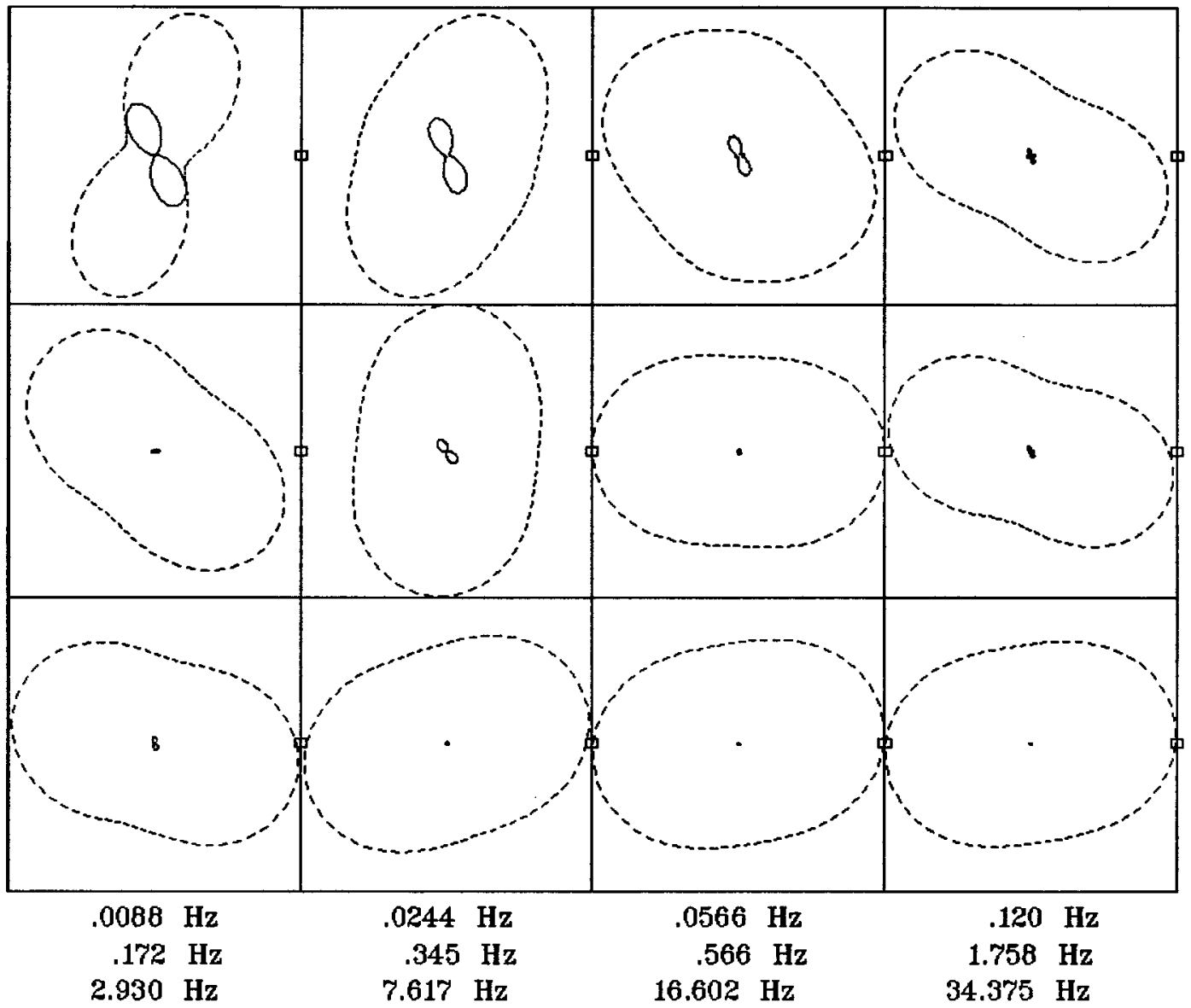

Client:

Remote: none

Rotation:

Filename: ap31m.avg

Channels: Ch1 Ch2 Ch3 Ch4 Ch5 Ch3 Ch4

Plotted: 15:22 Jul 20, 2005

Acquired: 09:5 Jul 10, 2005

< EMI - ElectroMagnetic Instruments 
TIPPER MAGNITUDE

Wells, NV 100k

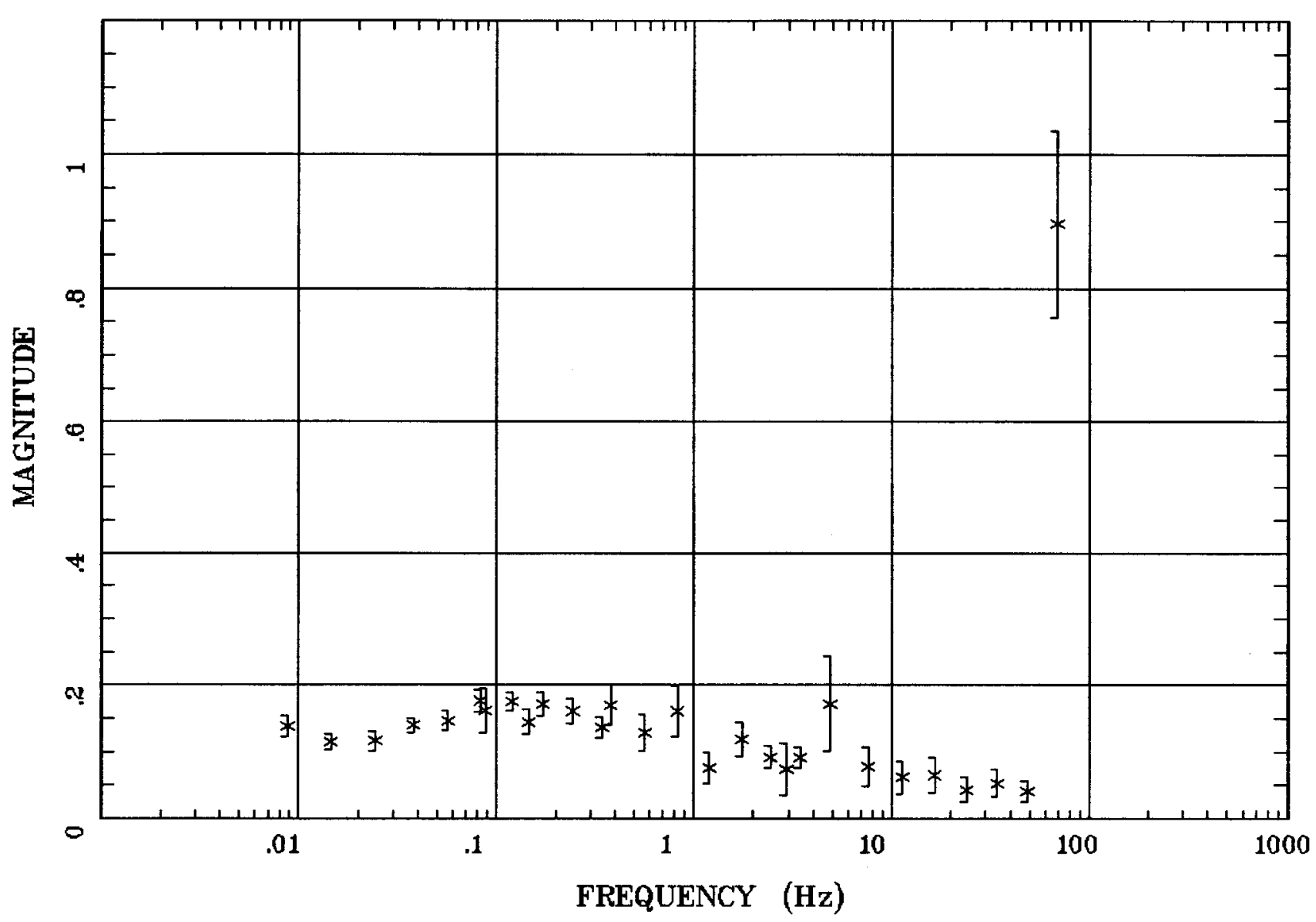

Client:

Remote: none

Acquired: 09:5 Jul 10, 2005

Survey Co:USGS
Rotation:

Filename: ap31m.avg

Channels: Ch1 Ch2 Ch3 Ch4 Ch5 Ch3 Ch4

Plotted: 15:22 Jul 20, 2005

< EMI - ElectroMagnetic Instruments > 
Wells, NV 100k

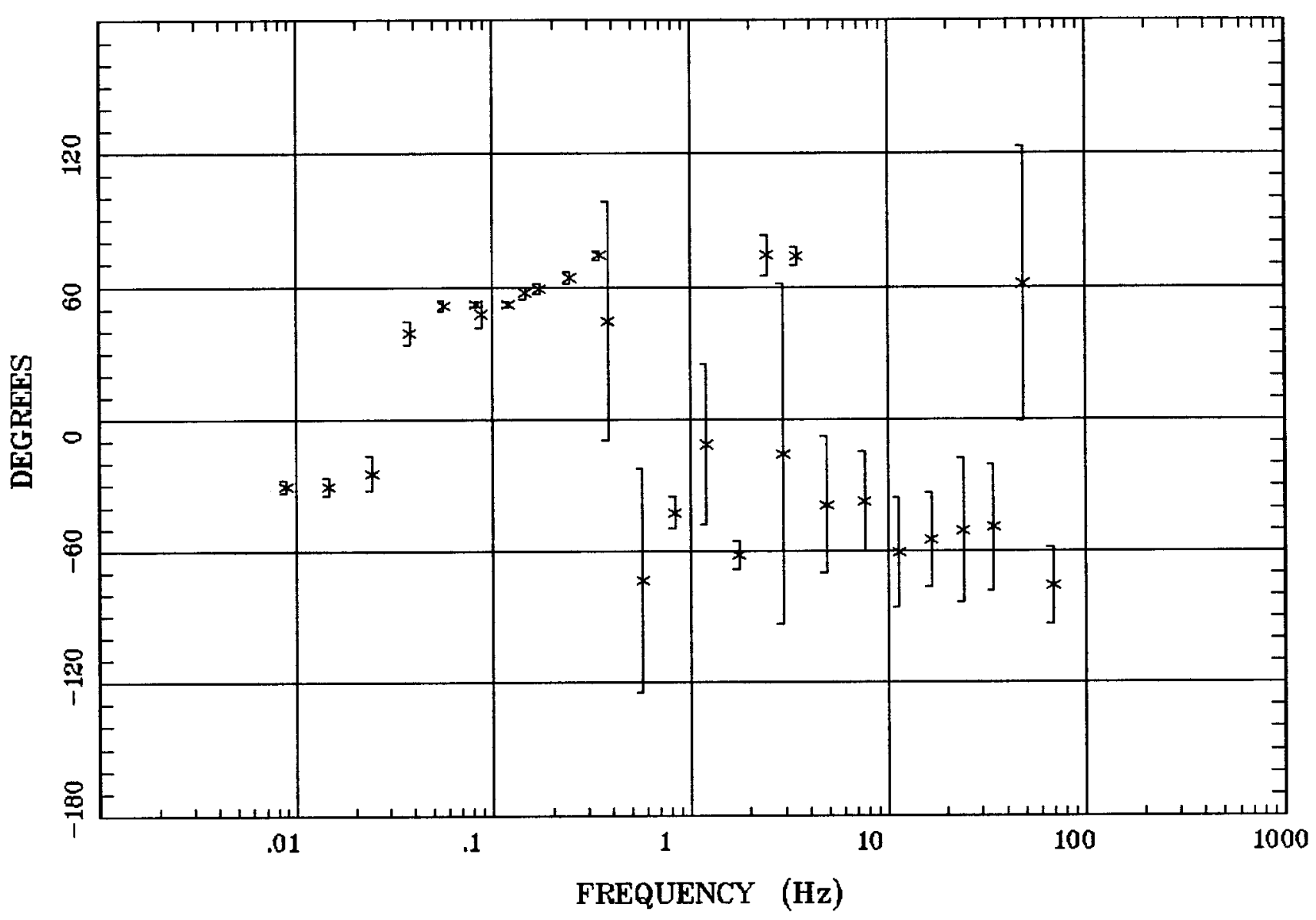

Client:

Remote: none

Acquired: 09:5 Jul 10, 2005

Survey Co:USGS
Rotation:

Filename: ap31m.avg

Channels: Ch1 Ch2 Ch3 Ch4 Ch5 Ch3 Ch4

Plotted: 15:22 Jul 20, 2005

$<$ EMI - ElectroMagnetic Instruments > 
HzHx.x Coh HzHy.o

Wells, NV 100k

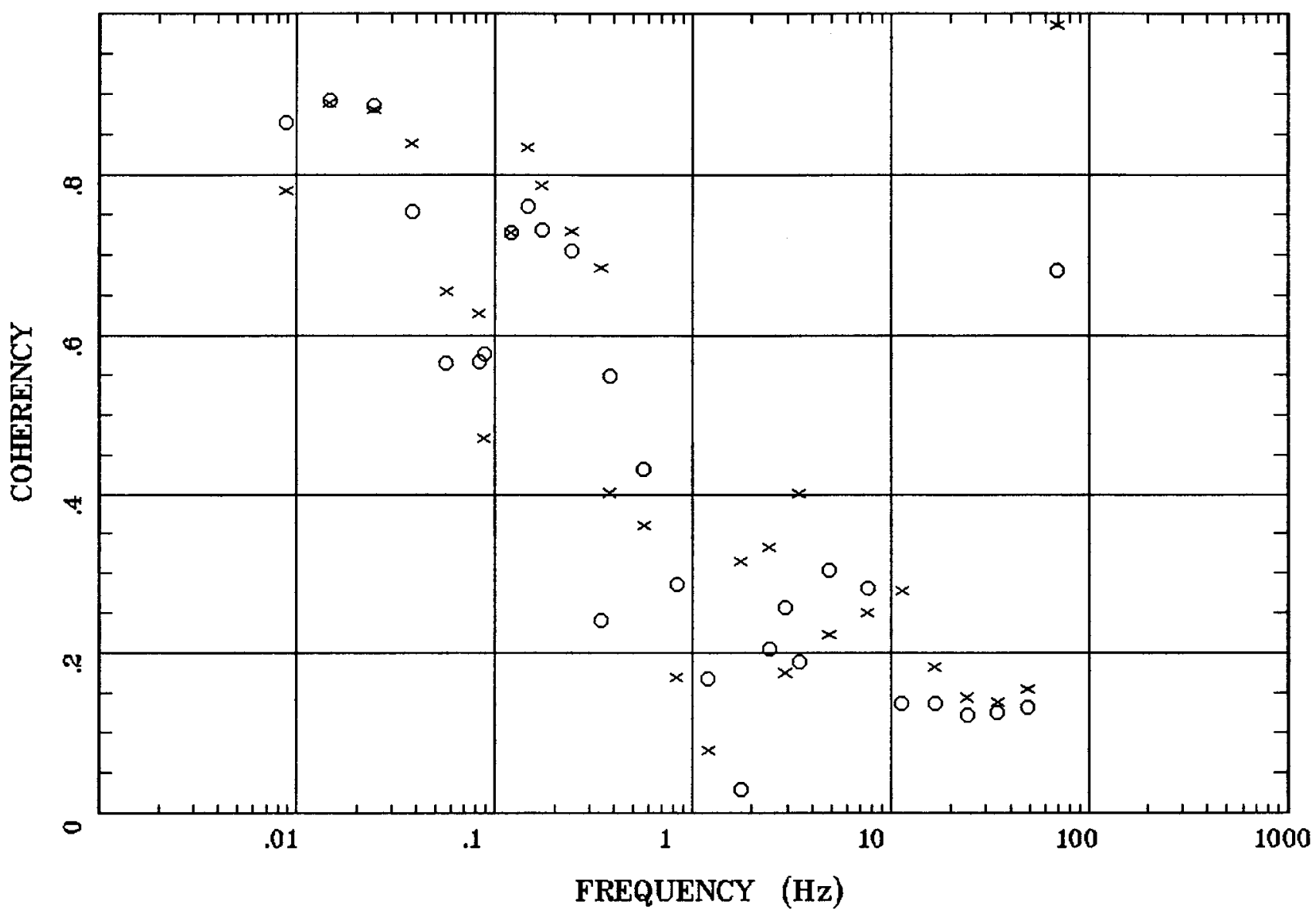

Client:

Remote: none

Acquired: 09:5 Jul 10, 2005

Survey Co:USGS
Rotation:

Filename: ap31m.avg

Channels: Ch1 Ch2 Ch3 Ch4 Ch5 Ch3 Ch4

Plotted: 15:22 Jul 20, 2005

< EMI - ElectroMagnetic Instruments 
APPARENT RESISTIVITY Wells, NV 100k

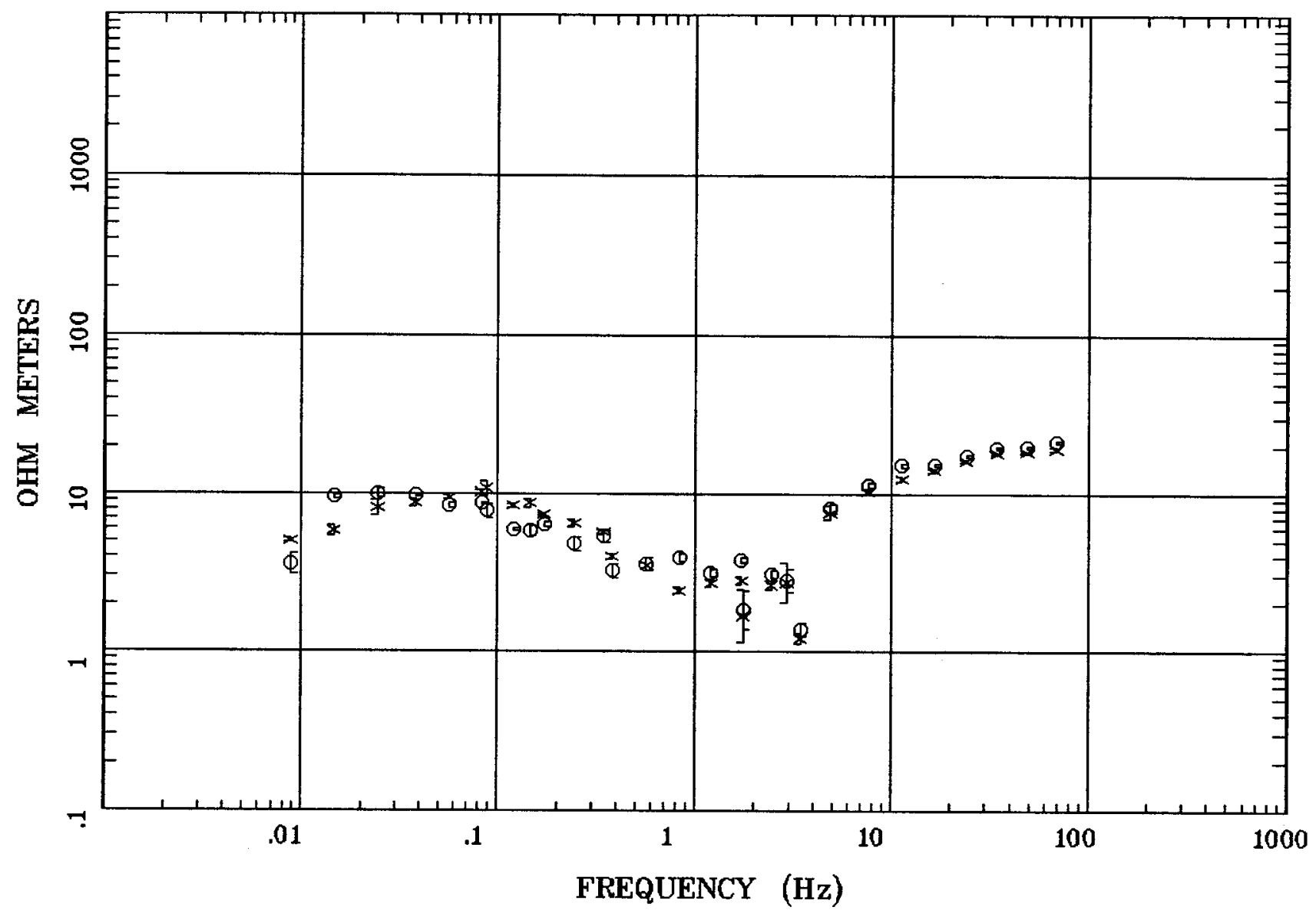

Client:

Remote: none

Acquired: 13:3 Jul 10, 2005

Survey Co:USGS
Rotation:

Filename: ap30mall.avg

Channels: Ch1 Ch2 Ch3 Ch4 Ch5 Ch3 Ch4

Plotted: 14:26 Jul 20, 2005

< EMI - ElectroMagnetic Instruments 
IMPEDANCE PHASE

Wells, NV 100k

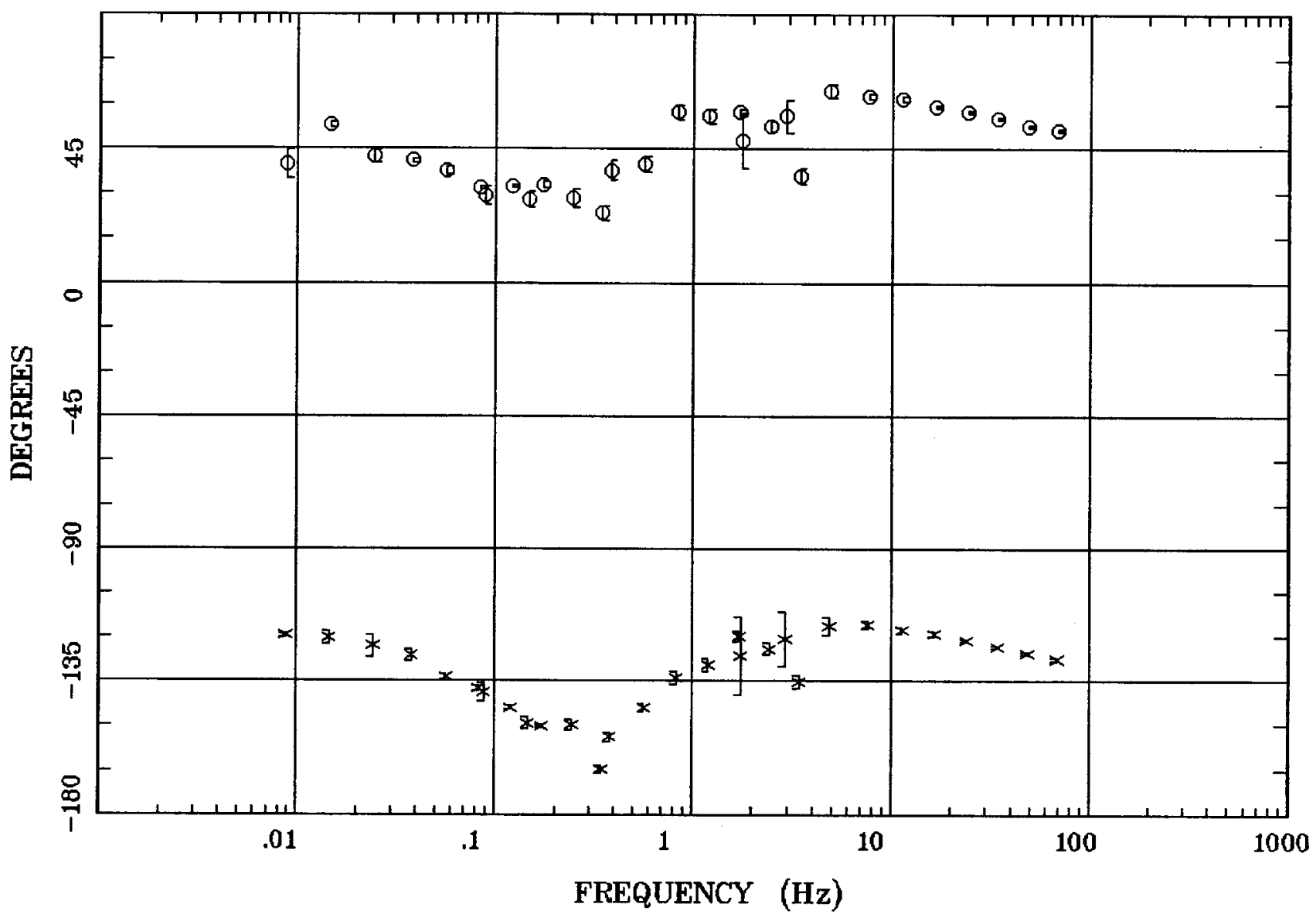

Client:

Remote: none

Acquired: 13:3 Jul 10, 2005 Survey Co:USGS
Rotation:

Filename: ap30mall.avg

Channels: Ch1 Ch2 Ch3 Ch4 Ch5 Ch3 Ch4

Plotted: 14:26 Jul 20, 2005

$<$ EMI - ElectroMagnetic Instruments 
Station 30

IMPEDANCE SKEW

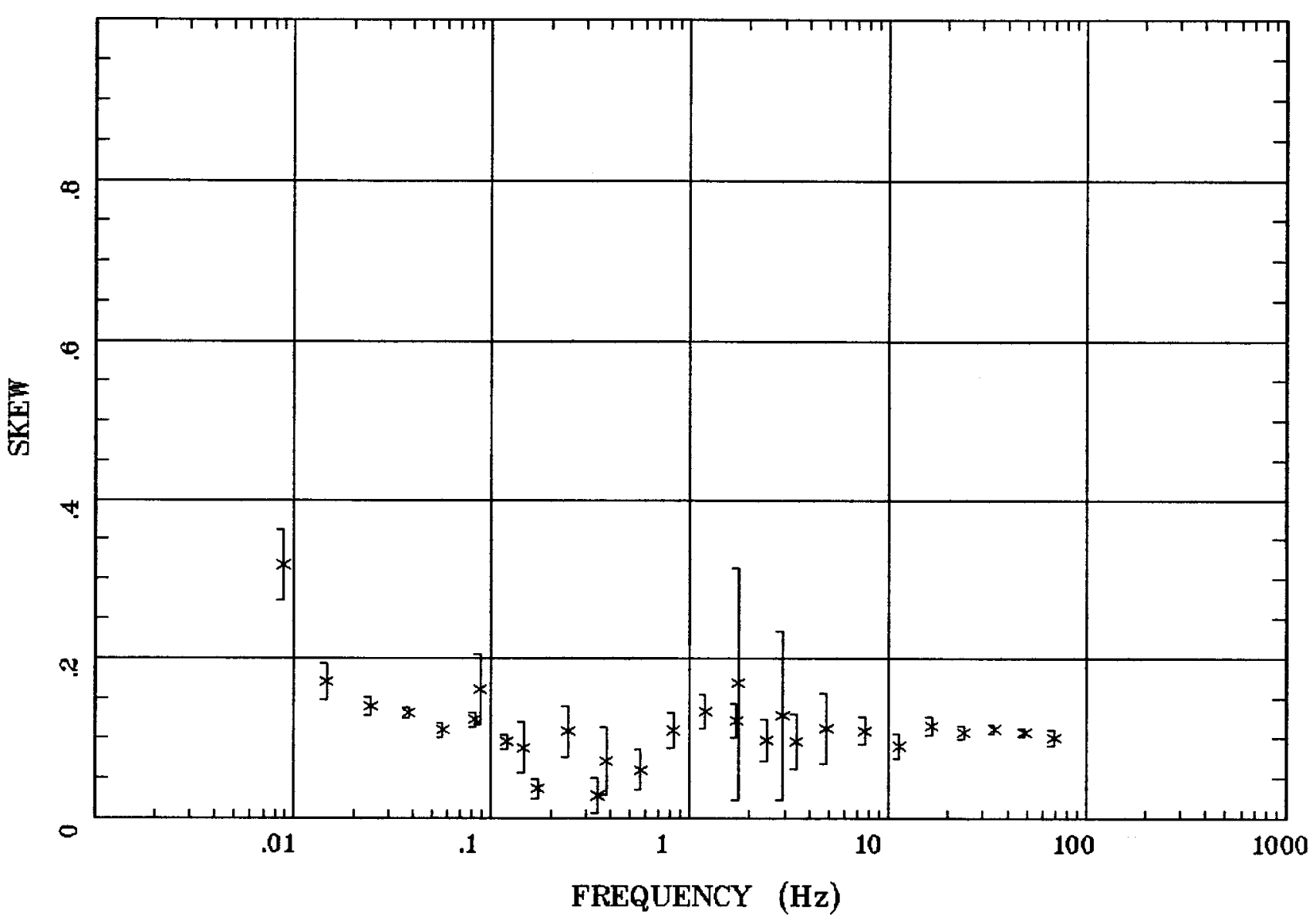

Client:

Remote: none Acquired: 13:3 Jul 10, 2005 Survey Co:USGS
Rotation:

Filename: ap $30 \mathrm{mall} . \mathrm{avg}$

Channels: Ch1 Ch2 Ch3 Ch4 Ch5 Ch3 Ch4 Plotted: 14:26 Jul 20, 2005

< EMI - ElectroMagnetic Instruments > 
Station 30

E MULT Coh.

Wells, NV 100k

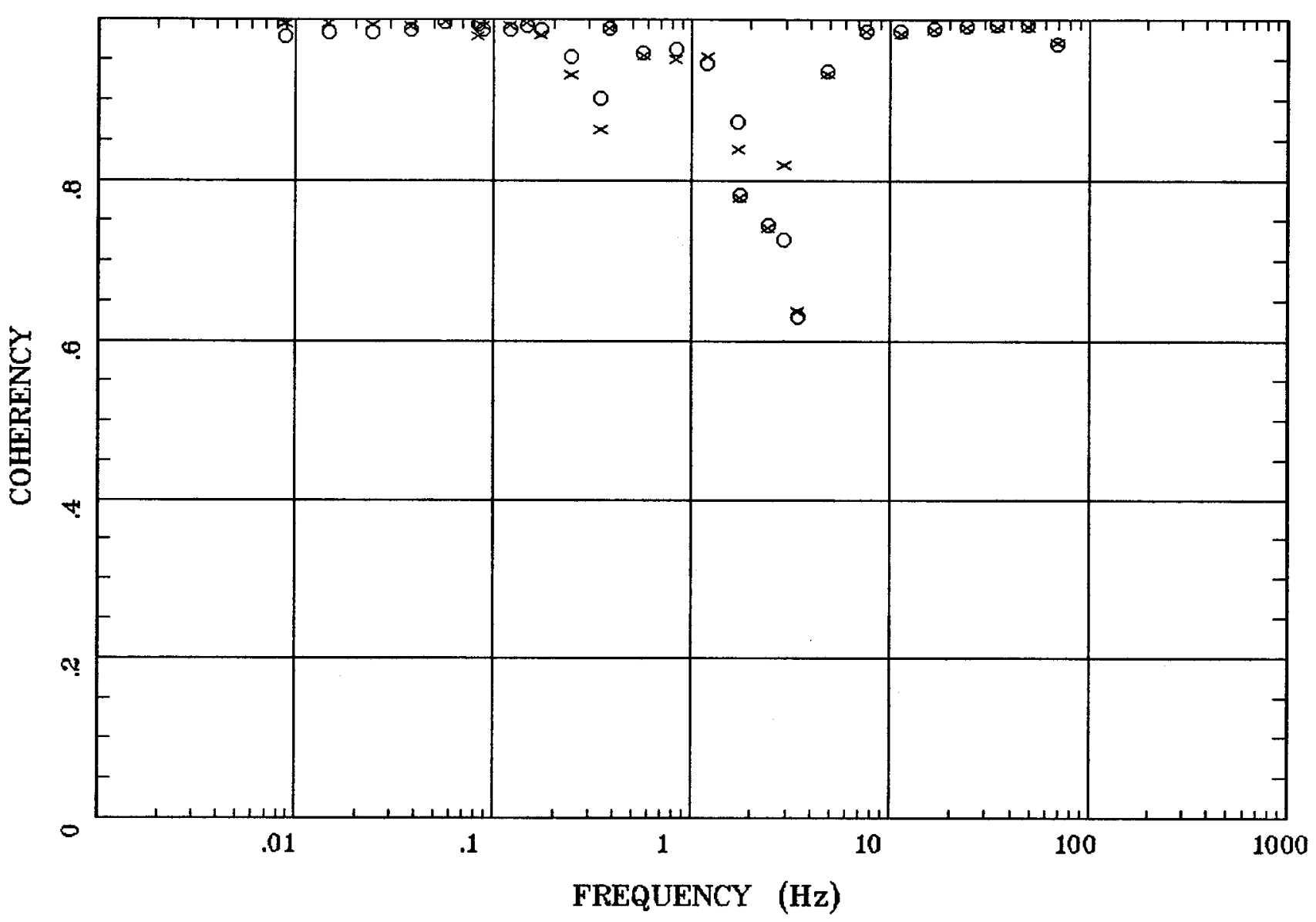

Client:

Rotation:

Remote: none

Filename: ap30mall.avg

Acquired: 13:3 Jul 10, 2005

Survey Co:USGS

Channels: Ch1 Ch2 Ch3 Ch4 Ch5 Ch3 Ch4

Plotted: 14:26 Jul 20, 2005

< EMI - ElectroMagnetic Instruments > 


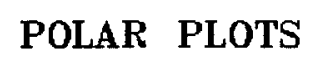

Wells, NV 100k

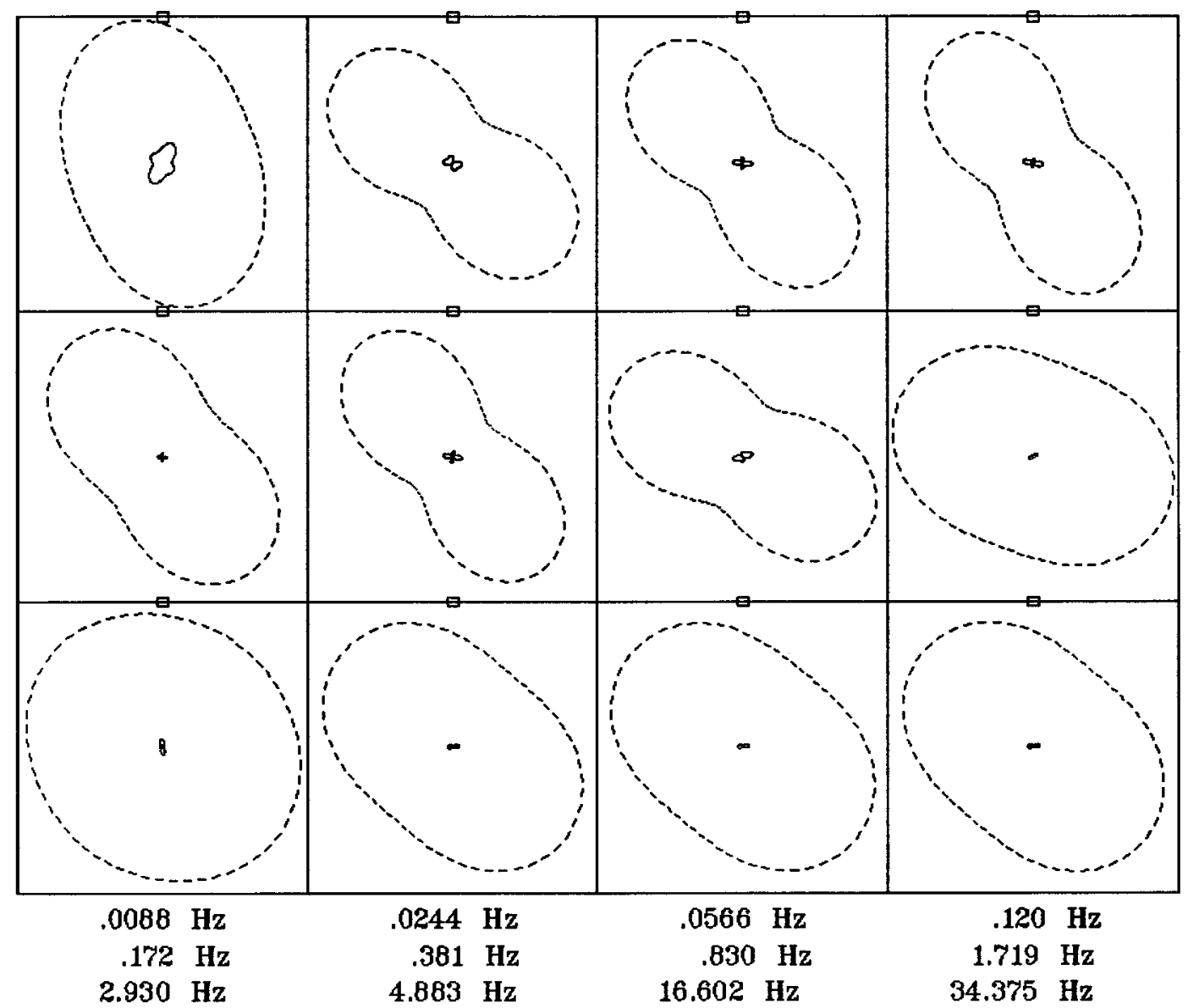

Client:

Remote: none

Acquired: 13:3 Jul 10, 2005

Survey Co:USGS
Rotation:

Filename: ap30mall.avg

Channels: Ch1 Ch2 Ch3 Ch4 Ch5 Ch3 Ch4

Plotted: 14:26 Jul 20, 2005

< EMI - ElectroMagnetic Instruments > 
TIPPER MAGNITUDE

Wells, NV 100k

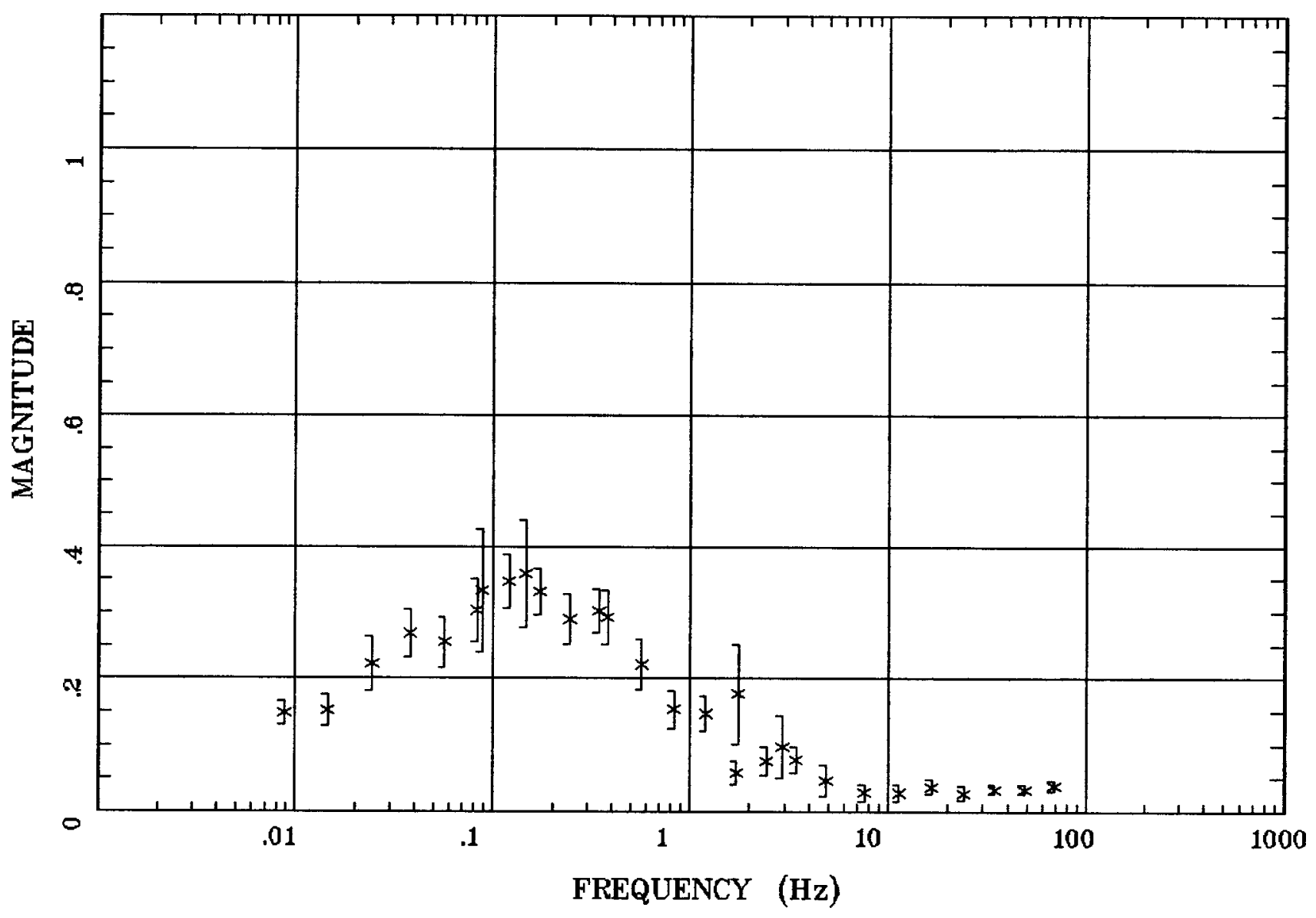

Client:

Remote: none Acquired: 13:3 Jul 10, 2005

Survey Co:USGS
Rotation:

Filename: ap30mall.avg

Channels: Ch1 Ch2 Ch3 Ch4 Ch5 Ch3 Ch4

Plotted: 14:26 Jul 20, 2005

< EMI - ElectroMagnetic Instruments 
Station 30

TIPPER STRIKE

Wells, NV 100k

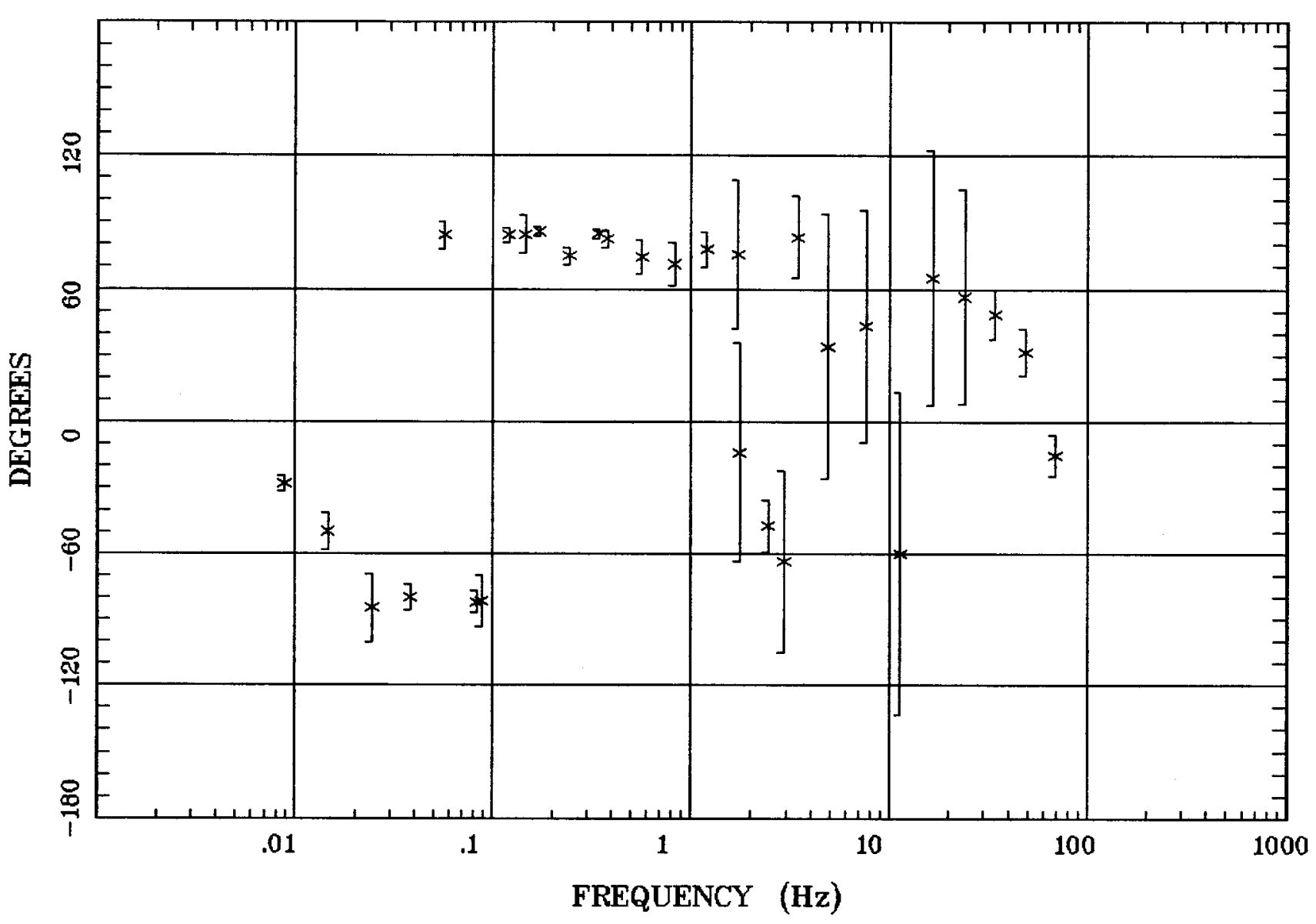

Client:

Remote: none Acquired: 13:3 Jul 10, 2005 Survey Co:USGS
Rotation:

Filename: ap30mall.avg

Channels: Ch1 Ch2 Ch3 Ch4 Ch5 Ch3 Ch4 Plotted: 14:26 Jul 20, 2005

< EMI - ElectroMagnetic Instruments > 
HzHx.x Coh HzHy.o

Wells, NV 100k

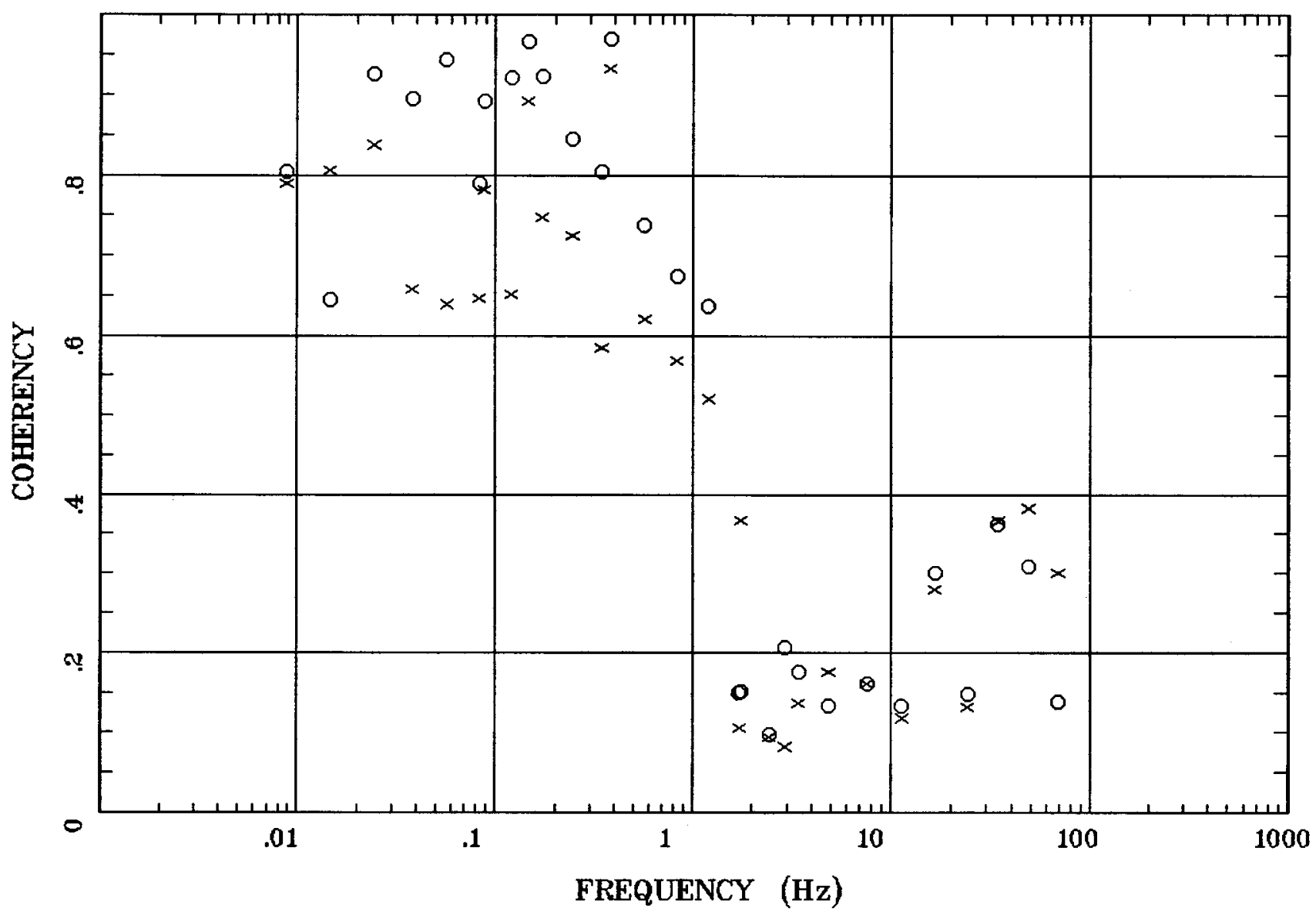

Client:

Remote: none

Acquired: 13:3 Jul 10, 2005

Survey Co:USGS
Rotation:

Filename: ap30mall.avg

Channels: Ch1 Ch2 Ch3 Ch4 Ch5 Ch3 Ch4

Plotted: 14:26 Jul 20, 2005

< EMI - ElectroMagnetic Instruments > 
APPARENT RESISTIVITY Wells, NV 100k

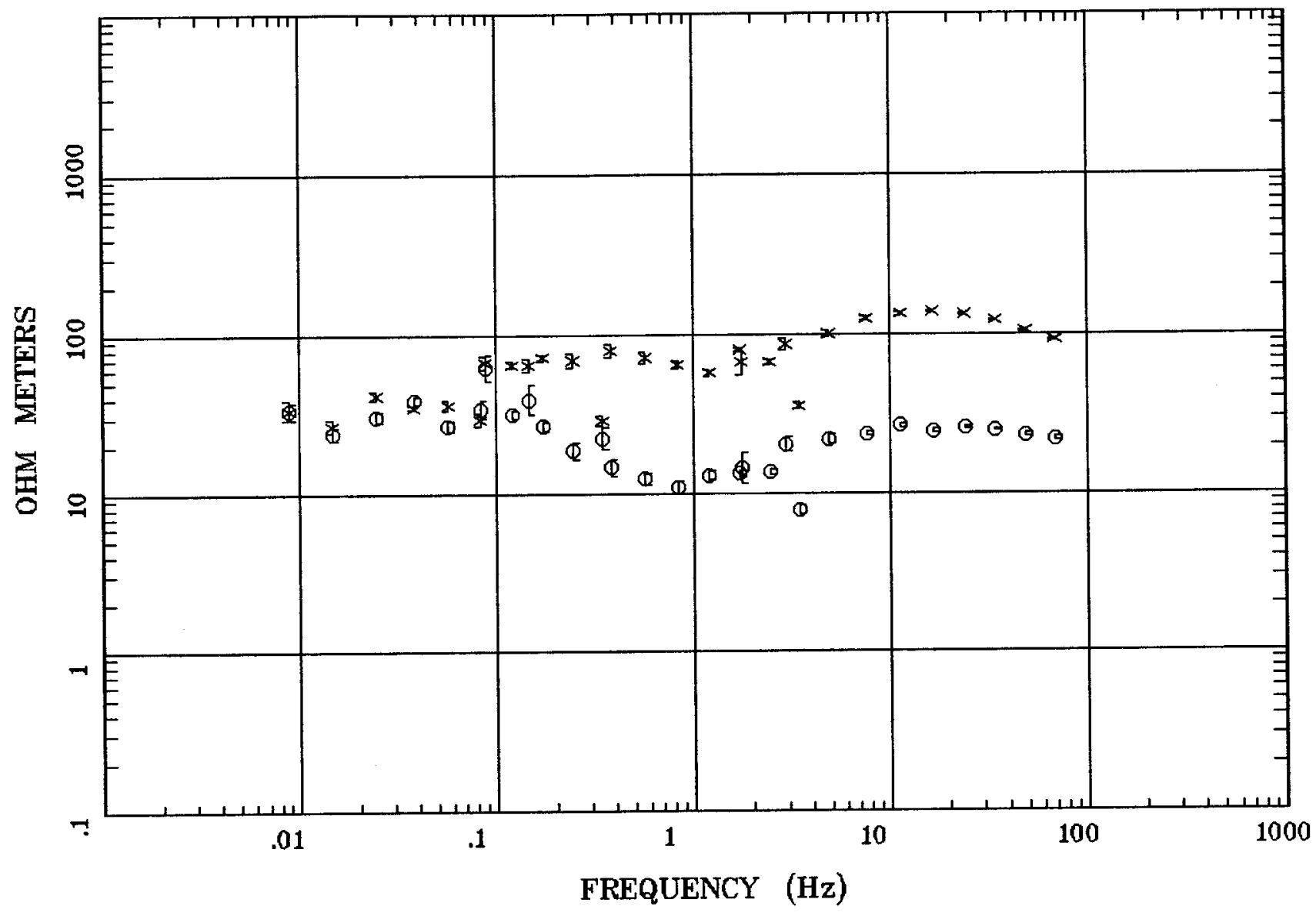

Client:

Remote: none

Acquired: 14:5 Jul 09, 2005 Survey Co:USGS
Rotation:

Filename: ap29mall.avg

Channels: Ch1 Ch2 Ch3 Ch4 Ch5 Ch3 Ch4 Plotted: 14:25 Jul 20, 2005

< EMI - ElectroMagnetic Instruments > 
IMPEDANCE PHASE

Wells, NV 100k

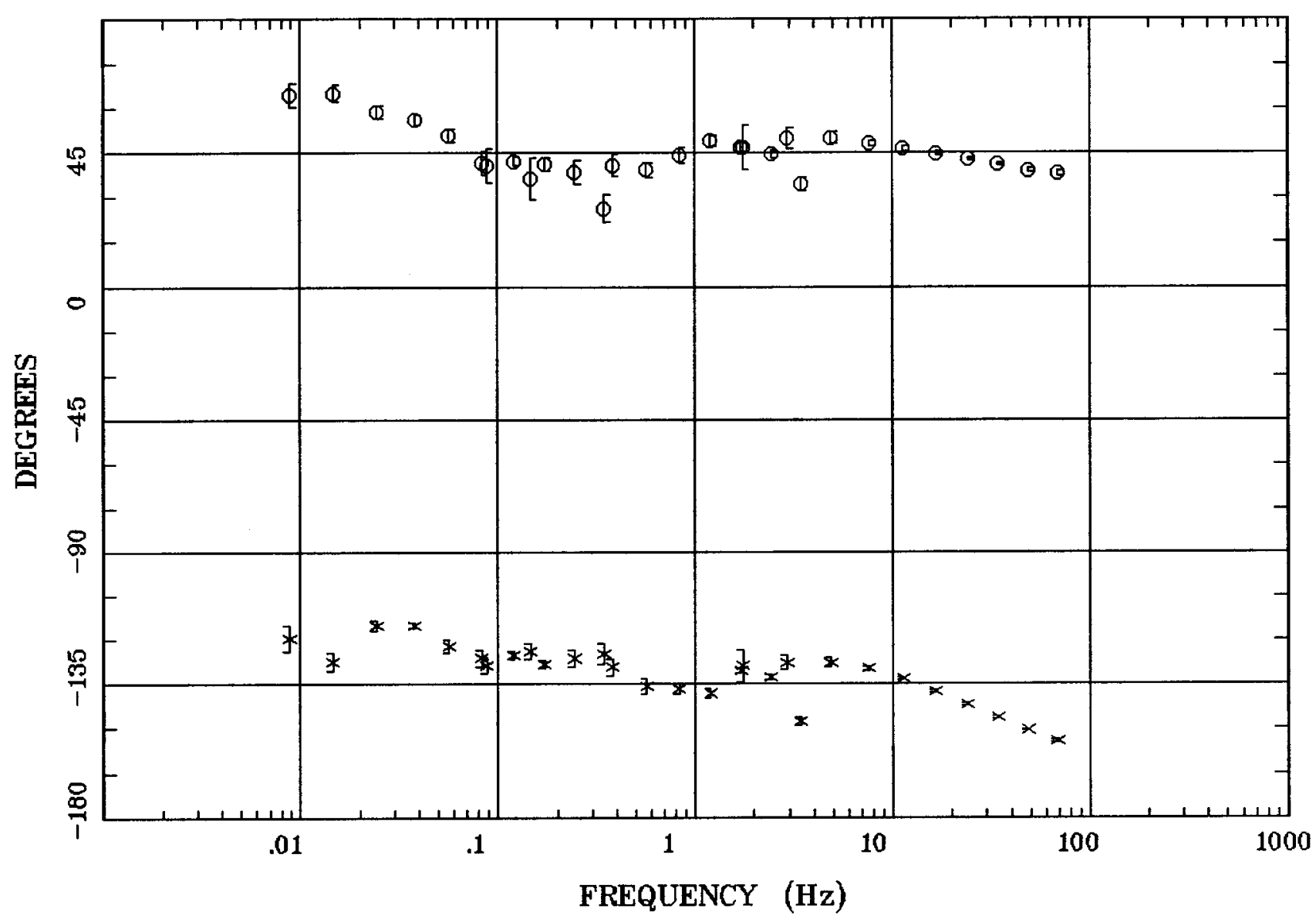

Client:

Remote: none

Acquired: 14:5 Jul 09, 2005

Survey Co:USGS
Rotation:

Filename: ap29mall.avg

Channels: Ch1 Ch2 Ch3 Ch4 Ch5 Ch3 Ch4

Plotted: 14:25 Jul 20, 2005

< EMI - ElectroMagnetic Instruments > 
IMPEDANCE SKEW

Wells, NV 100k

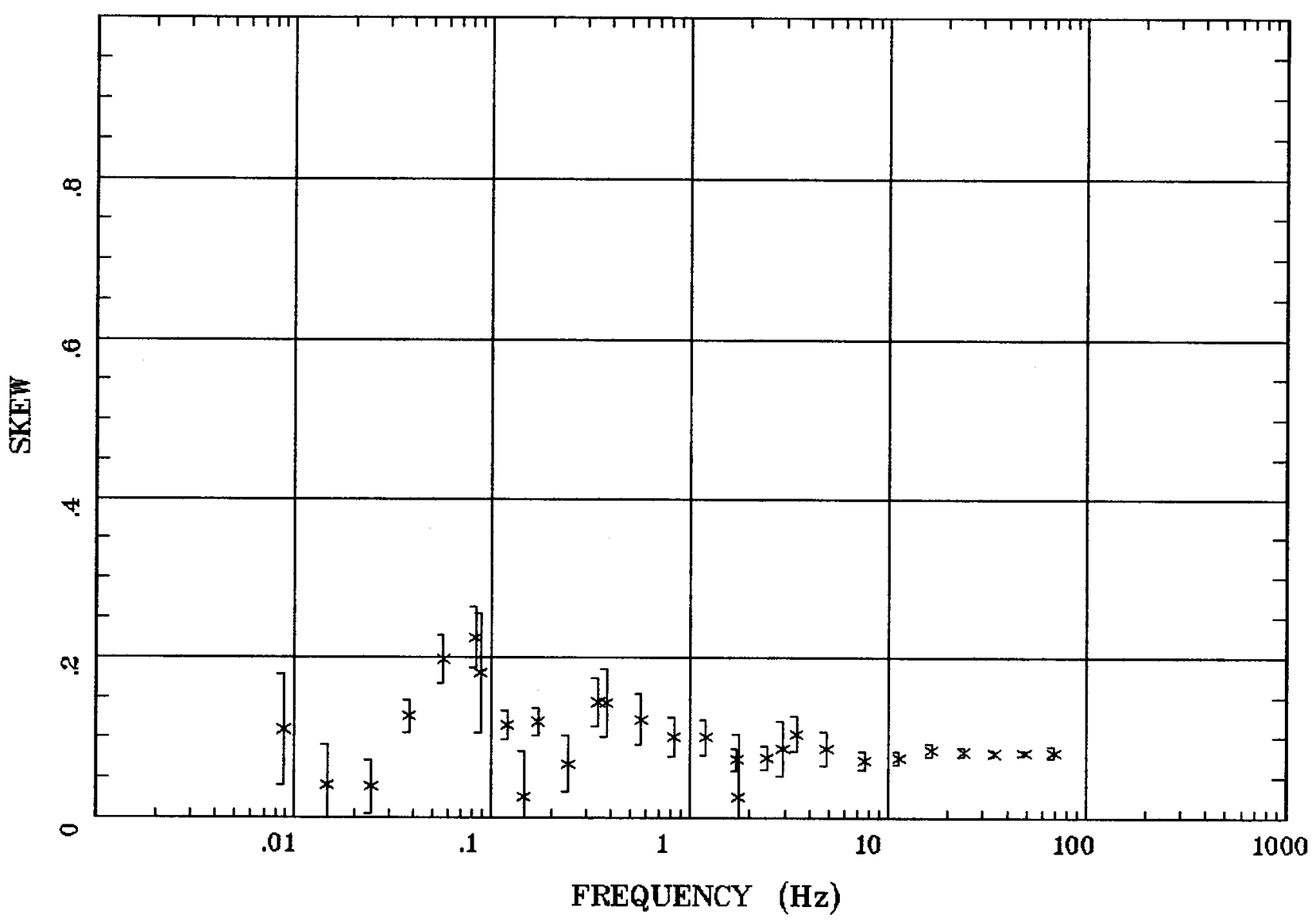

Client:

Remote: none

Acquired: 14:5 Jul 09, 2005

Survey Co:USGS

Rotation:

Filename: ap29mall.avg

Channels: Ch1 Ch2 Ch3 Ch4 Ch5 Ch3 Ch4

Plotted: 14:25 Jul 20, 2005

< EMI - ElectroMagnetic Instruments > 
Station 29

E MULT Coh. Wells, NV 100k

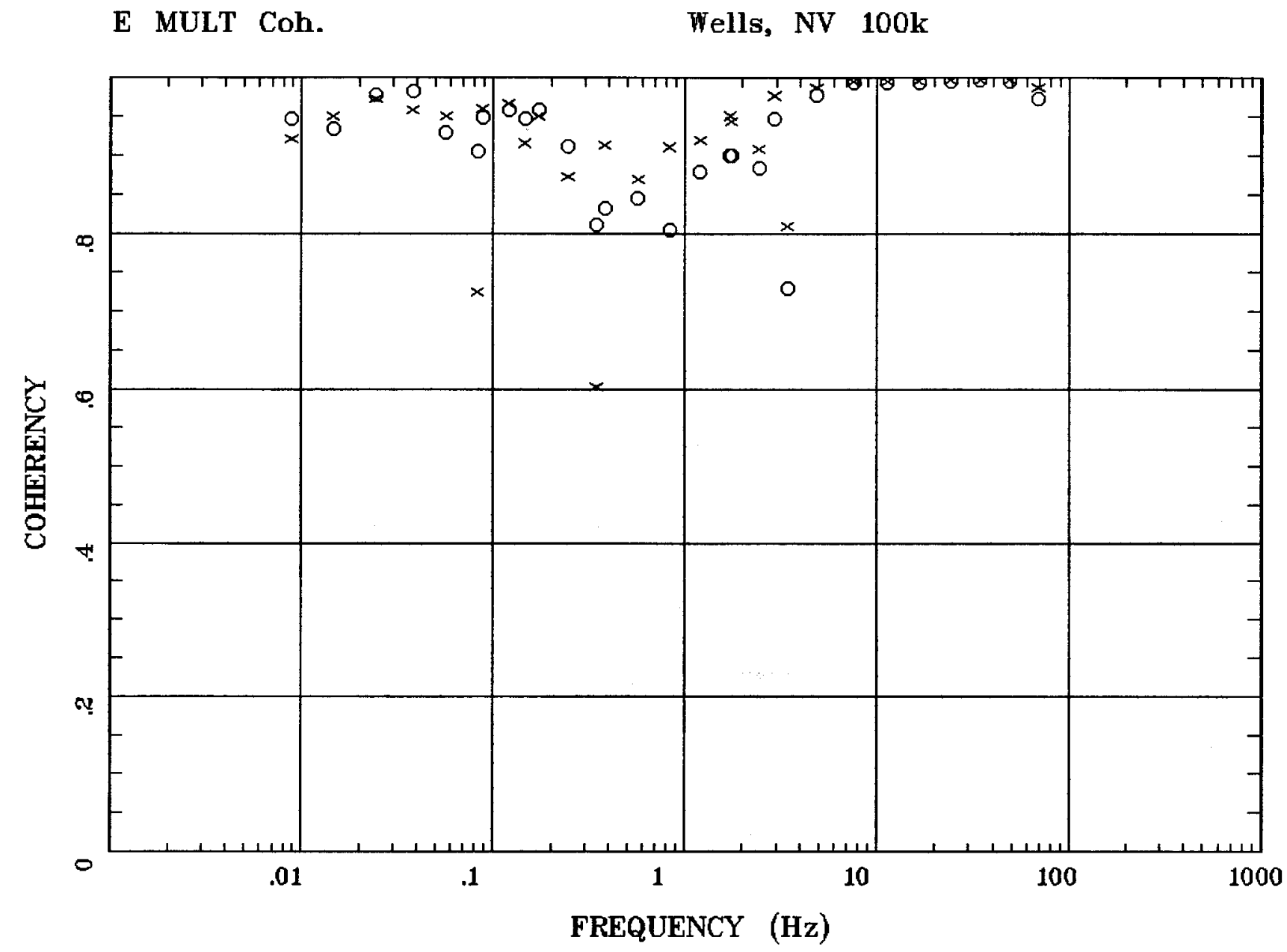

Client:

Remote: none

Acquired: 14:5 Jul 09, 2005 Survey Co:USGS
Rotation:

Filename: ap29mall.avg

Channels: Ch1 Ch2 Ch3 Ch4 Ch5 Ch3 Ch4 Plotted: 14:25 Jul 20, 2005

< EMI - ElectroMagnetic Instruments 


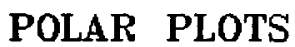

Wells, NV 100k

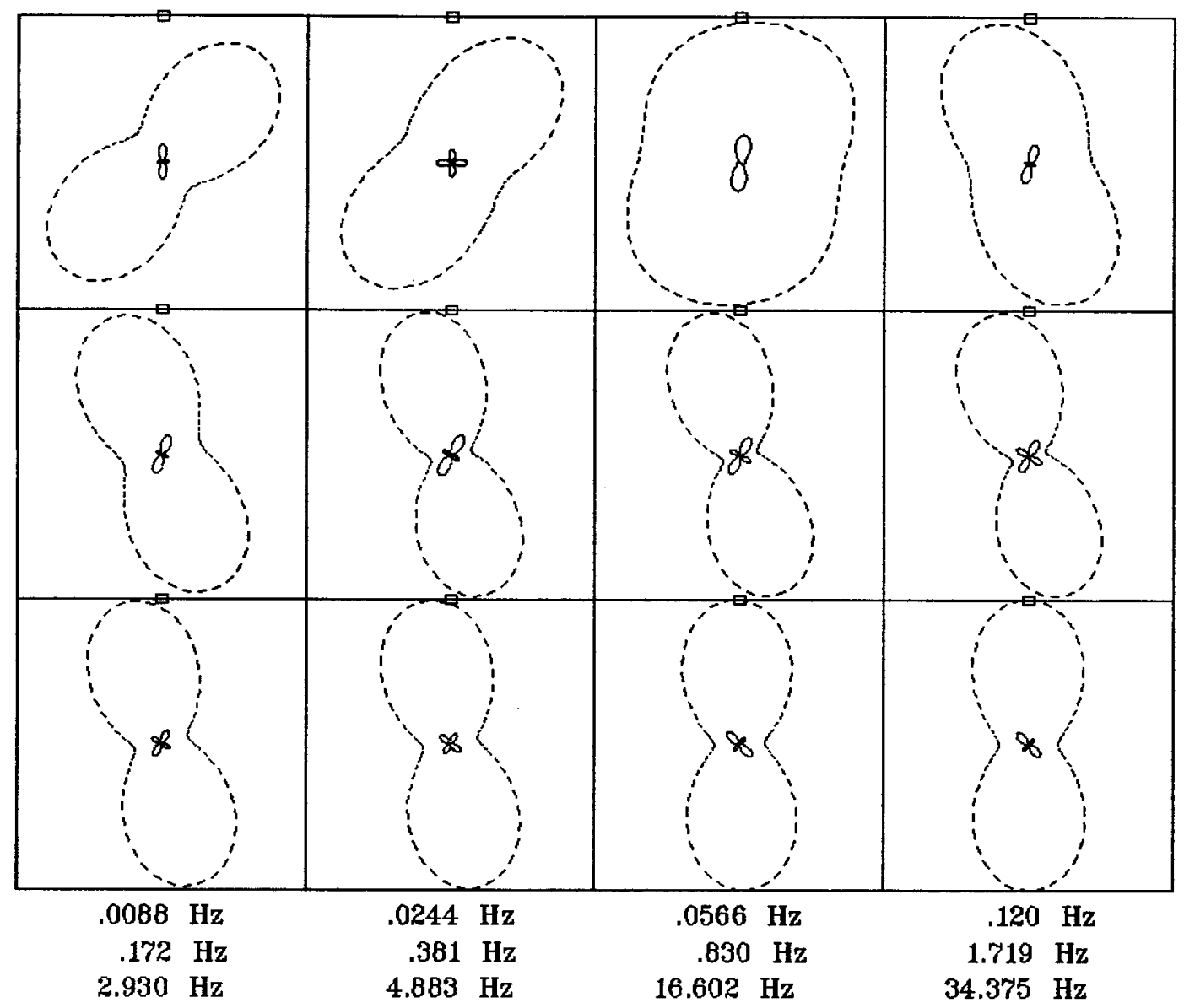

Client:

Remote: none

Acquired: 14:5 Jul 09, 2005

Survey Co:USGS
Rotation:

Filename: ap29mall.avg

Channels: Ch1 Ch2 Ch3 Ch4 Ch5 Ch3 Ch4

Plotted: 14:25 Jul 20, 2005

<EMI - ElectroMagnetic Instruments > 
TIPPER MAGNITUDE

Wells, NV 100k

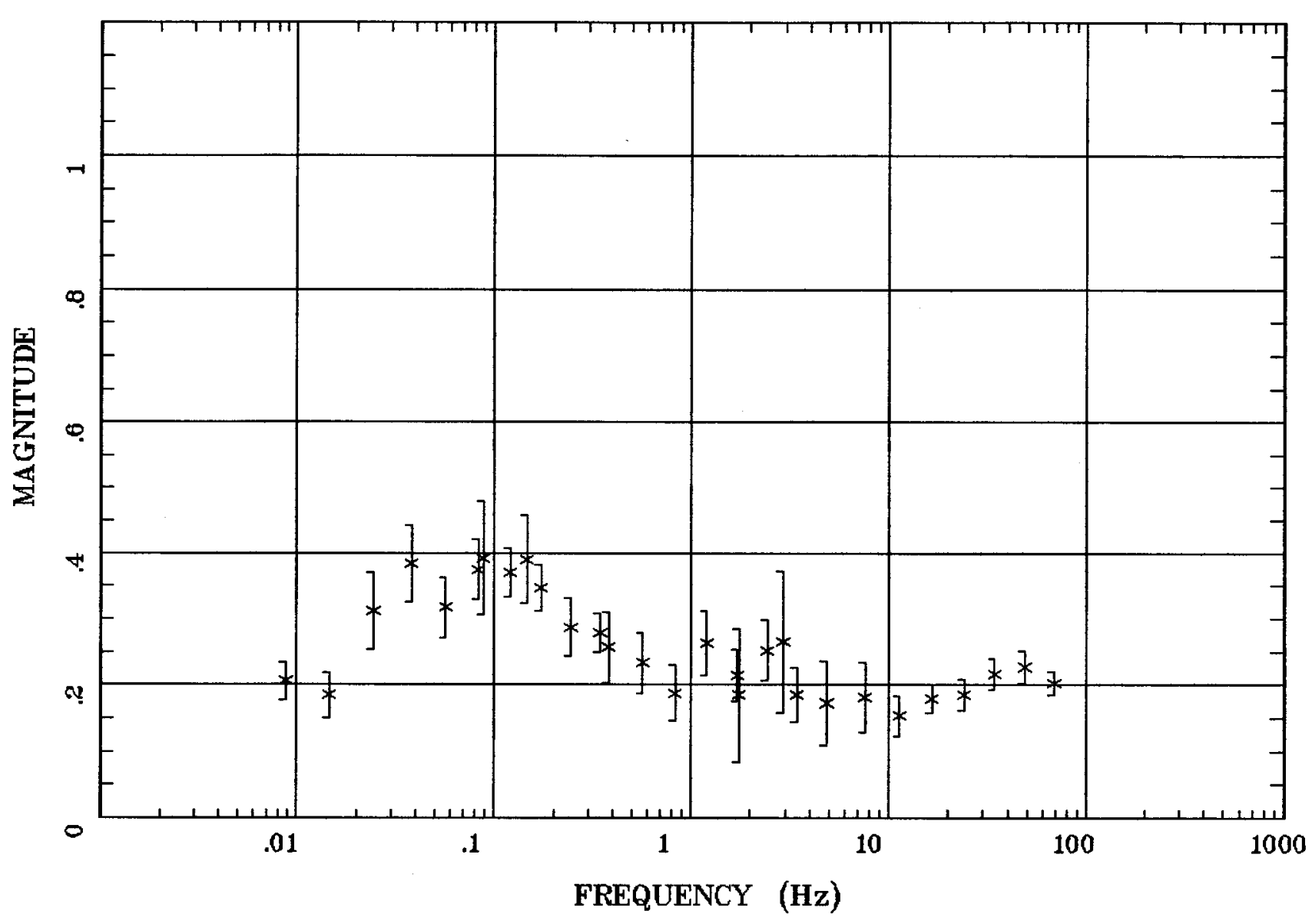

Client:

Remote: none

Acquired: 14:5 Jul 09, 2005 Survey Co:USGS
Rotation:

Filename: ap29mall.avg

Channels: Ch1 Ch2 Ch3 Ch4 Ch5 Ch3 Ch4

Plotted: 14:25 Jul 20, 2005

$<$ EMI - ElectroMagnetic Instruments 
TIPPER STRIKE

Wells, NV $100 \mathrm{k}$

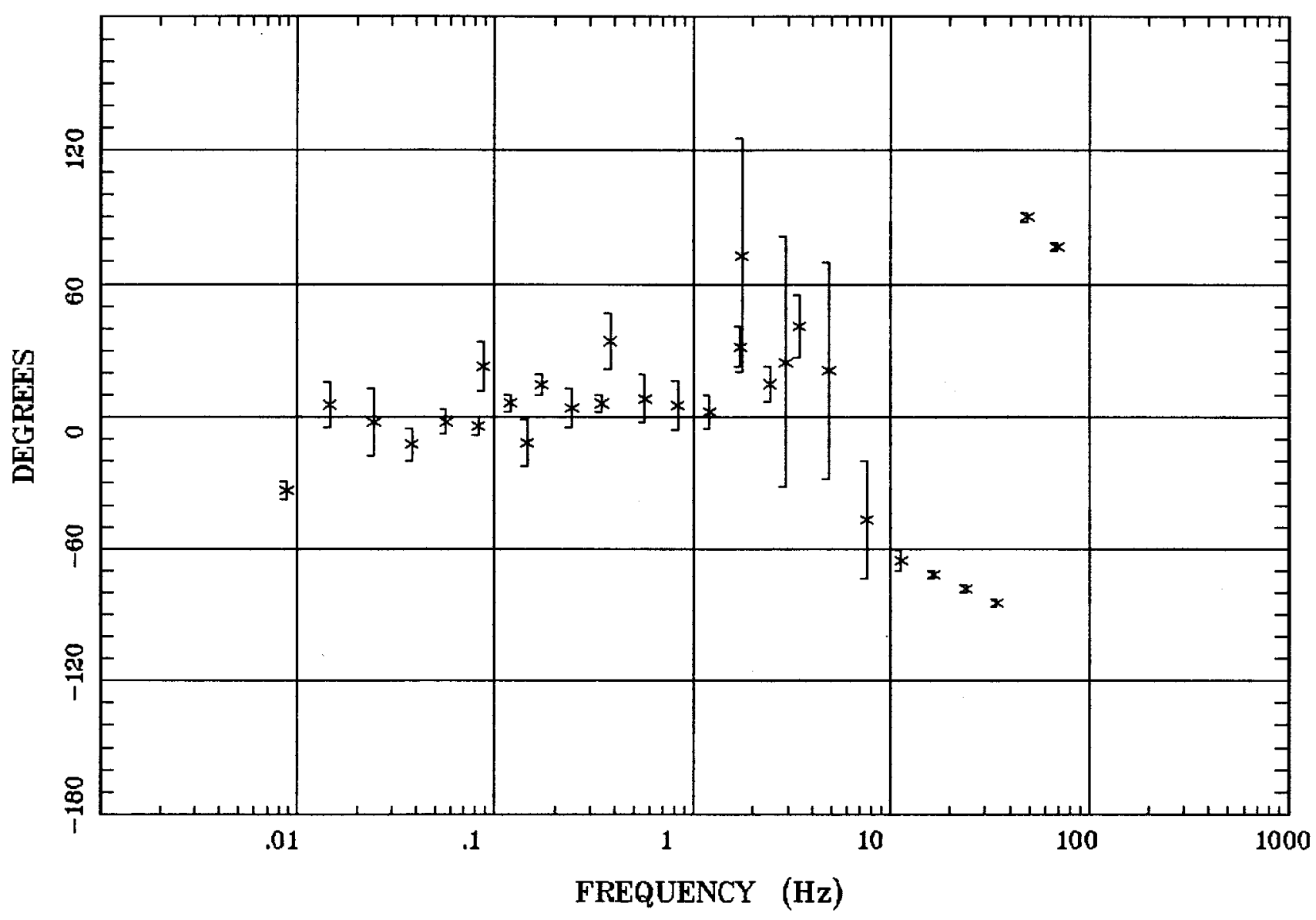

Client:

Remote: none

Acquired: 14:5 Jul 09, 2005

Survey Co:USGS
Rotation:

Filename: ap29mall.avg

Channels: Ch1 Ch2 Ch3 Ch4 Ch5 Ch3 Ch4

Plotted: 14:25 Jul 20, 2005

< EMI - ElectroMagnetic Instruments 
Station 29

HzHx.x Coh HzHy.o

Wells, NV 100k

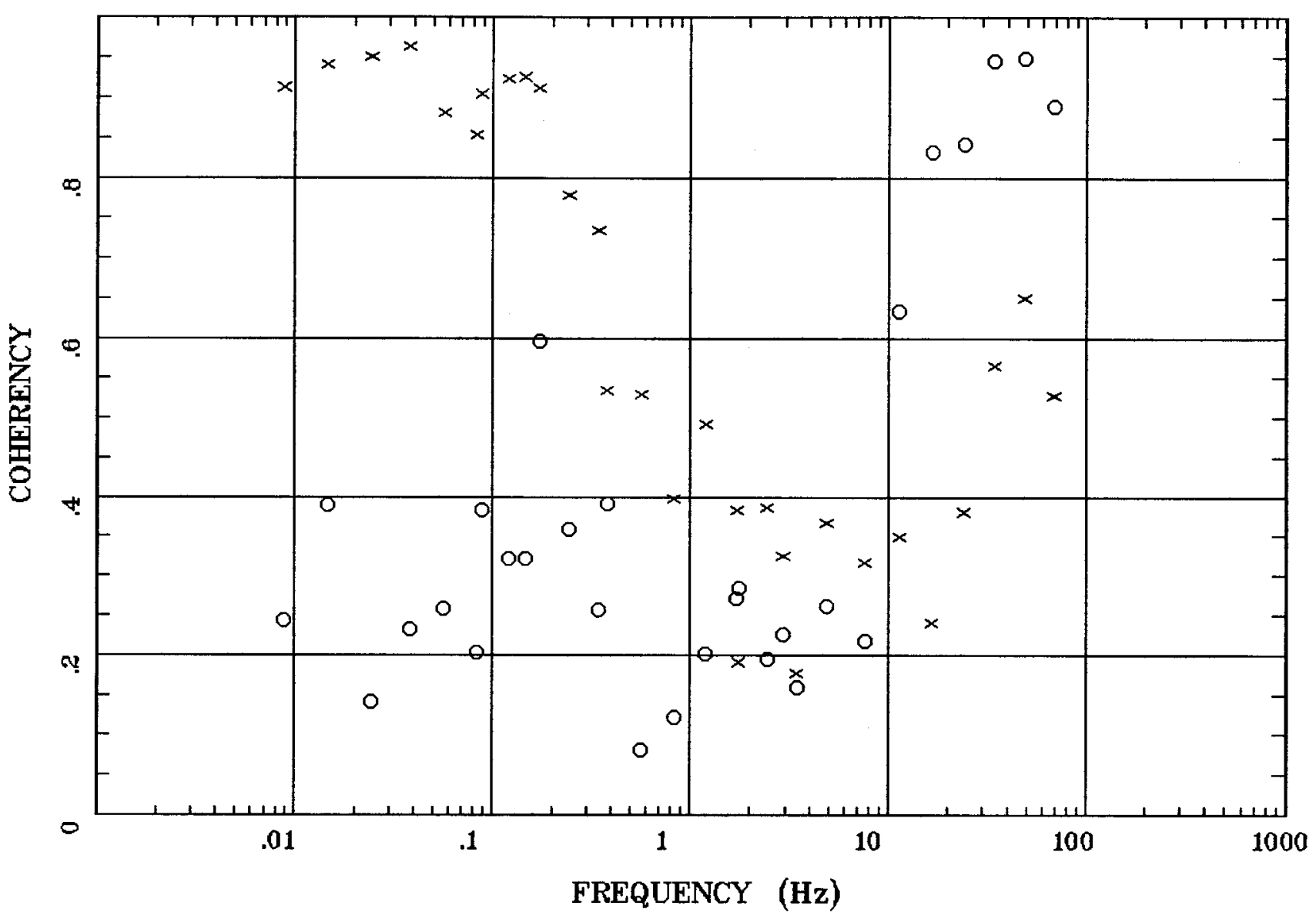

Client:

Remote: none

Acquired: 14:5 Jul 09, 2005

Survey Co:USGS
Rotation:

Filename: ap29mall.avg

Channels: Ch1 Ch2 Ch3 Ch4 Ch5 Ch3 Ch4

Plotted: 14:25 Jul 20, 2005

< EMI - ElectroMagnetic Instruments > 


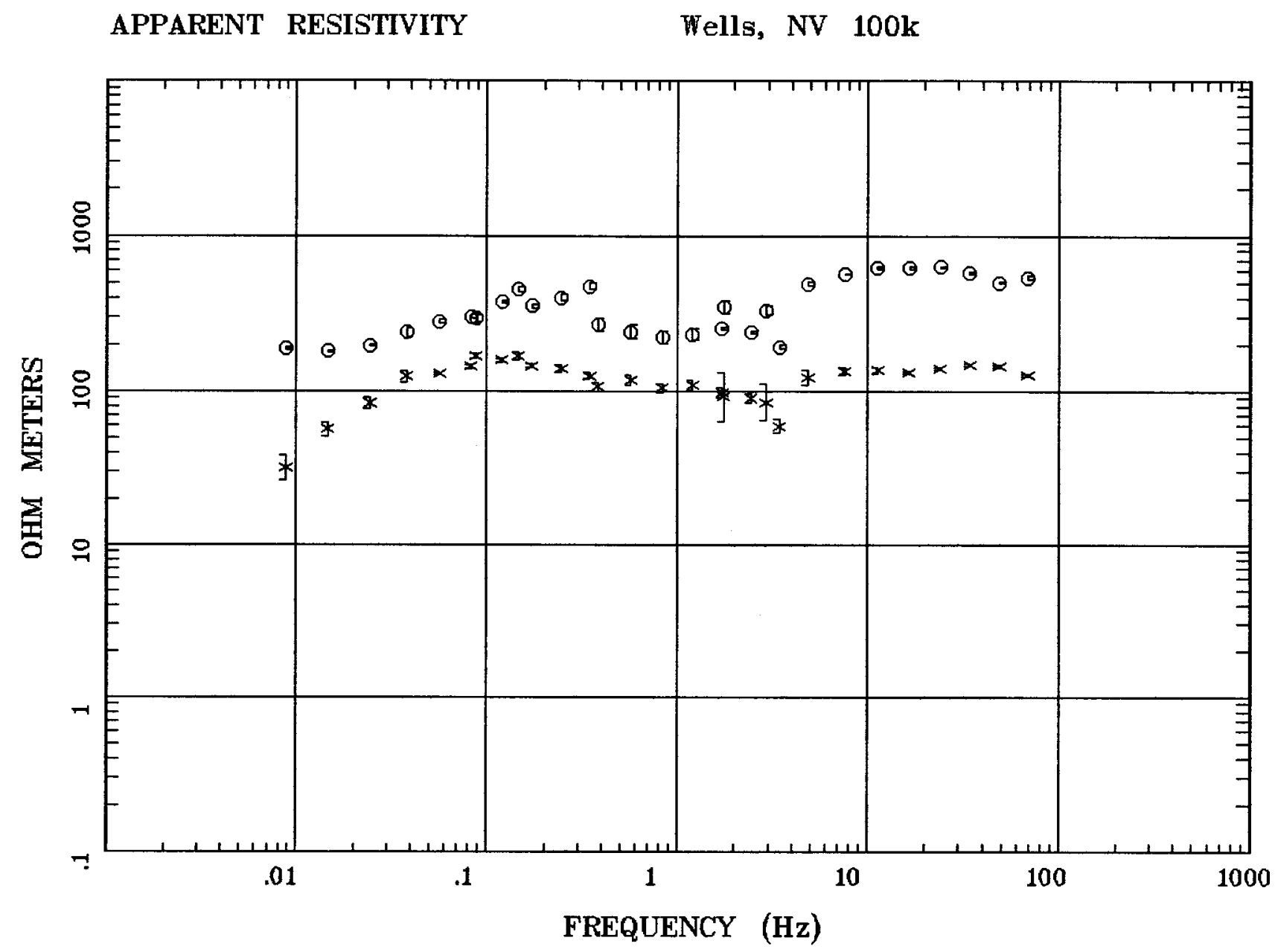

Client:

Remote: none

Acquired: 10:2 Jul 09, 2005

Survey Co:USGS

\section{Rotation:}

Filename: ap28mall.avg

Channels: Ch1 Ch2 Ch3 Ch4 Ch5 Ch3 Ch4 Plotted: 14:24 Jul 20, 2005

< EMI - ElectroMagnetic Instruments > 
IMPEDANCE PHASE

Wells, NV 100k

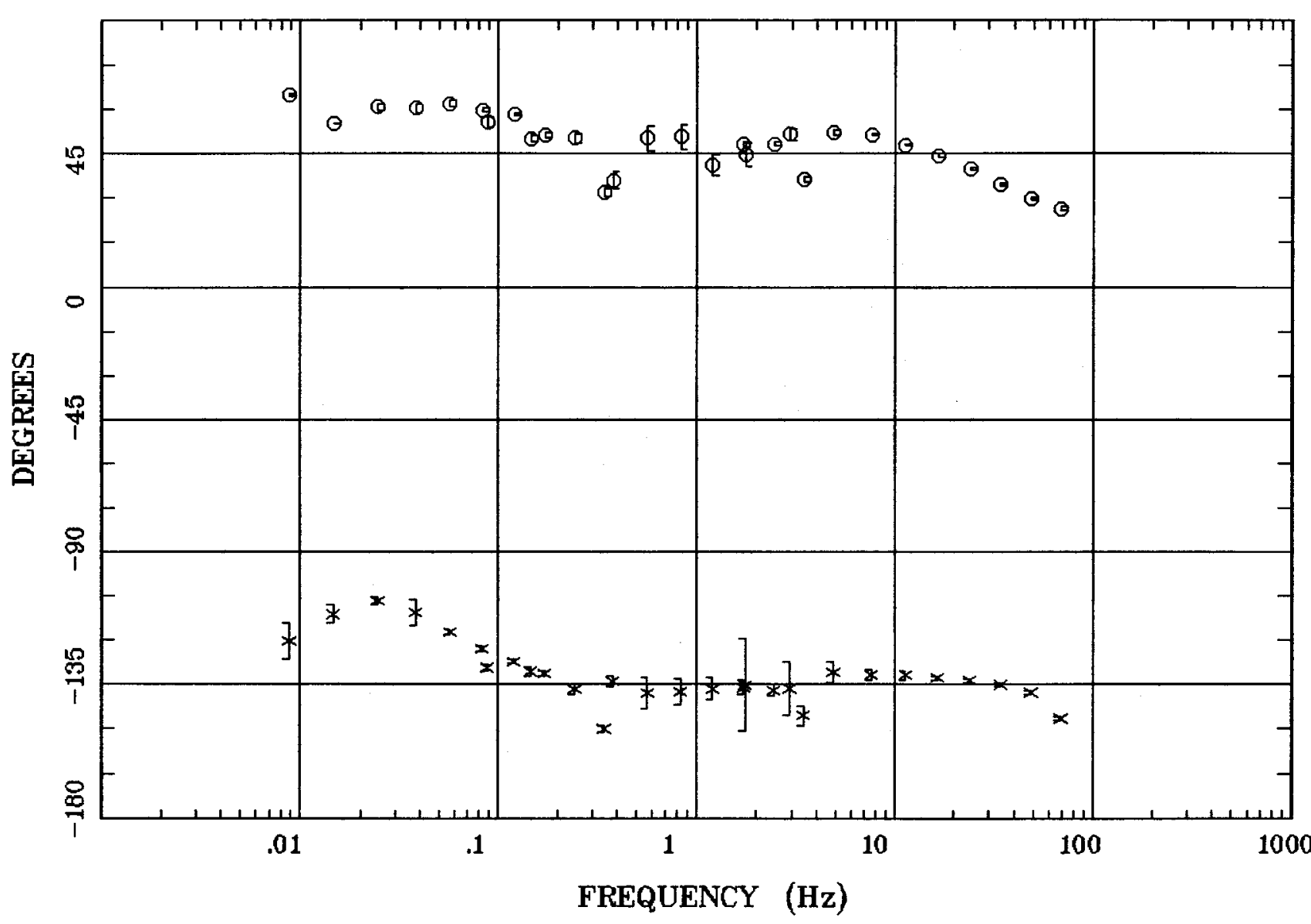

Client:

Remote: none

Acquired: 10:2 Jul 09, 2005 Survey Co:USGS
Rotation:

Filename: ap28mall.avg Channels: Ch1 Ch2 Ch3 ch4 Ch5 Ch3 Ch4 Platted: 14:24 Jul 20, 2005

< EMI - ElectroMagnetic Instruments 


\section{Station 28}

IMPEDANCE SKEW

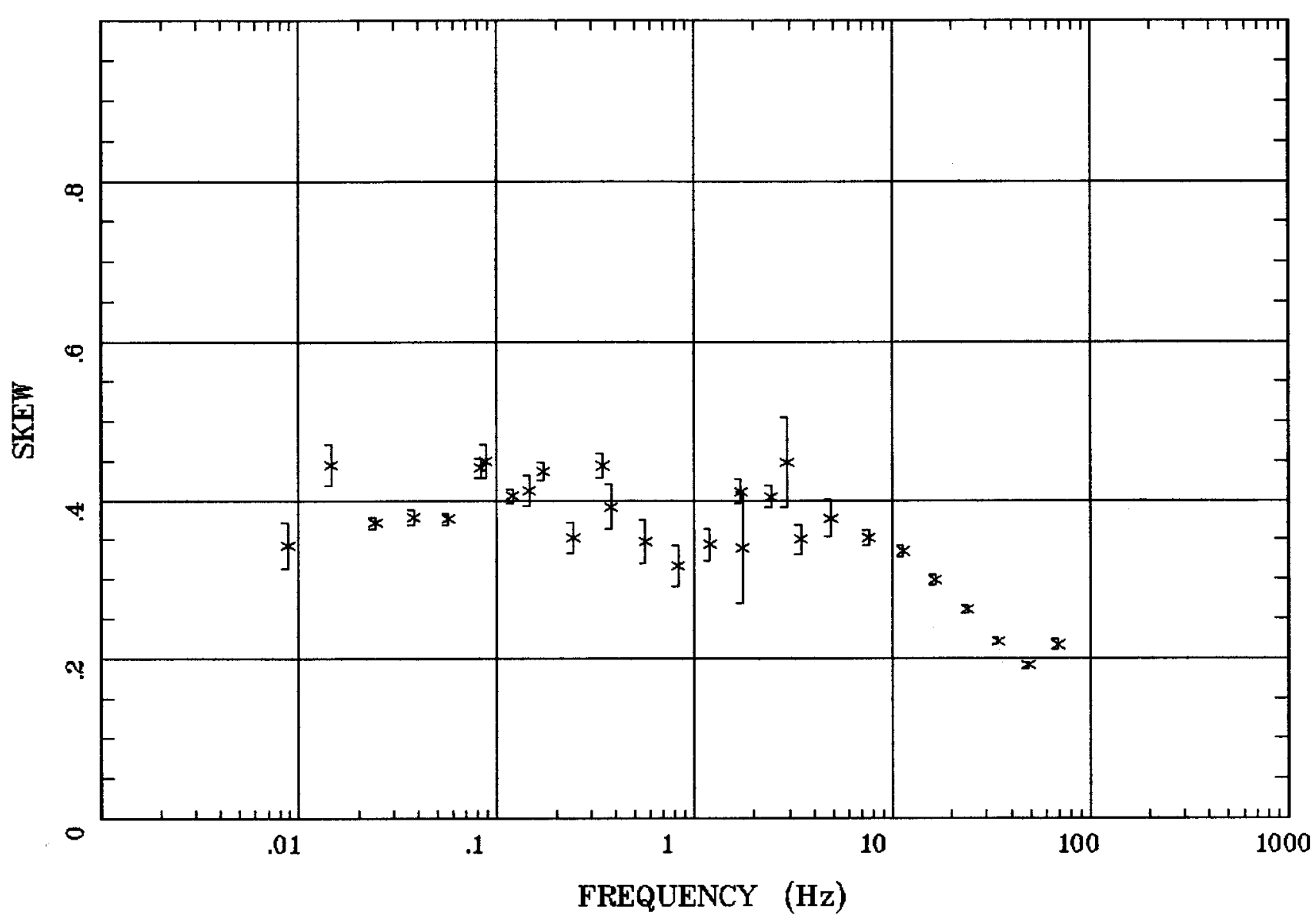

Client:

Remote: none

Acquired: 10:2 Jul 09, 2005 Survey Co:USGS

\section{Rotation:}

Filename: ap26mall.avg

Channels: Ch1 Ch2 Ch3 Ch4 Ch5 Ch3 Ch4 Plotted: 14:24 Jul 20, 2005

< EMI - ElectroMagnetic Instruments > 
E MULT Coh.

Wells, NV 100k

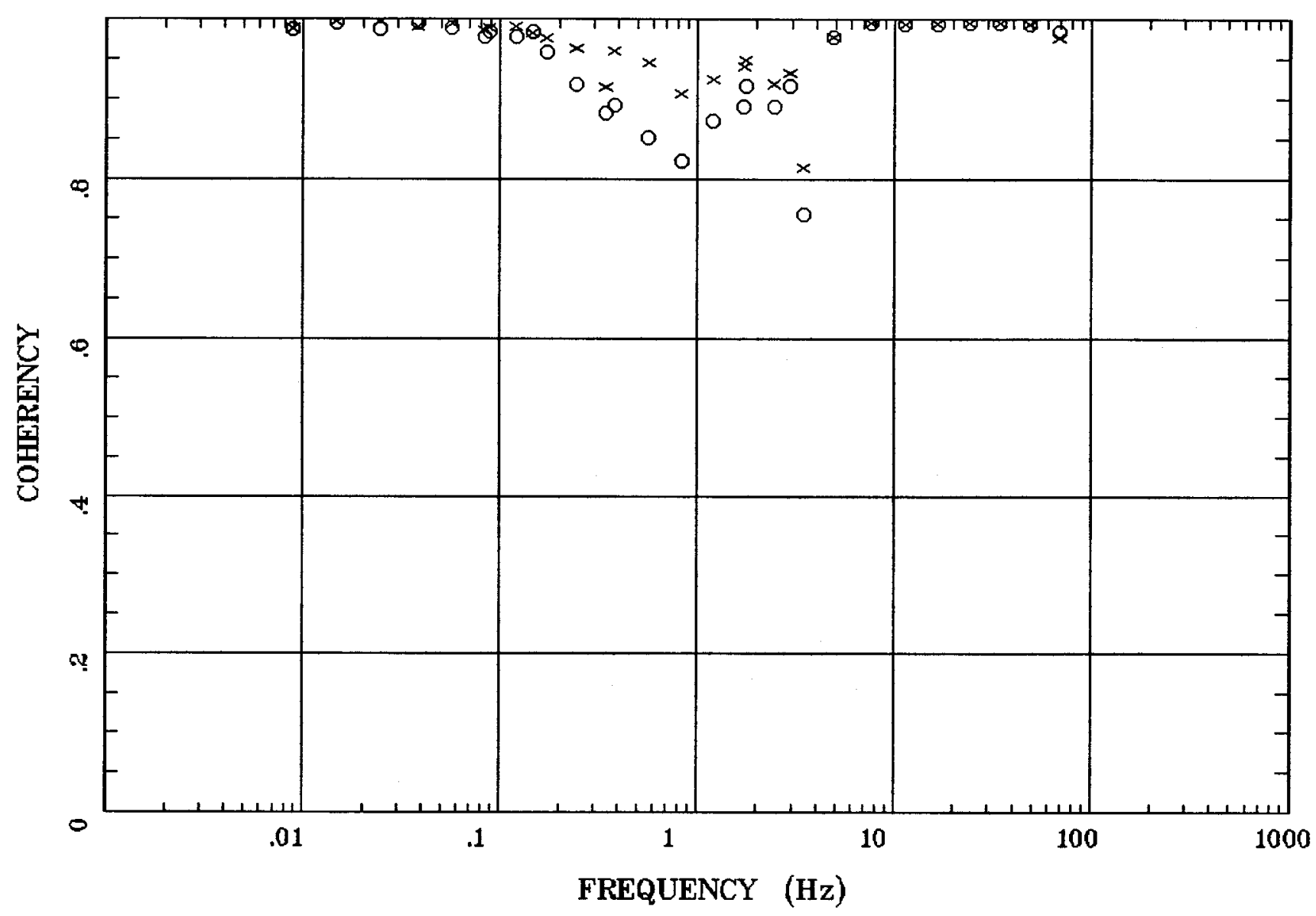

Client:

Remote: none

Acquired: 10:2 Jul 09, 2005

Survey Co:USGS
Rotation:

Filename: ap28mall.avg

Channels: Ch1 Ch2 Ch3 Ch4 Ch5 Ch3 Ch4

Plotted: 14:24 Jul 20, 2005

< EMI - ElectroMagnetic Instruments > 


\section{POLAR PLOTS}

Wells, NV 100k

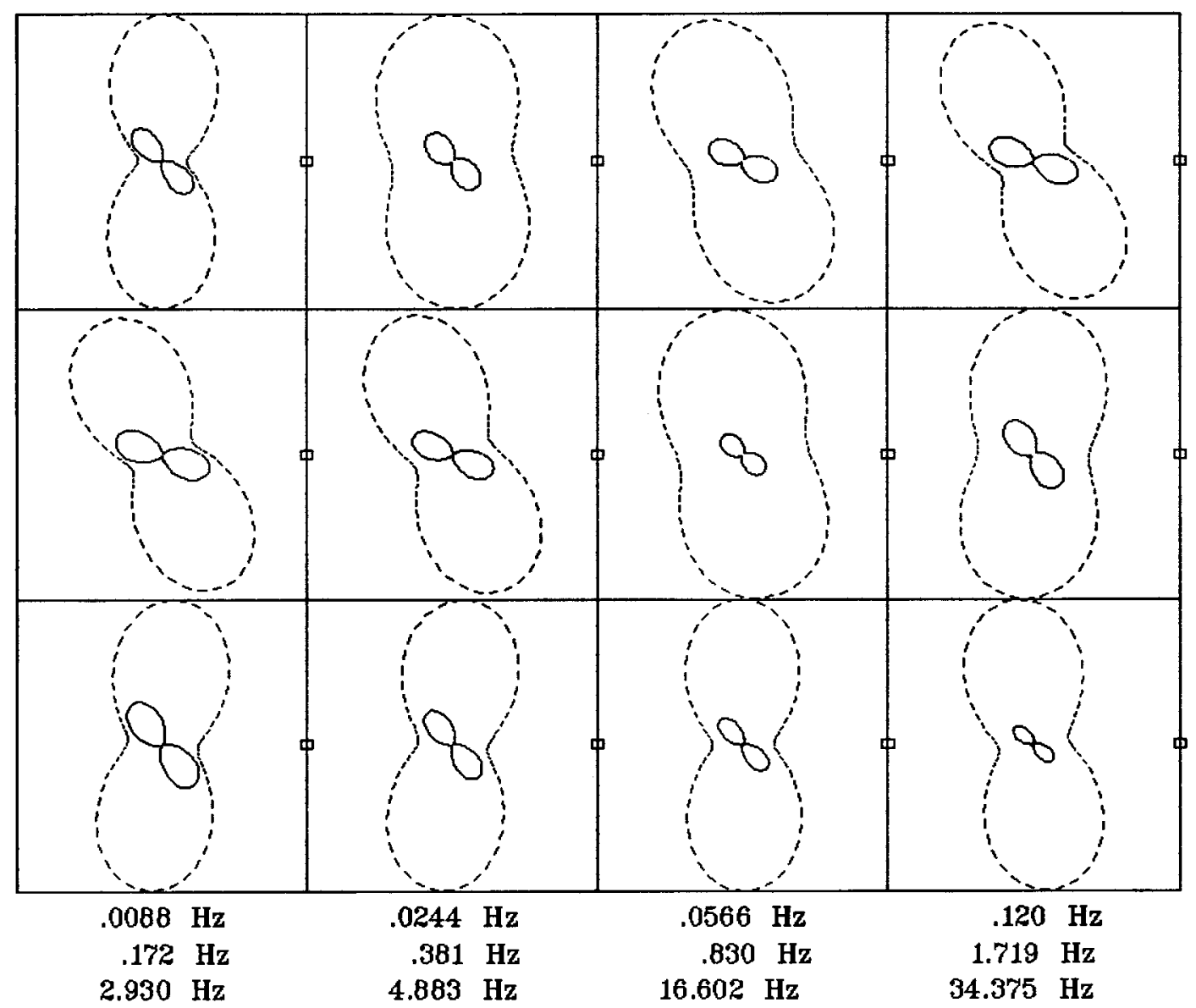

Rotation:

Client:

Remote: none

Acquired: 10:2 Jul 09, 2005 Survey Co:USGS
Filename: ap28mall.avg

Channels: Ch1 Ch2 Ch3 Ch4 Ch5 Ch3 Ch4 Plotted: 14:24 Jul 20, 2005

$<$ EMI - ElectroMagnetic Instruments 
TIPPER MAGNITUDE

Wells, NV 100k

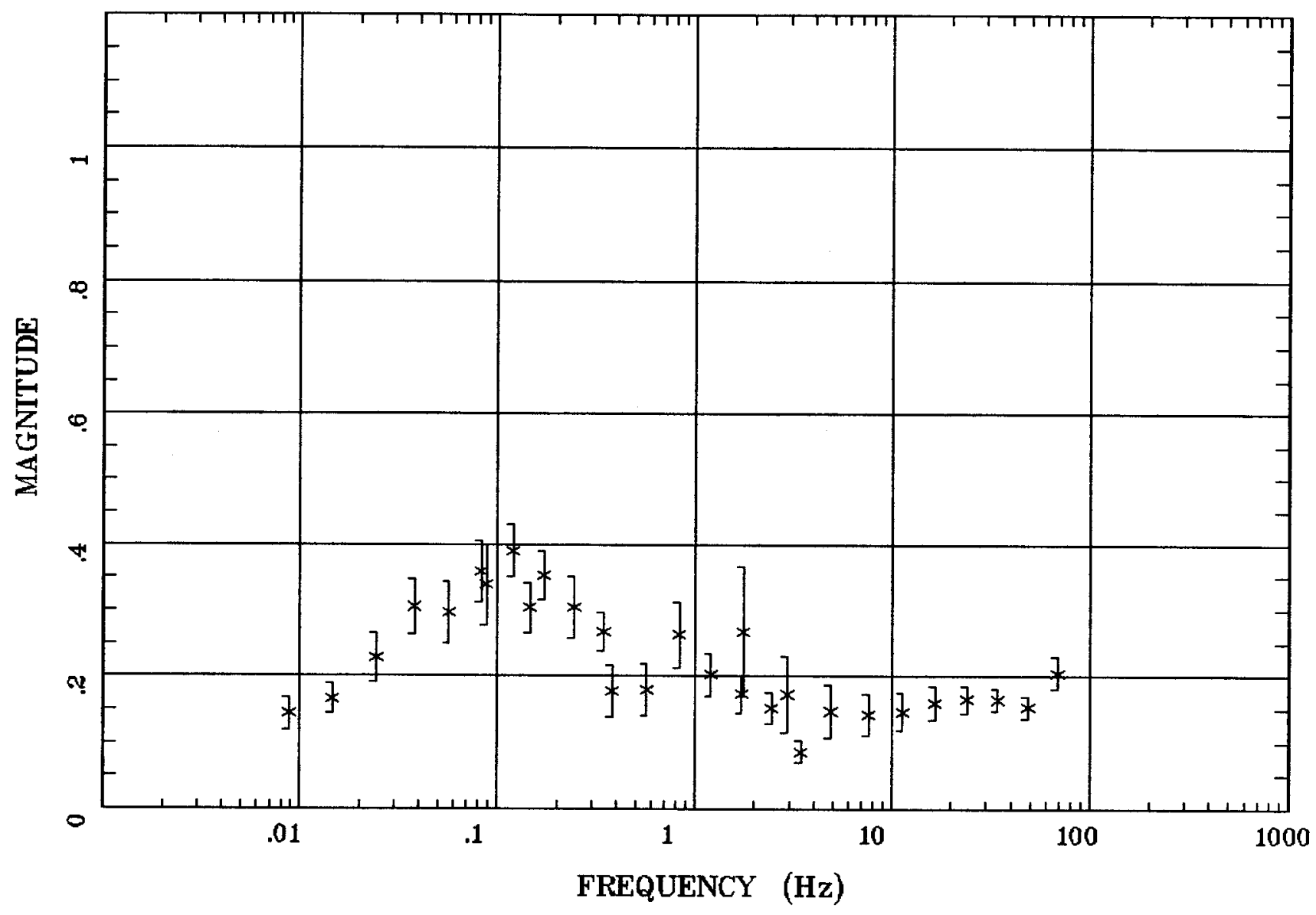

Client:

Remote: none

Acquired: 10:2 Jul 09, 2005 Survey Co:USGS
Rotation:

Filename: ap28mall.avg

Channels: Ch1 Ch2 Ch3 Ch4 Ch5 Ch3 Ch4

Plotted: 14:24 Jul 20, 2005

$<$ EMI - ElectroMagnetic Instruments 
TIPPER STRIKE

Wells, NV 100k

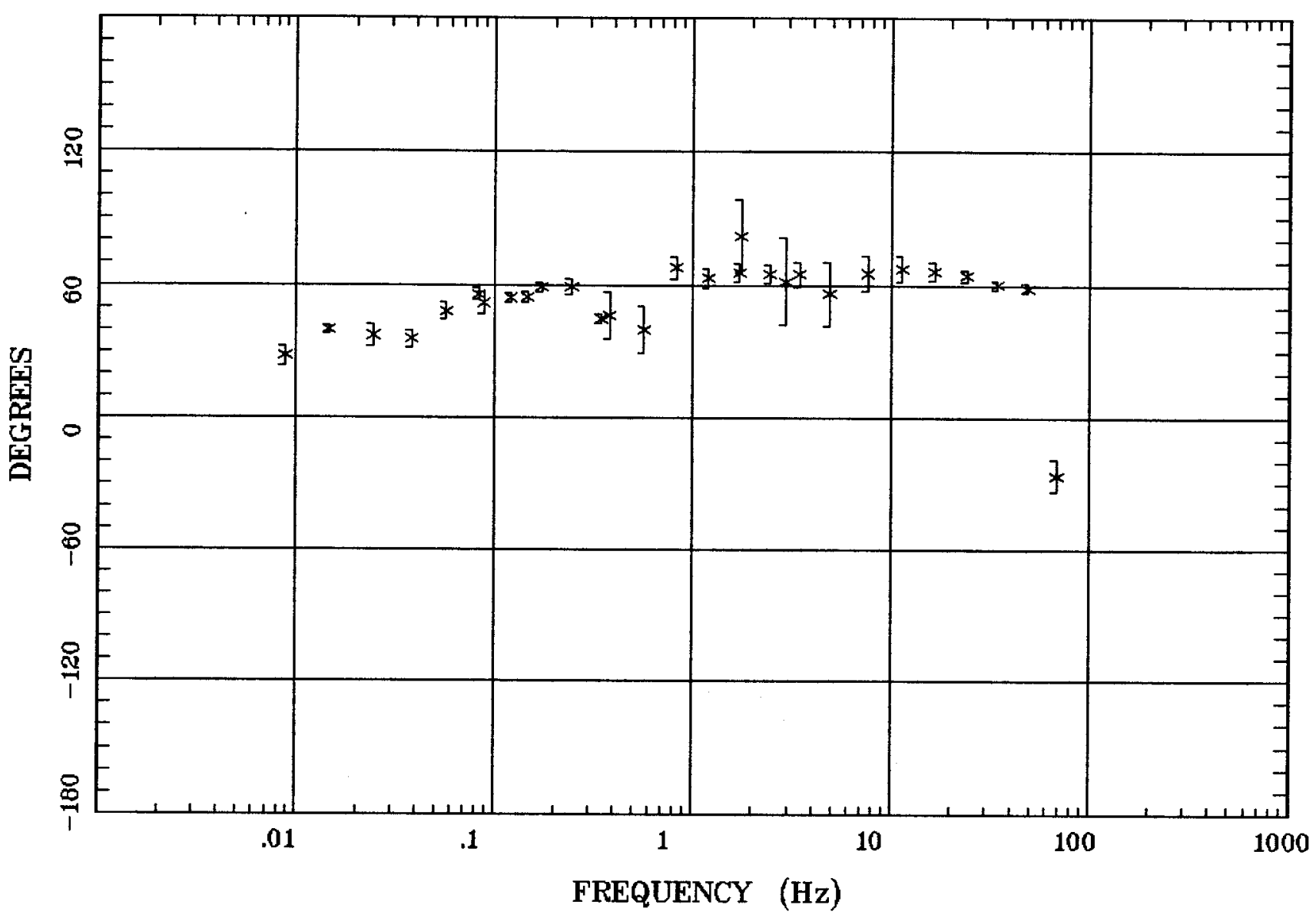

Client:

Rotation:

Remote: none

Filename: ap28mall.avg

Acquired: 10:2 Jul 09, 2005

Channels: Ch1 Ch2 Ch3 Ch4 Ch5 Ch3 Ch4

Plotted: 14:24 Jul 20, 2005

Survey Co:USGS

< EMI - ElectroMagnetic Instruments > 
HzHx.x Coh HzHy.o

Wells, NV 100k

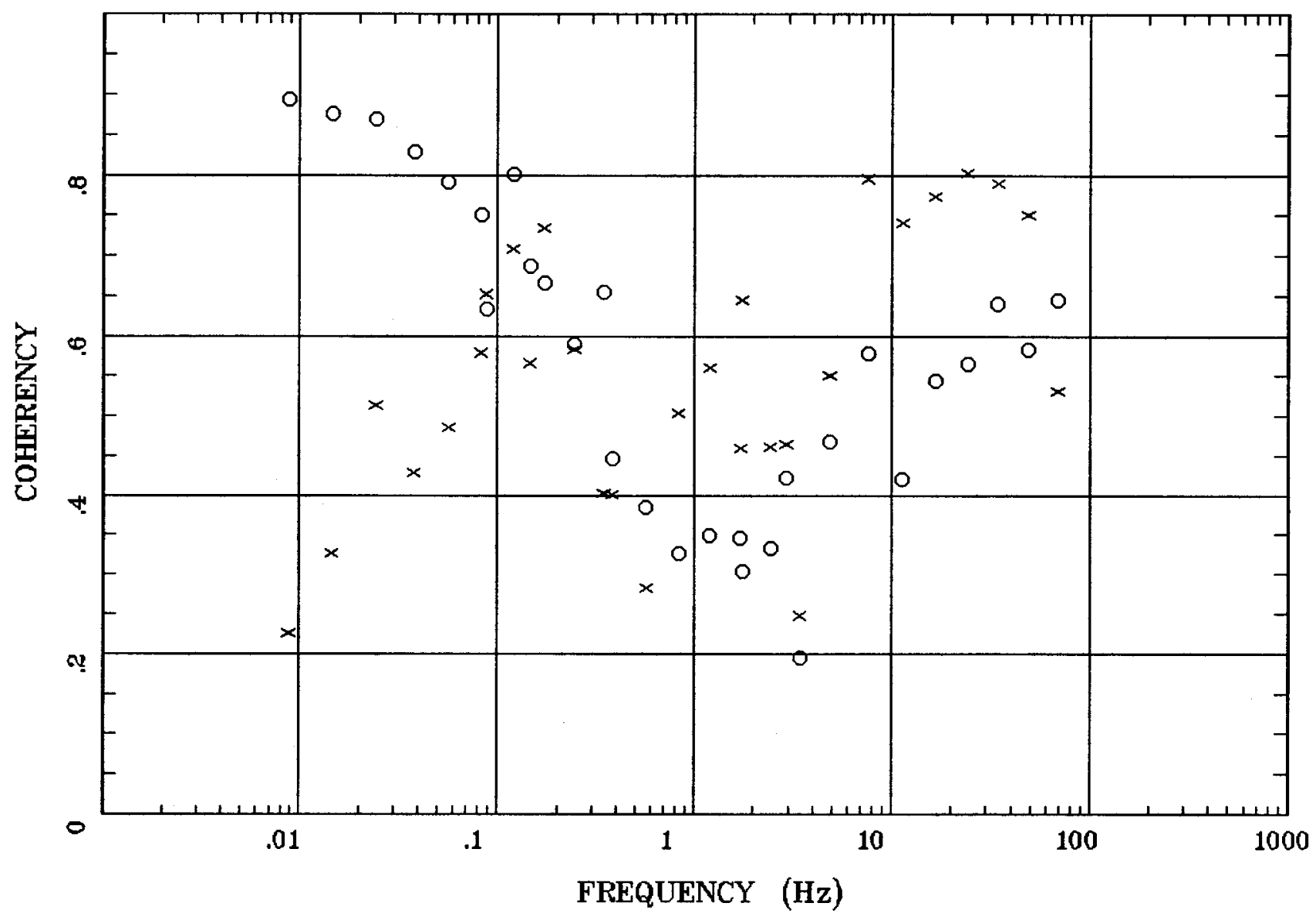

Client:

Remote: none

Acquired: 10:2 Jul 09, 2005

Survey Co:USGS
Rotation:

Filename: ap28mall.avg

Channels: Ch1 Ch2 Ch3 Ch4 Ch5 Ch3 Ch4

Plotted: 14:24 Jul 20, 2005

$<$ EMI - ElectroMagnetic Instruments 
Station 27

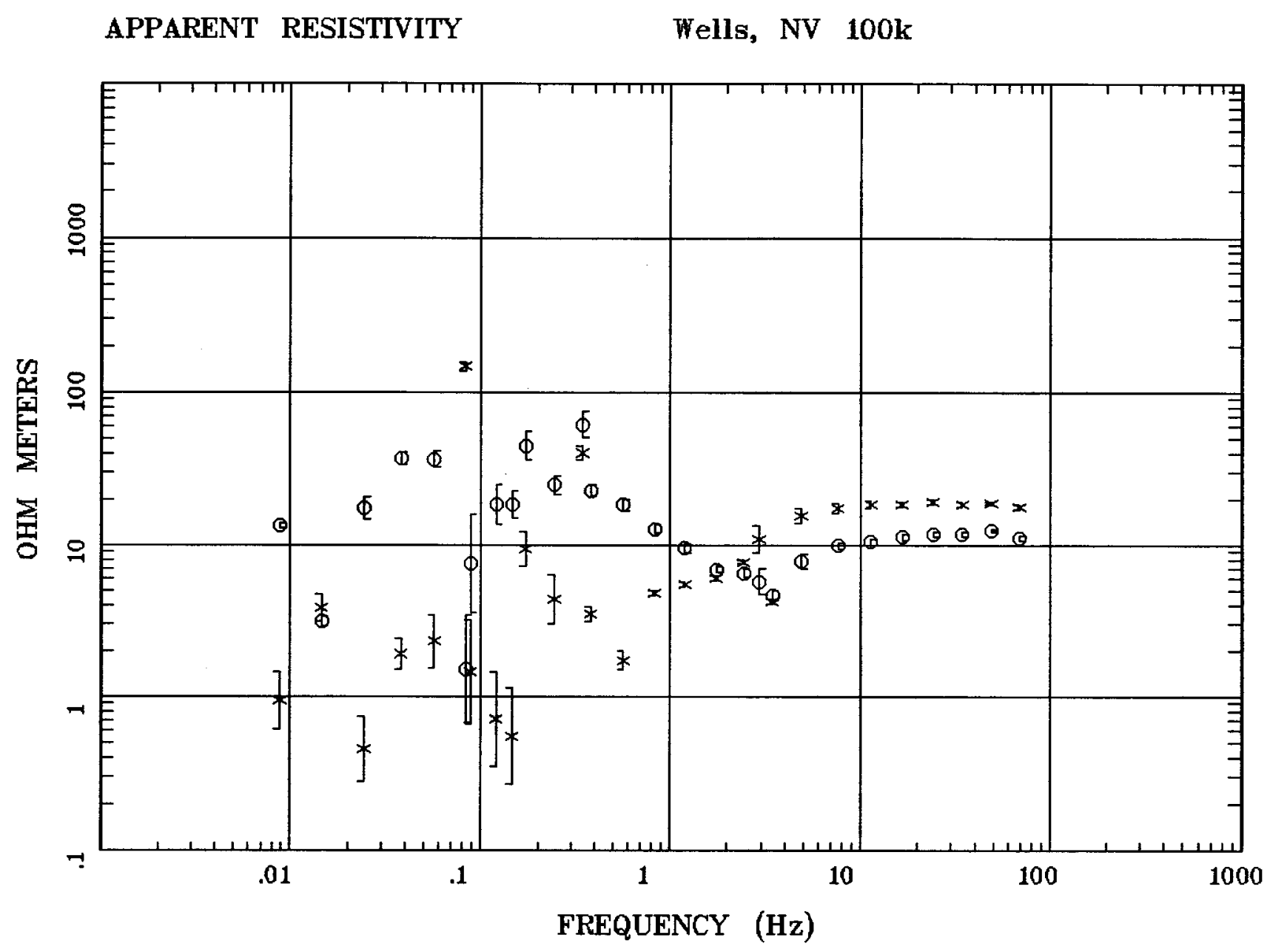

Client:

Remote: none

Acquired: 19:1 Jul 08, 2005

Survey Co:USGS
Rotation:

Filename: ap27nal.avg

Channels: Ch1 Ch2 Ch3 Ch4 Ch5 Ch3 Ch4

Plotted: 11:47 Jul 19, 2005

< EMI - ElectroMagnetic Instruments 
Station 27

IMPEDANCE PHASE

Wells, NV 100k

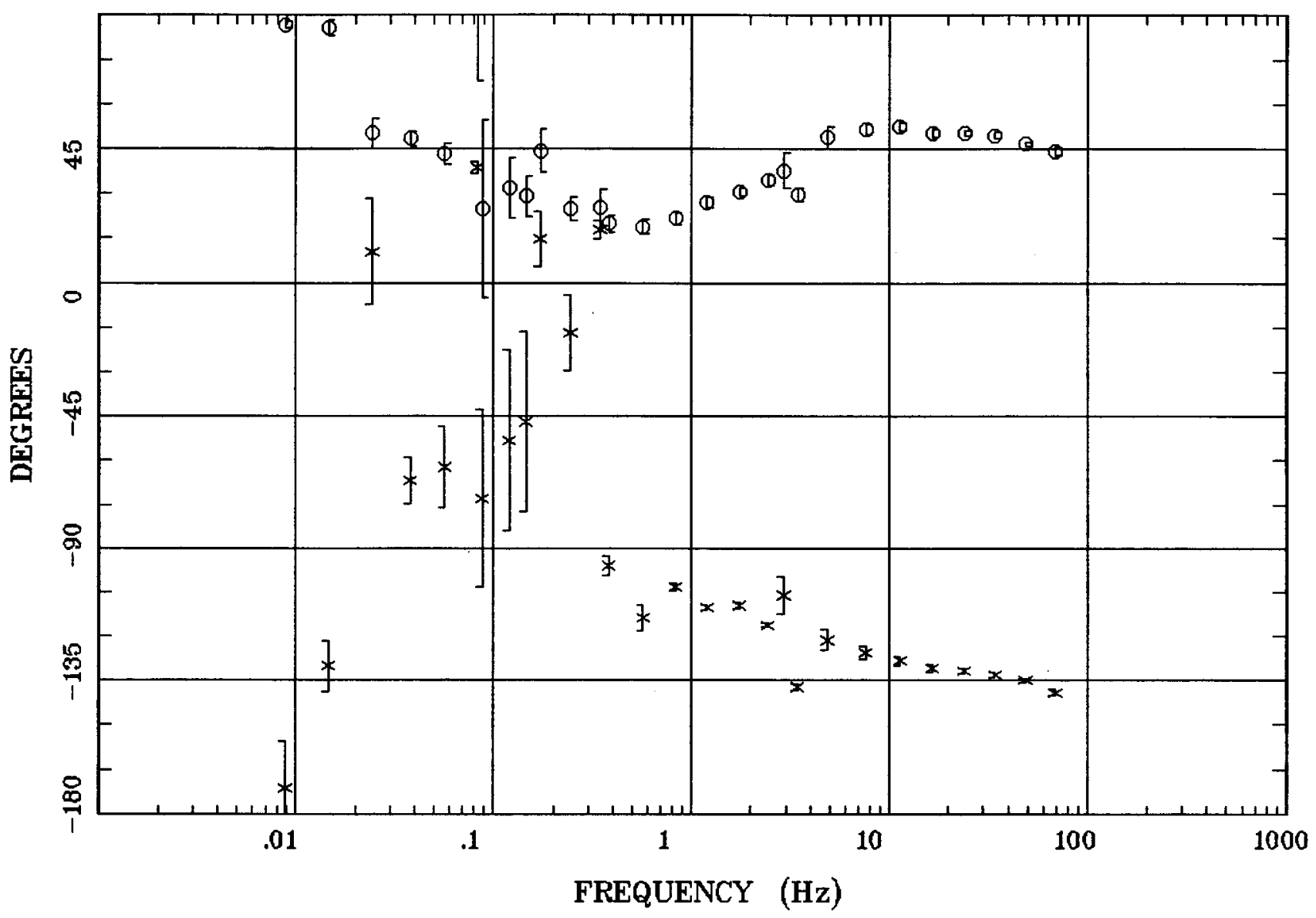

Client:

Remote: none

Acquired: 19:1 Jul 08, 2005

Survey Co:USGS
Rotation:

Filename: ap27nal.avg

Channels: Ch1 Ch2 Ch3 Ch4 Ch5 Ch3 Ch4

Plotted: 11:47 Jul 19, 2005

< EMI - ElectroMagnetic Instruments > 
Wells, NV 100k

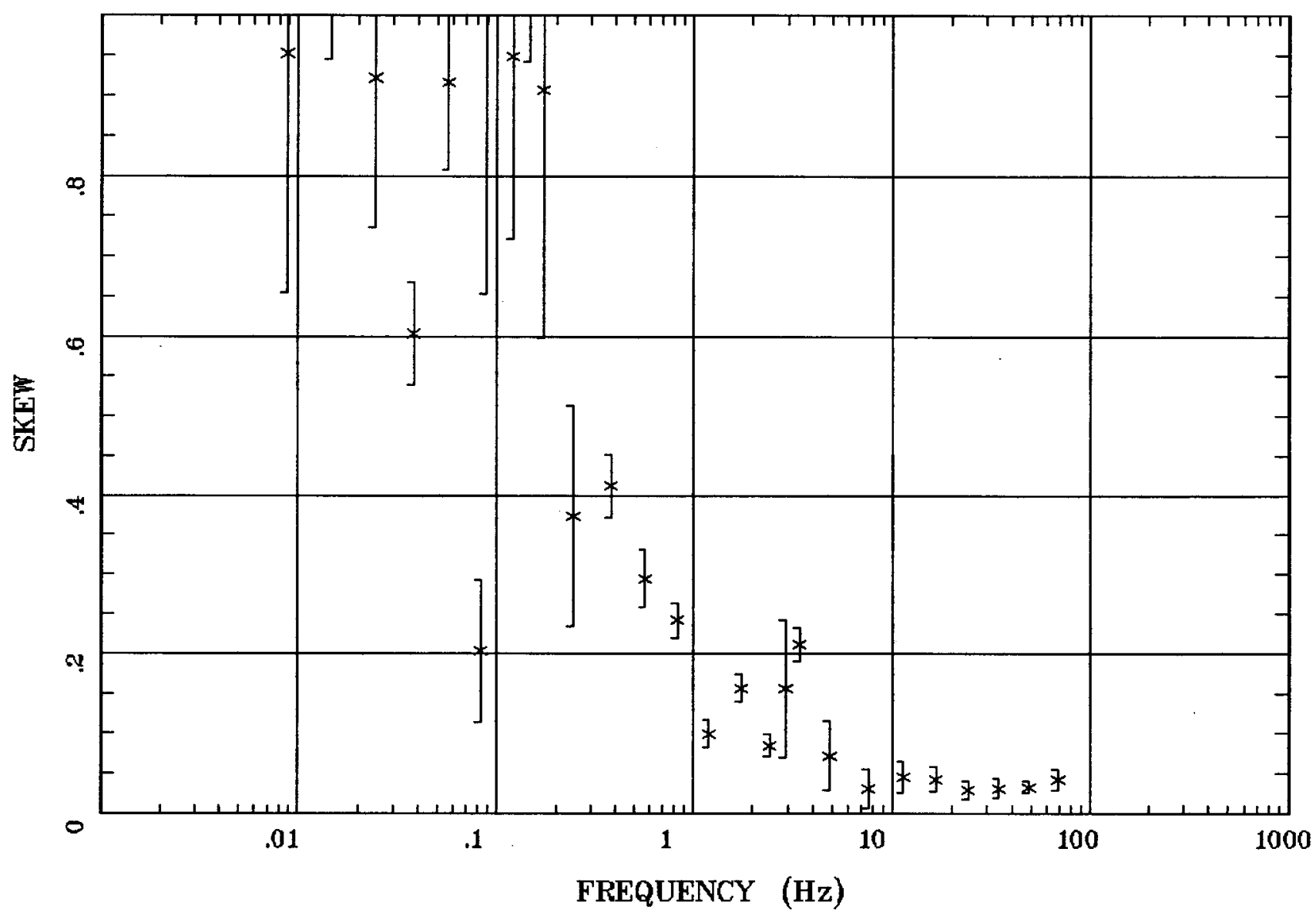

Client:

Remote: none

Acquired: 19:1 Jul 08, 2005

Survey Co:USGS
Rotation:

Filename: ap27nal.arg

Channels: Ch1 Ch2 Ch3 Ch4 Ch5 Ch3 Ch4

Plotted: 11:47 Jul 19, 2005

< EMI - ElectroMagnetic Instruments > 
E MULT Coh.

Wells, NV 100k

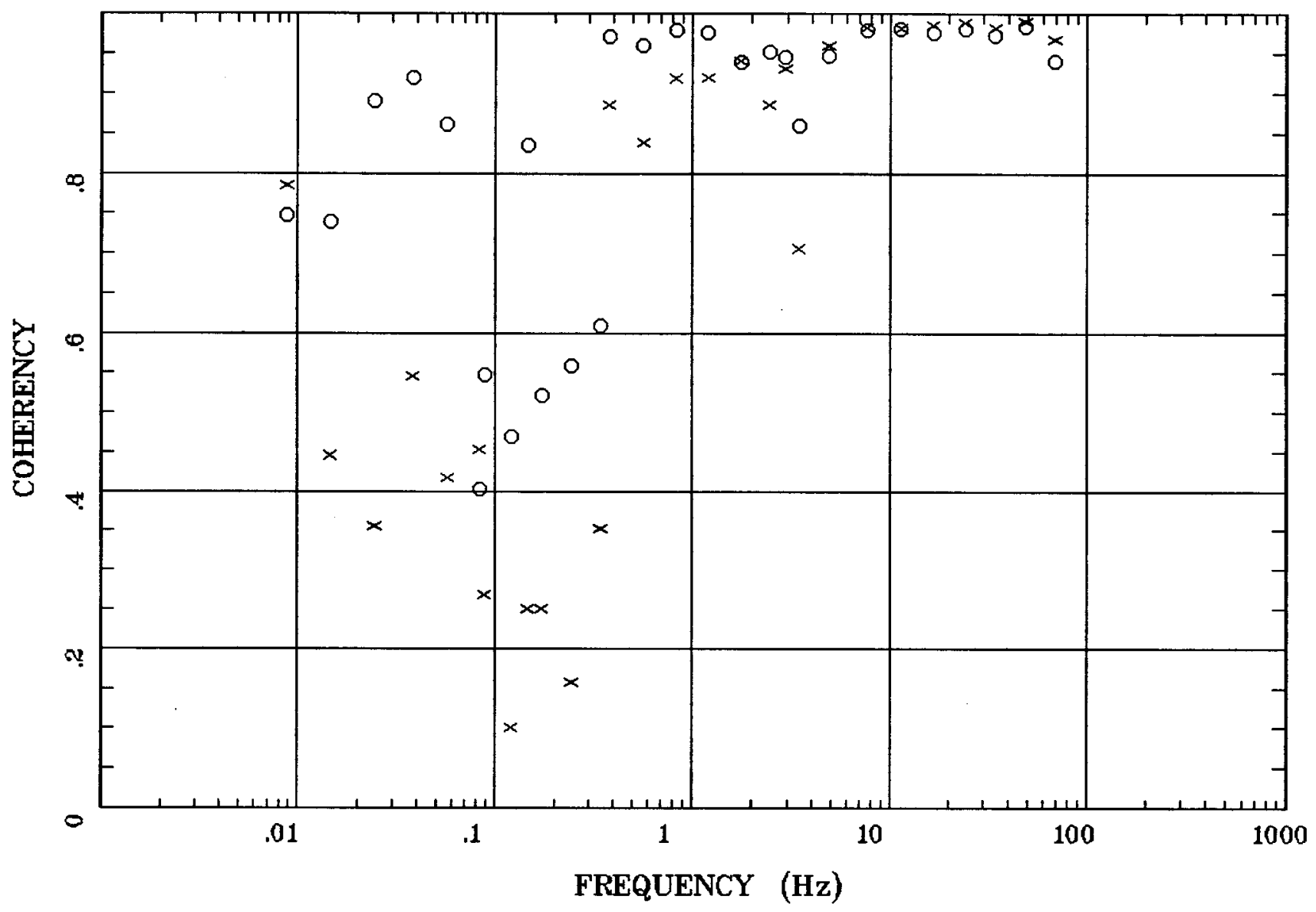

Client:

Remote: none

Acquired: 19:1 Jul 08, 2005

Survey Co:USGS
Rotation:

Filename: ap27nal.avg

Channels: Ch1 Ch2 Ch3 Ch4 Ch5 Ch3 Ch4

Plotted: 11:47 Jul 19, 2005

$<$ EMI - ElectroMagnetic Instruments 
POLAR PLOTS

Wells, NV 100k

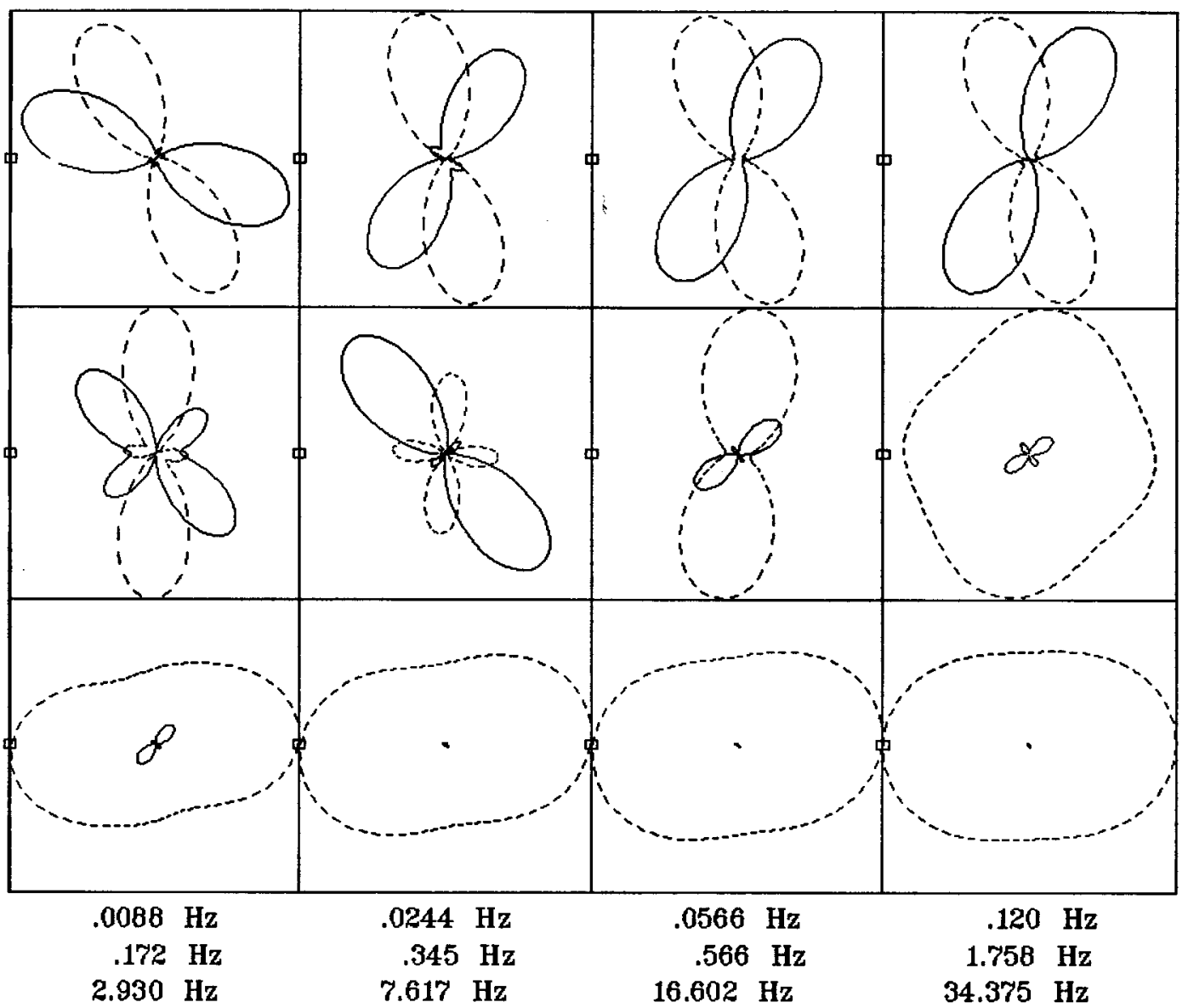

Client:

Remote: none

Acquired: 19:1 Jul 08, 2005

Survey Ca:USGS
Rotation:

Filename: ap27nal.avg

Channels: Ch1 Ch2 Ch3 Ch4 Ch5 Ch3 Ch4

Plotted: 11:47 Jul 19, 2005

< EMI - ElectroMagnetic Instruments > 


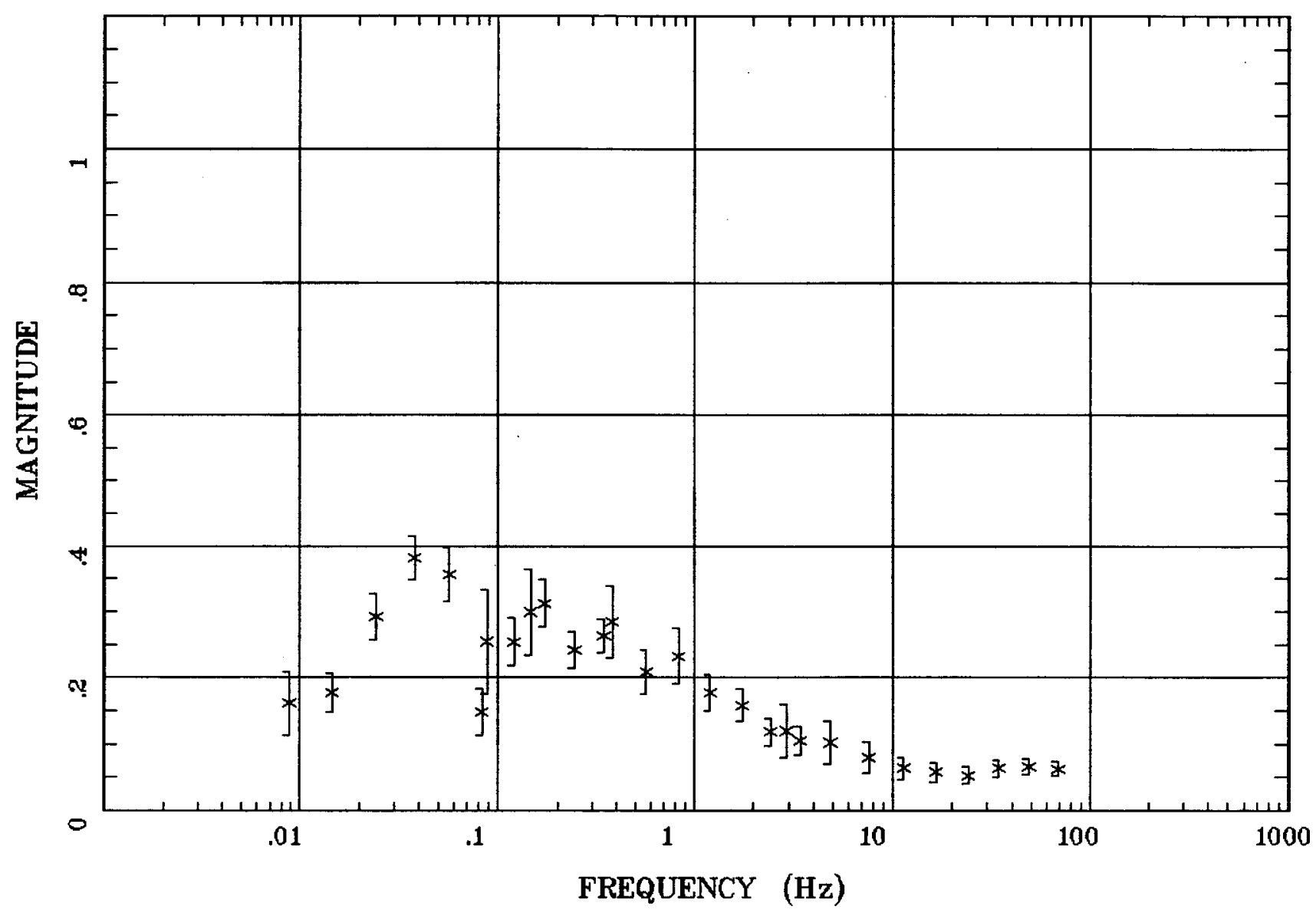

Client:

Remote: none

Acquired: 19:1 Jul 08, 2005

Survey Co:USGS
Rotation:

Filename: ap27nal.avg

Channels: Ch1 Ch2 Ch3 Ch4 Ch5 Ch3 Ch4

Platted: 11:47 Jul 19, 2005

< EMI - ElectroMagnetic Instruments > 


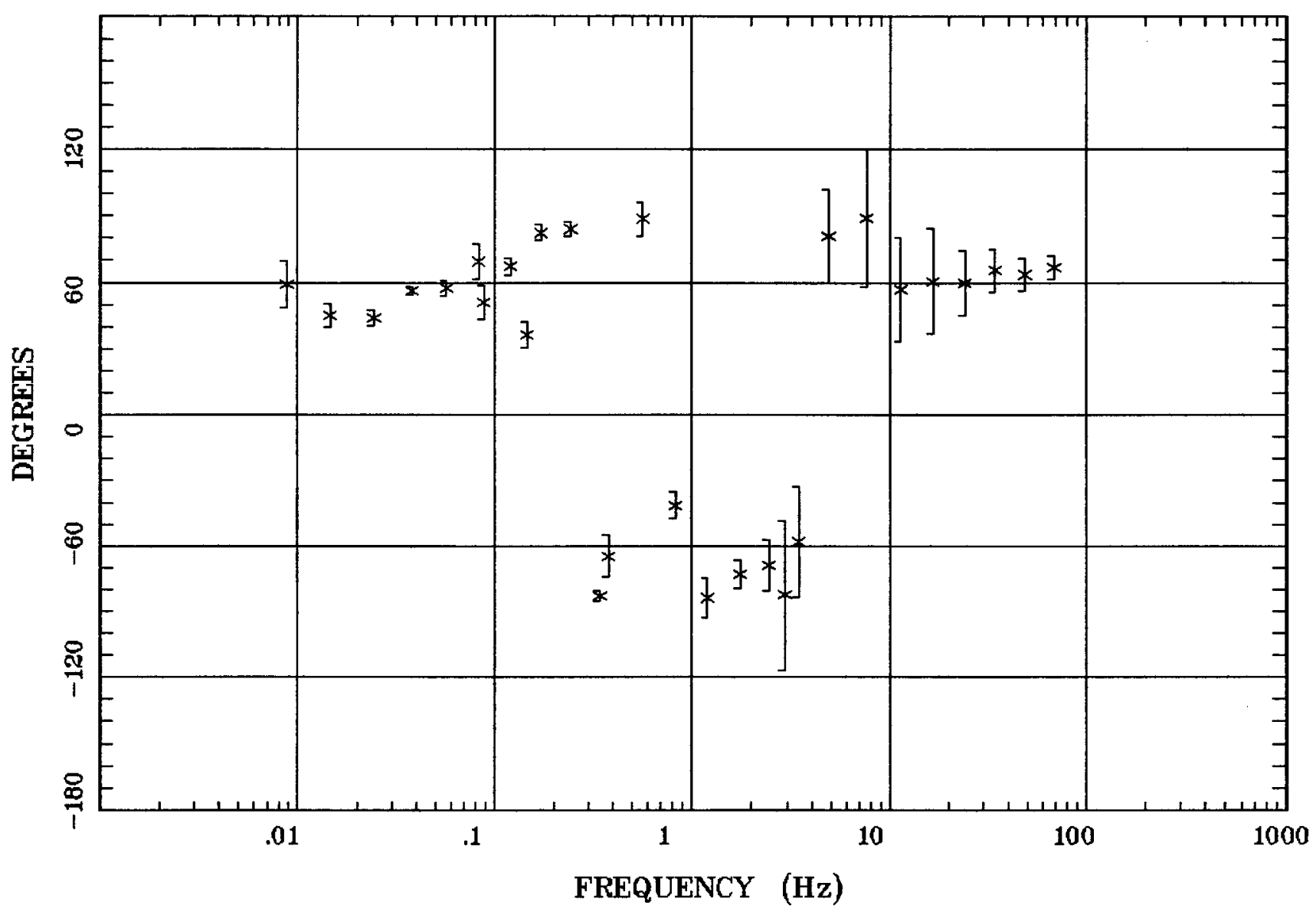

Client:

Remote: none

Acquired: 19:1 Jul 08, 2005 Survey Co:USGS
Rotation:

Filename: apz7nal.avg

Channels: Ch1 Ch2 Ch3 ch4 Ch5 Ch3 Ch4 Plotted: 11:47 Jul 19, 2005

$<$ EMI - ElectroMagnetic Instruments > 
HzHx.x Coh HzHy.o Wells, NV 100k

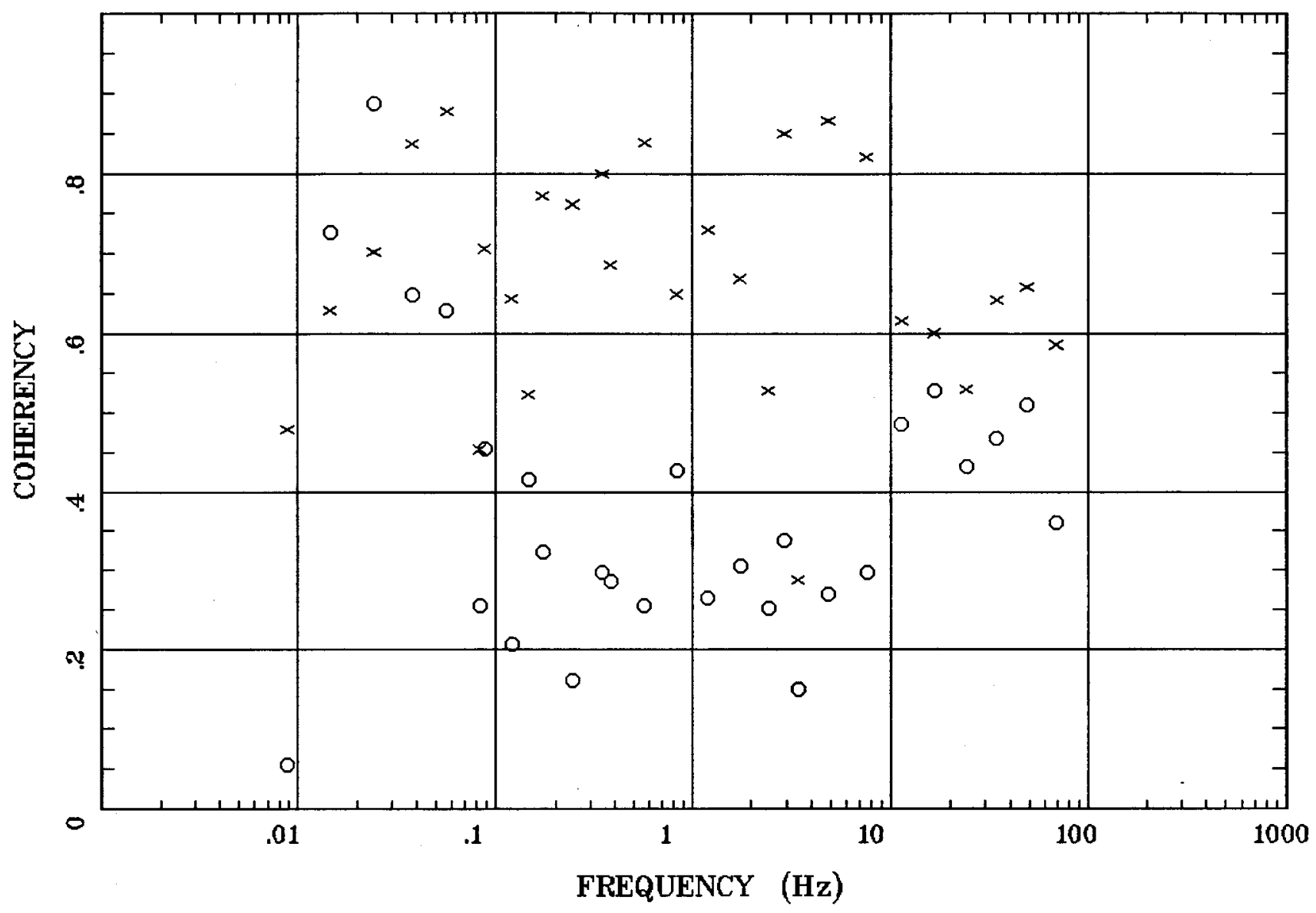

Client:

Remote: none

Acquired: 19:1 Jul 08, 2005

Survey Co:USGS
Rotation:

Filename: ap27nal.avg

Channels: Ch1 Ch2 Ch3 Ch4 Ch5 Ch3 Ch4

Plotted: 11:47 Jul 19, 2005

< EMI - ElectroMagnetic Instruments > 


\section{APPARENT RESISTIVITY Wells, NV 100k}

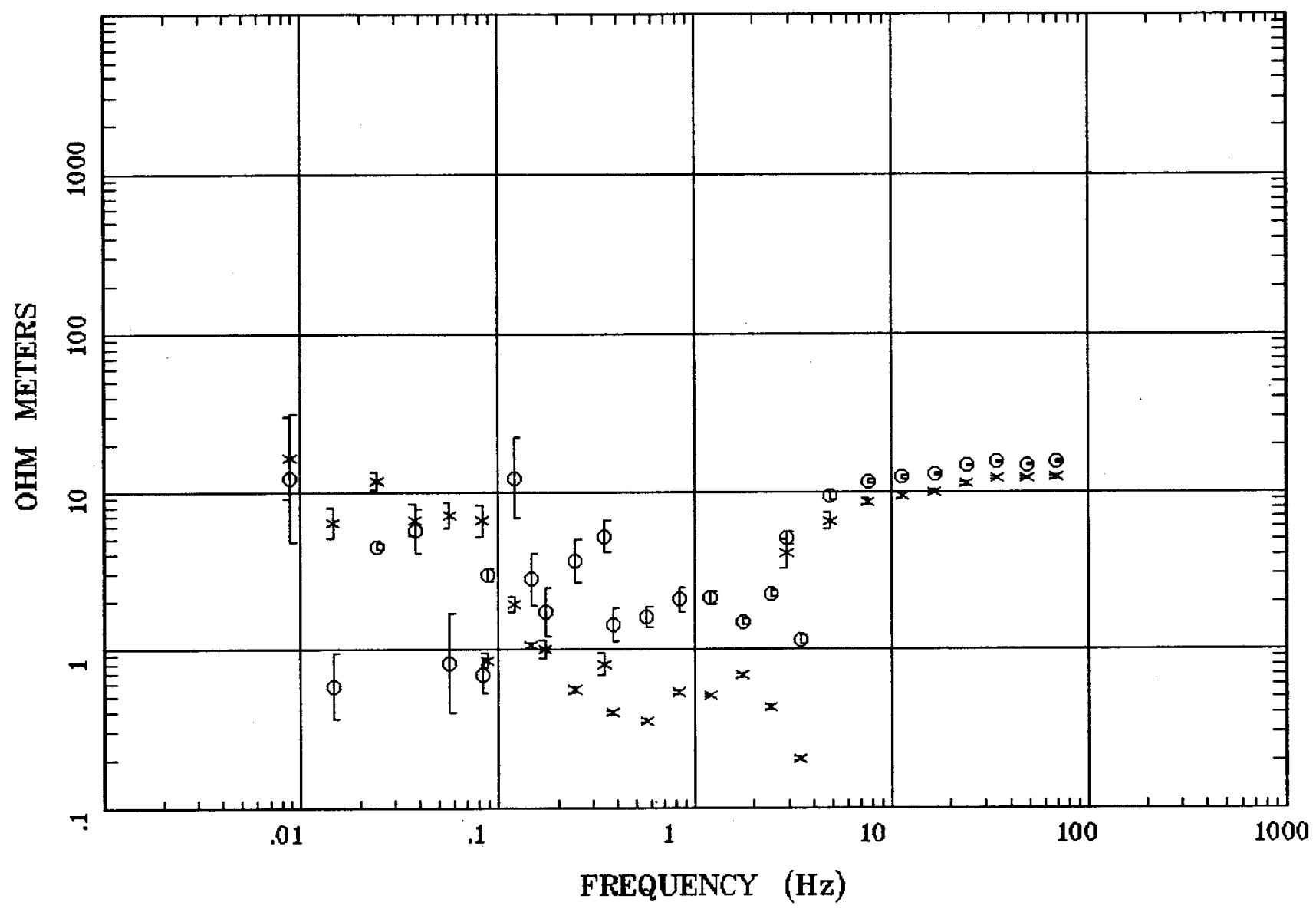

Client:

Remote: none

Acquired: 13:1 Jul 08, 2005 Survey Co:USGS
Rotation:

Filename: ap26mal.avg

Channels: Ch1 Ch2 Ch3 Ch4 Ch5 Ch3 Ch4 Plotted: 11:45 Jul 19, 2005

< EMI - ElectroMagnetic Instruments > 


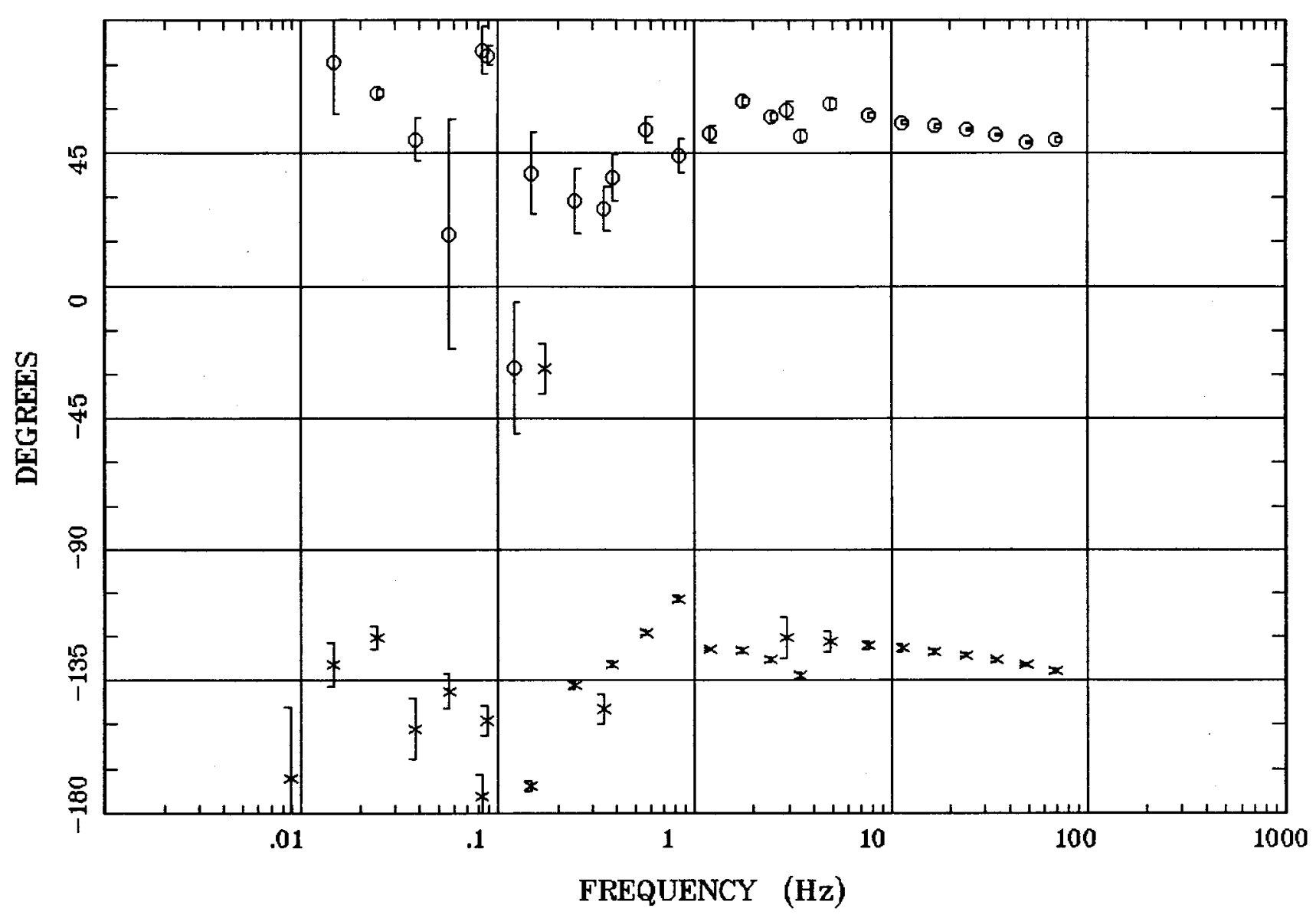

Client:

Remote: none

Acquired: 13:1 Jul 08, 2005 Survey Co:USGS
Rotation:

Filename: ap26mal.avg

Channels: Ch1 Ch2 Ch3 Ch4 Ch5 Ch3 Ch4 Plotted: 11:45 Jul 19, 2005

< EMI - ElectroMagnetic Instruments 


\section{Station 26}

IMPEDANCE SKEW

Wells, NV 100k

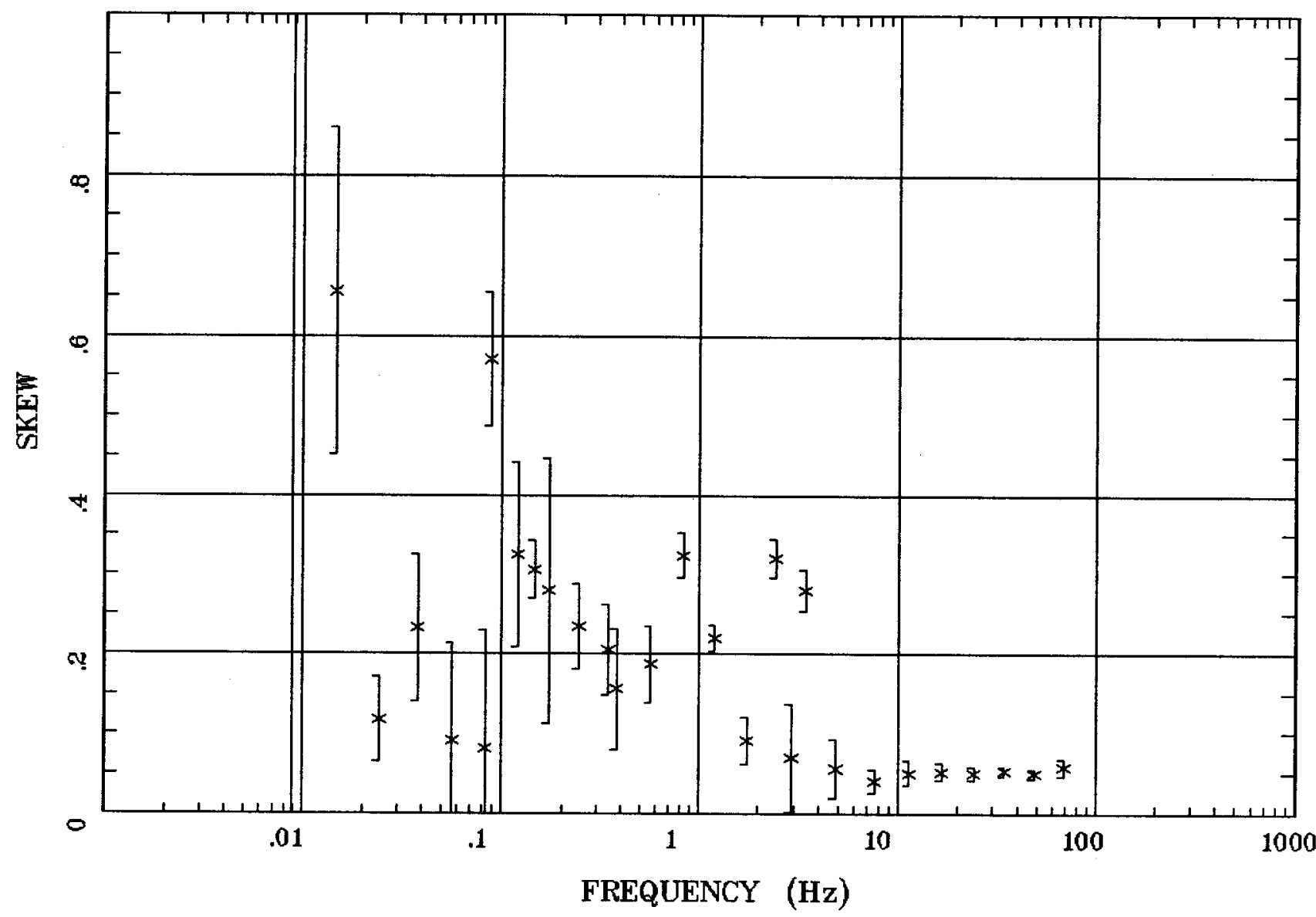

Client:

Remote: none

Acquired: 13:1 Jul 08, 2005

Survey Co:USGS
Rotation:

Filename: ap26mal.avg

Channels: Ch1 Ch2 Ch3 Ch4 Ch5 Ch3 Ch4

Plotted: 11:45 Jul 19, 2005

< EMI - ElectroMagnetic Instruments > 


\section{E MULT Coh.}

Wells, NV 100k

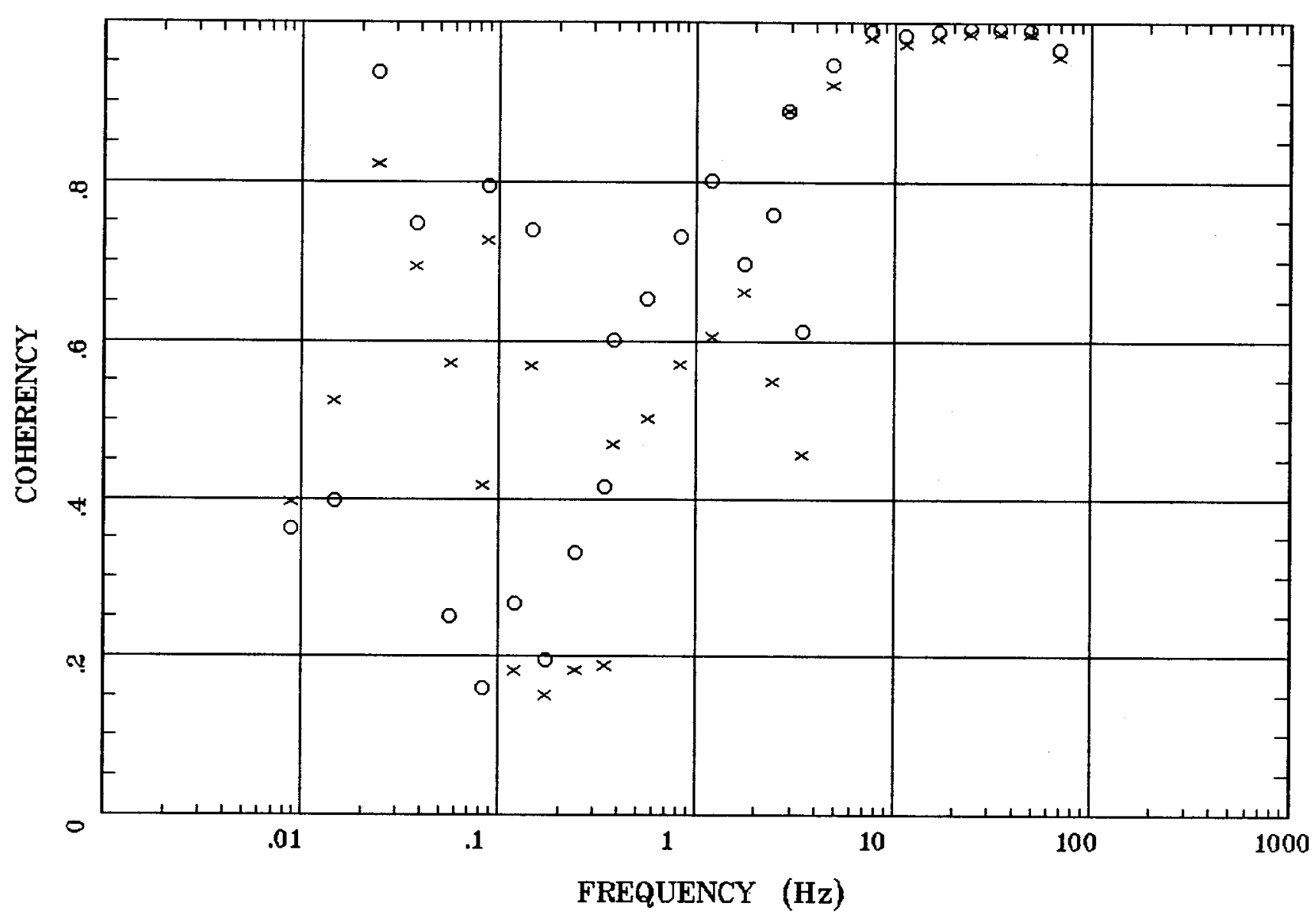

Client:

Remote: none

Acquired: $13: 1 \mathrm{Jul}$ 08, 2005 Survey Co:USGS
Rotation:

Filename: ap26mal.avg

Channels: Ch1 Ch2 Ch3 Ch4 Ch5 Ch3 Ch4

Plotted: 11:45 Jul 19, 2005

$<$ EMI - ElectroMagnetic Instruments 


\section{POLAR PLOTS}

Wells, NV 100k

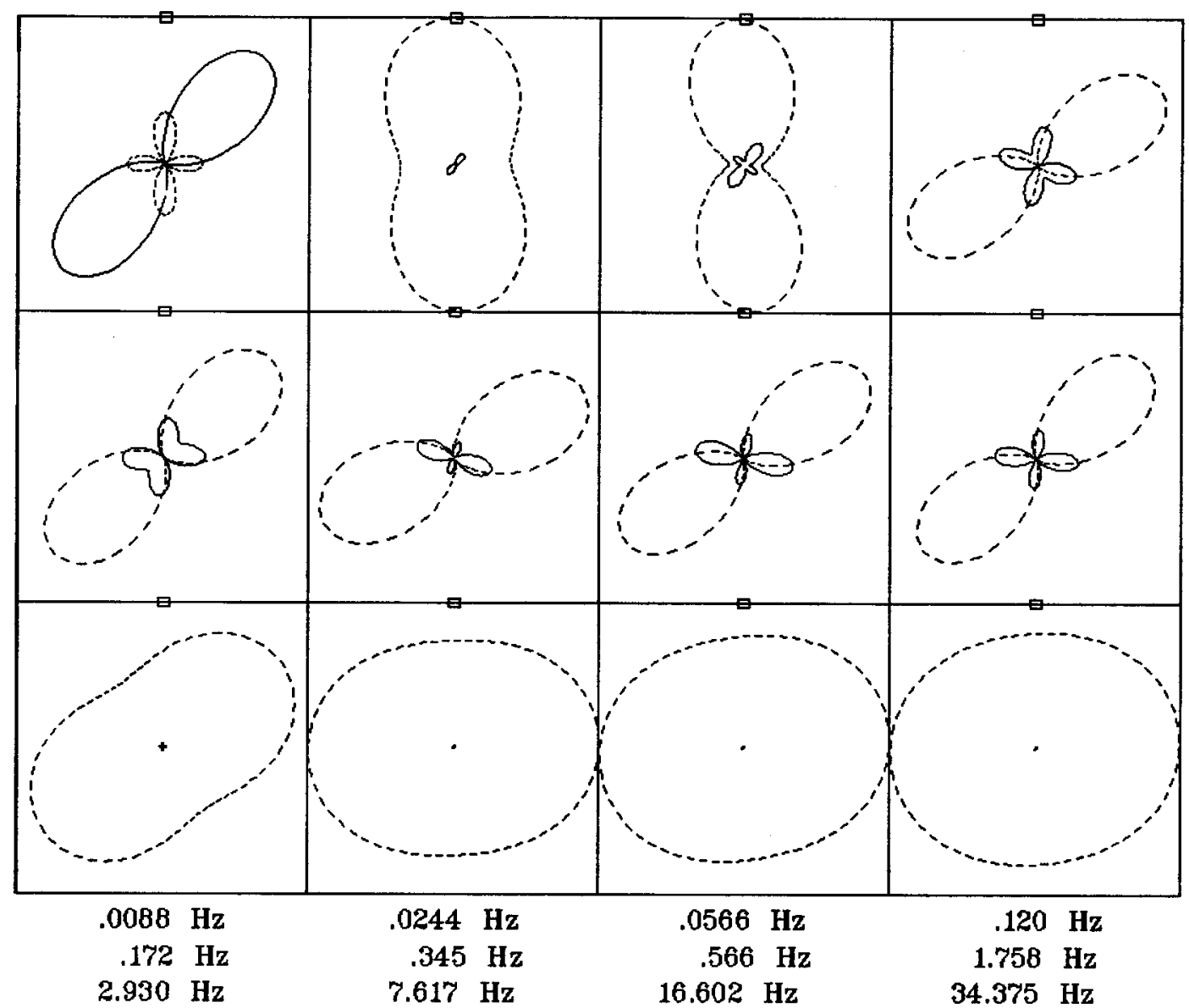

Client:

Remote: none

Acquired: 13:1 Jul 08, 2005 Survey Co:USGS

\section{Rotation:}

Filename: ap26mal.avg

Channels: Ch1 Ch2 Ch3 Ch4 Ch5 Ch3 Ch4 Plotted: 11:45 Jul 19, 2005

< EMI - ElectroMagnetic Instruments > 


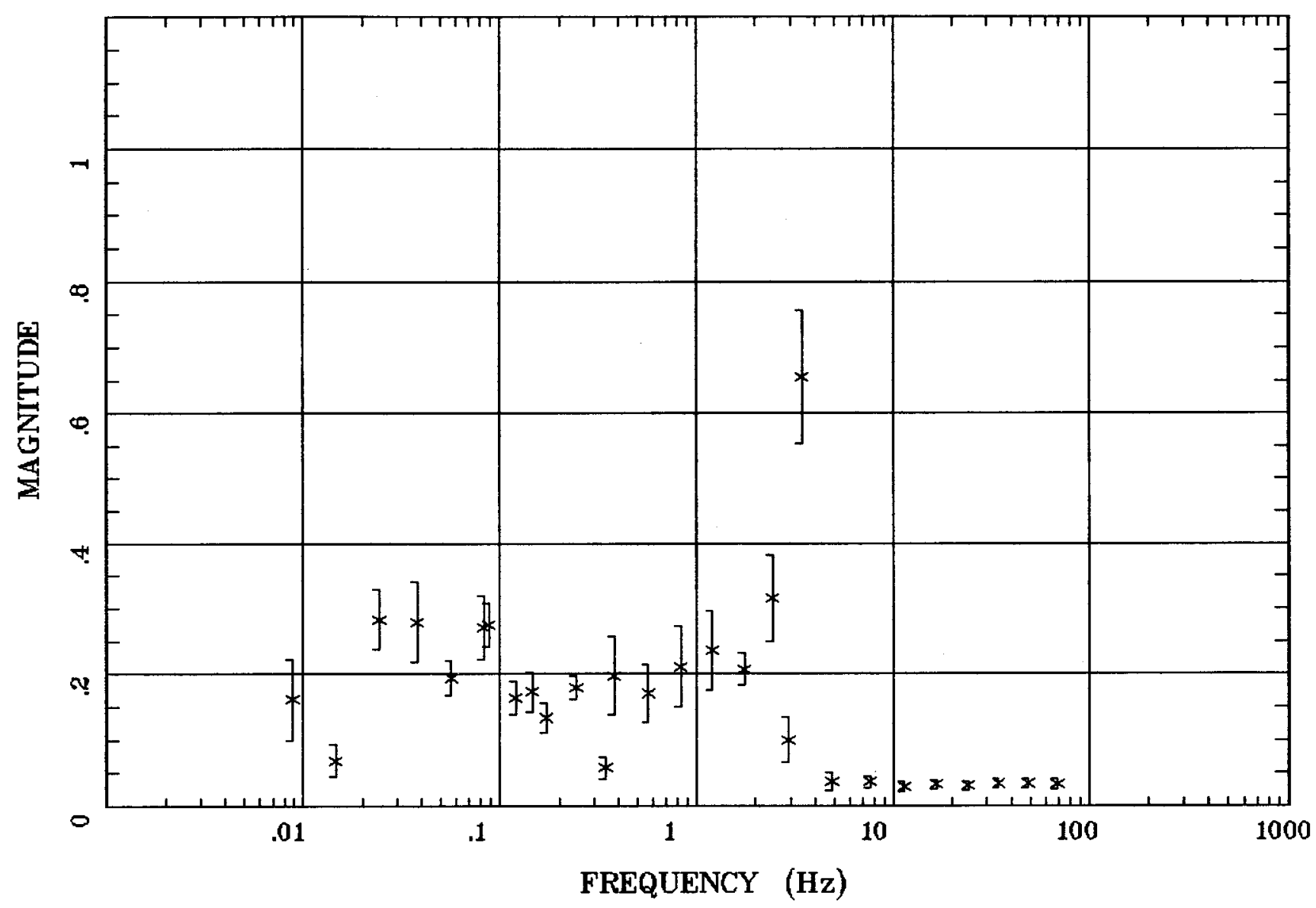

Client:

Remote: none

Acquired: 13:1 Jul 08, 2005

Survey Co:USGS
Rotation:

Filename: ap26mal.avg

Channels: Ch1 Ch2 Ch3 Ch4 Ch5 Ch3 Ch4

Plotted: 11:45 Jul 19, 2005

< EMI - ElectroMagnetic Instruments > 


\section{Station 26}

TIPPER STRIKE

Wells, NV 100k

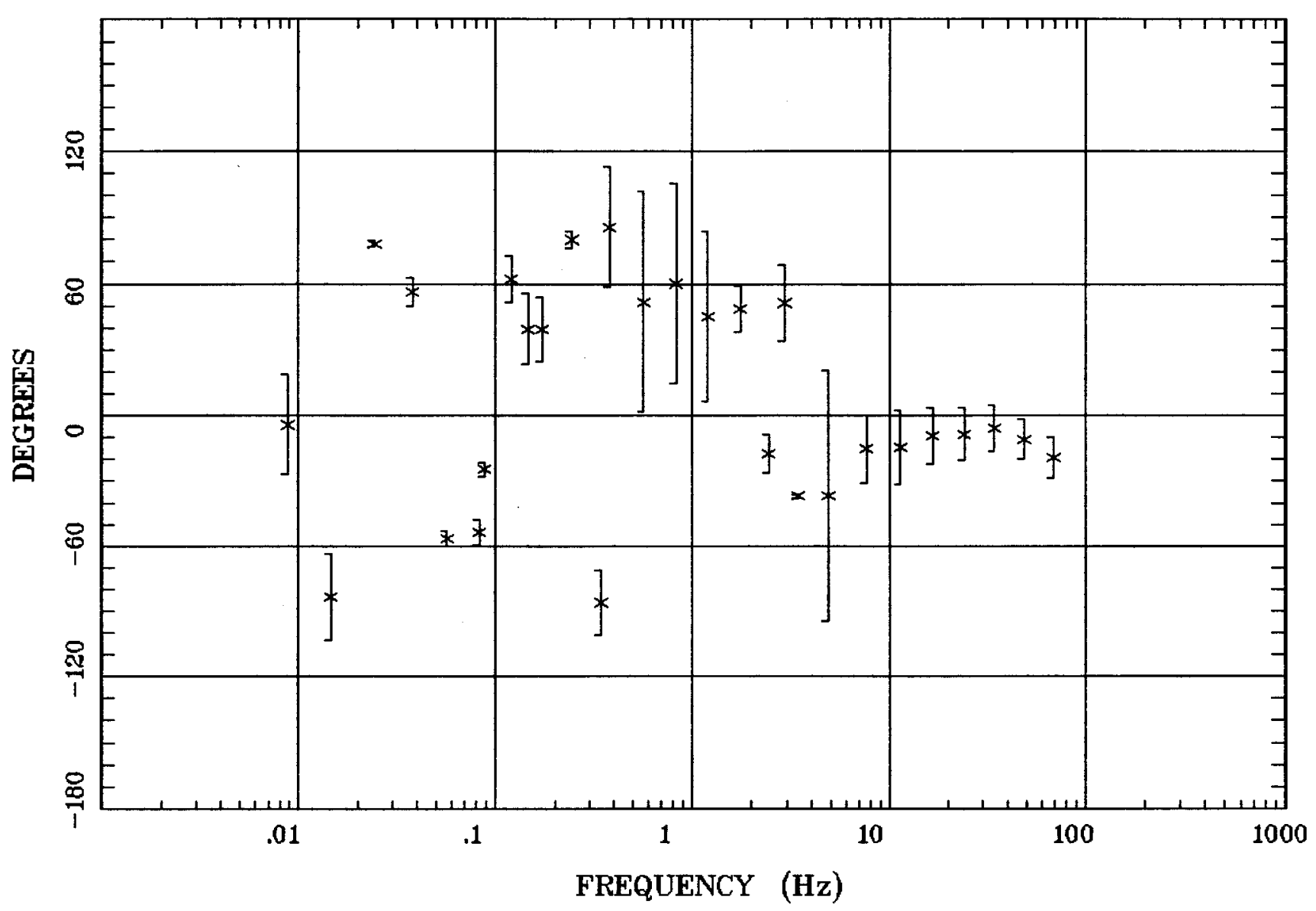

Client:

Remote: none

Acquired: 13:1 Jul 08, 2005

Survey Co:USGS
Rotation:

Filename: ap26mal.avg

Channels: Ch1 Ch2 Ch3 Ch4 Ch5 Ch3 Ch4

Plotted: 11:45 Jul 19, 2005

< EMI - ElectroMagnetic Instruments > 
HzHx.x Coh HzHy.o

Wells, NV 100k

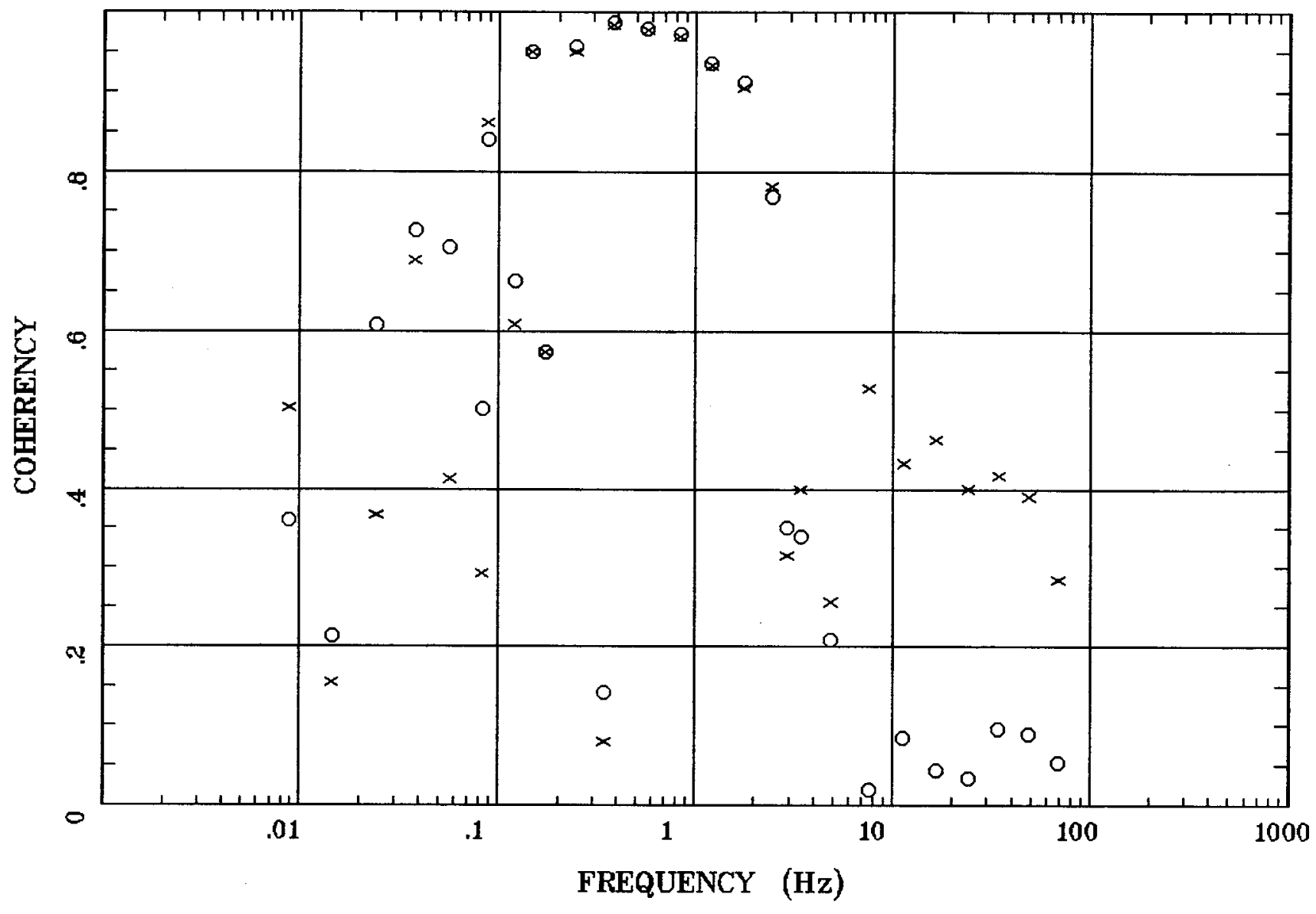

Client:

Remote: none

Acquired: 13:1 Jul 08, 2005 Survey Co:USGS
Rotation:

Filename: ap26mal.avg

Channels: Ch1 Ch2 Ch3 ch4 Ch5 Ch3 Ch4 Platted: 11:45 Jul 19, 2005

< EMI - ElectroMagnetic Instruments 
APPARENT RESISTIVITY

Wells, NV 100k

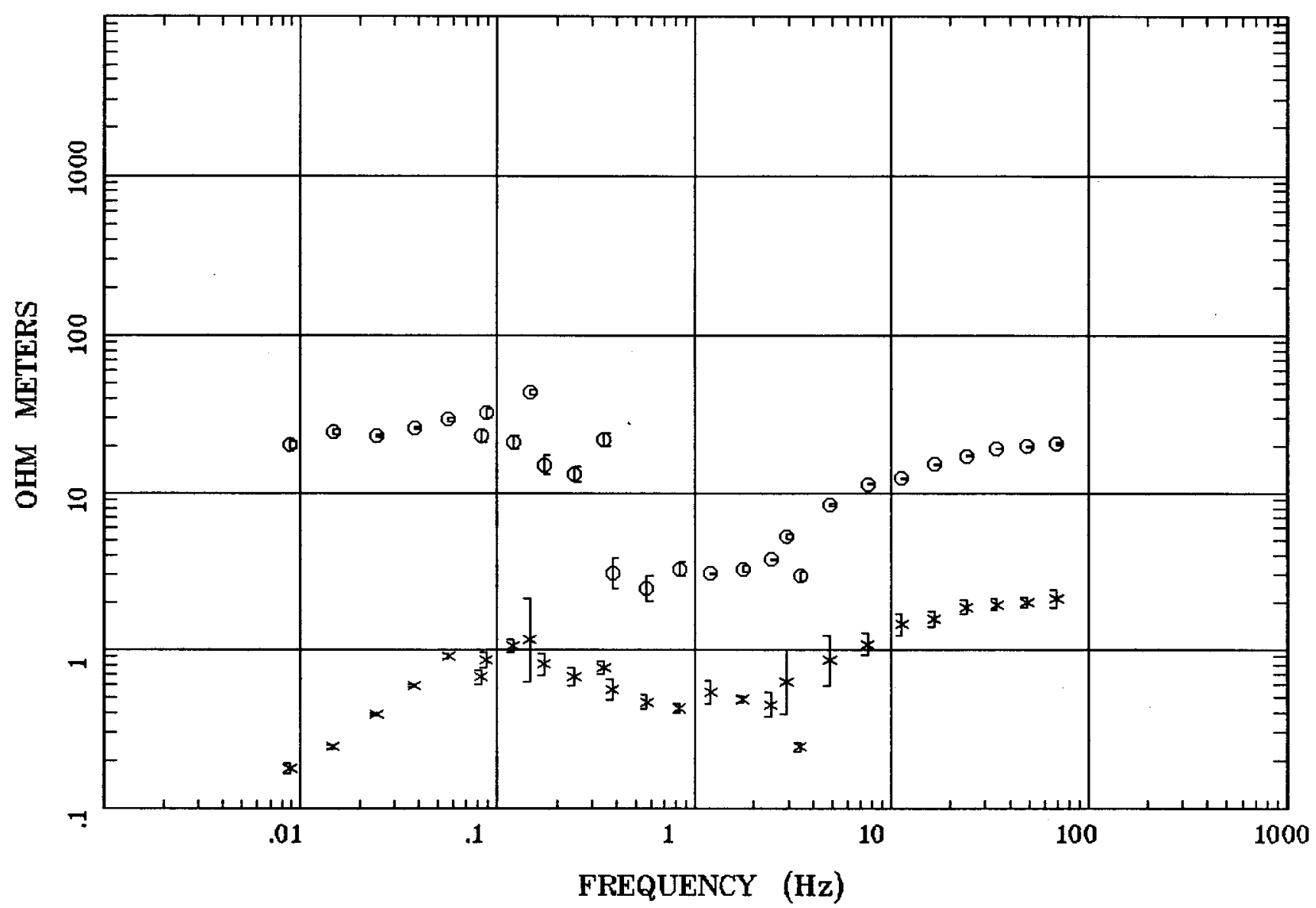

Client:

Remote: none

Acquired: 12:1 Jul 13, 2005

Survey Co:USGS
Rotation:

Filename: ap36n.avg

Channels: Ch1 Ch2 Ch3 Ch4 Ch5 Ch3 Ch4

Plotted: 08:47 Jul 19, 2005

$<$ EMI - ElectroMagnetic Instruments > 
Wells, NV 100k

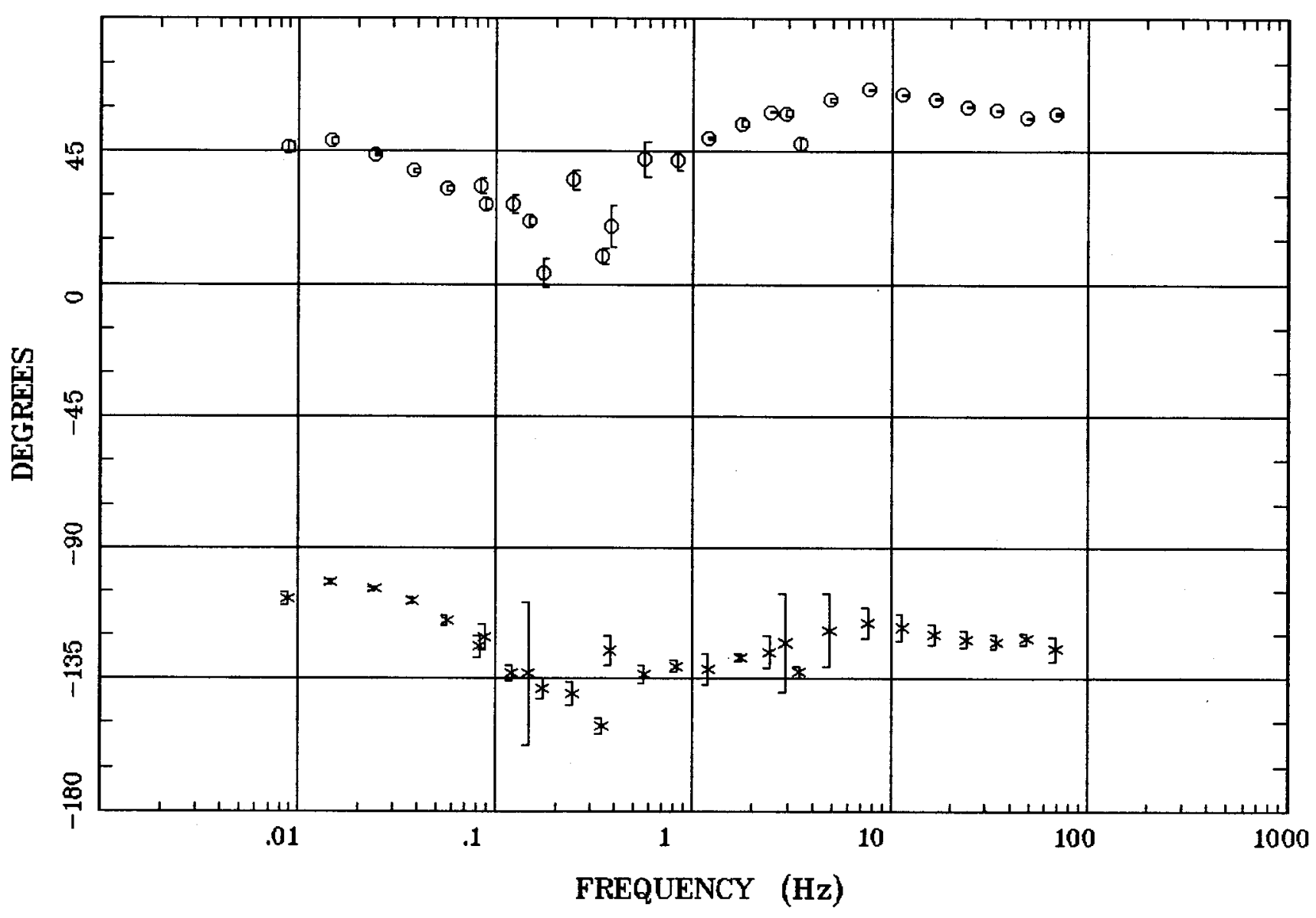

Client:

Remote: none

Acquired: 12:1 Jul 13, 2005

Survey Co:USGS
Rotation:

Filename: ap36n.avg

Channels: Ch1 Ch2 Ch3 Ch4 Ch5 Ch3 Ch4

Plotted: 08:47 Jul 19, 2005

< EMI - ElectroMagnetic Instruments 


\section{Station 36}

IMPEDANCE SKEW Wells, NV 100k

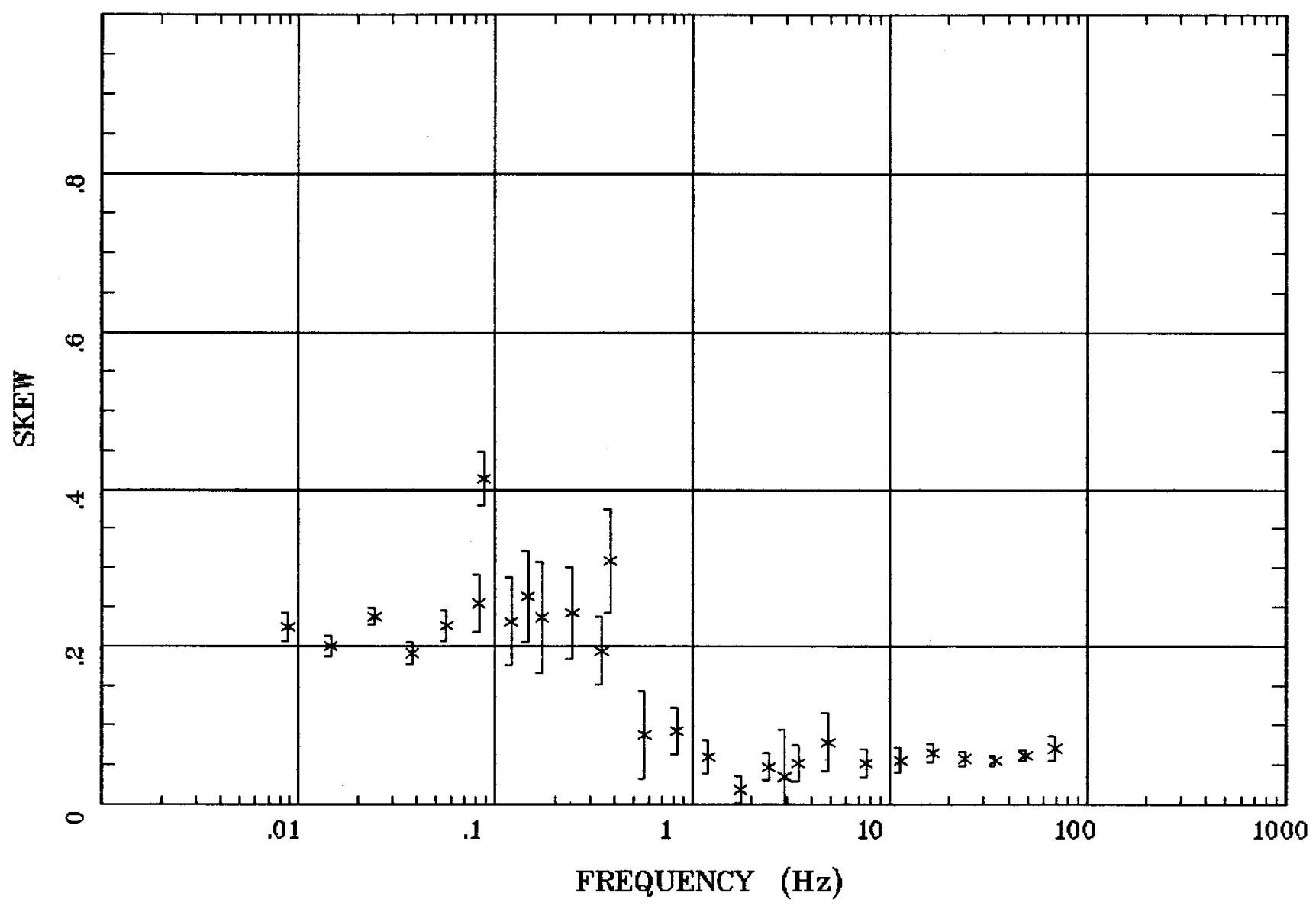

Client:

Rem ote: none

Acquired: 12:1 Jul 13, 2005

Survey Co:USGS
Rotation:

Filename: ap36n.avg

Channels: Ch1 Ch2 Ch3 Ch4 Ch5 Ch3 Ch4

Plotted: 08:47 Jul 19, 2005

$<$ EMI - ElectroMagnetic Instruments 
E MULT Coh.

Wells, NV 100k

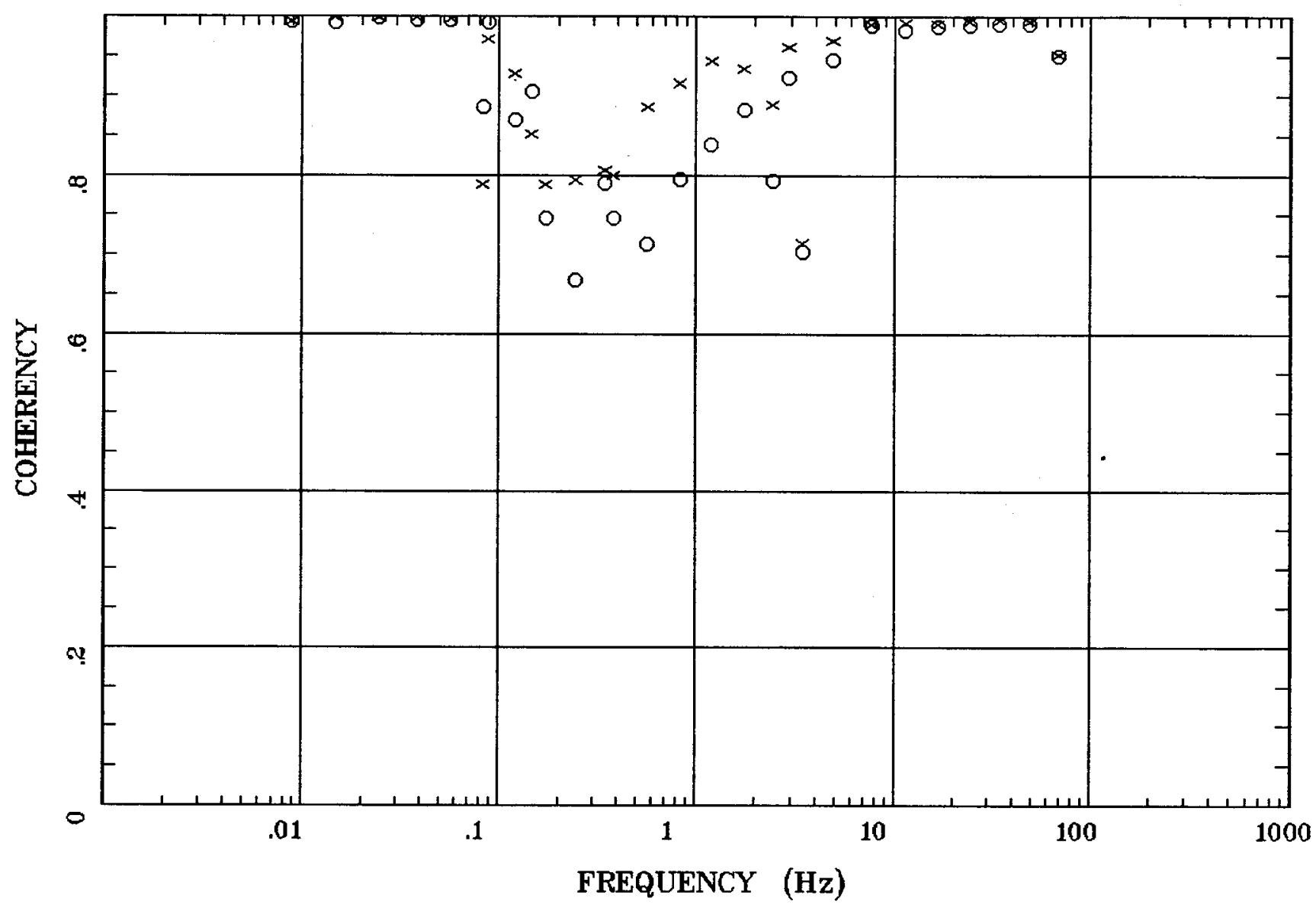

Client:

Remote: none

Acquired: 12:1 Jul 13, 2005

Survey Ca:USGS
Ratation:

Filename: ap36n.avg

Channels: Ch1 Ch2 Ch3 Ch4 Ch5 Ch3 Ch4

Plotted: 08:47 Jul 19, 2005

$<$ EMI - ElectroMagnetic Instruments 


\section{POLAR PLOTS}

Wells, NV 100k

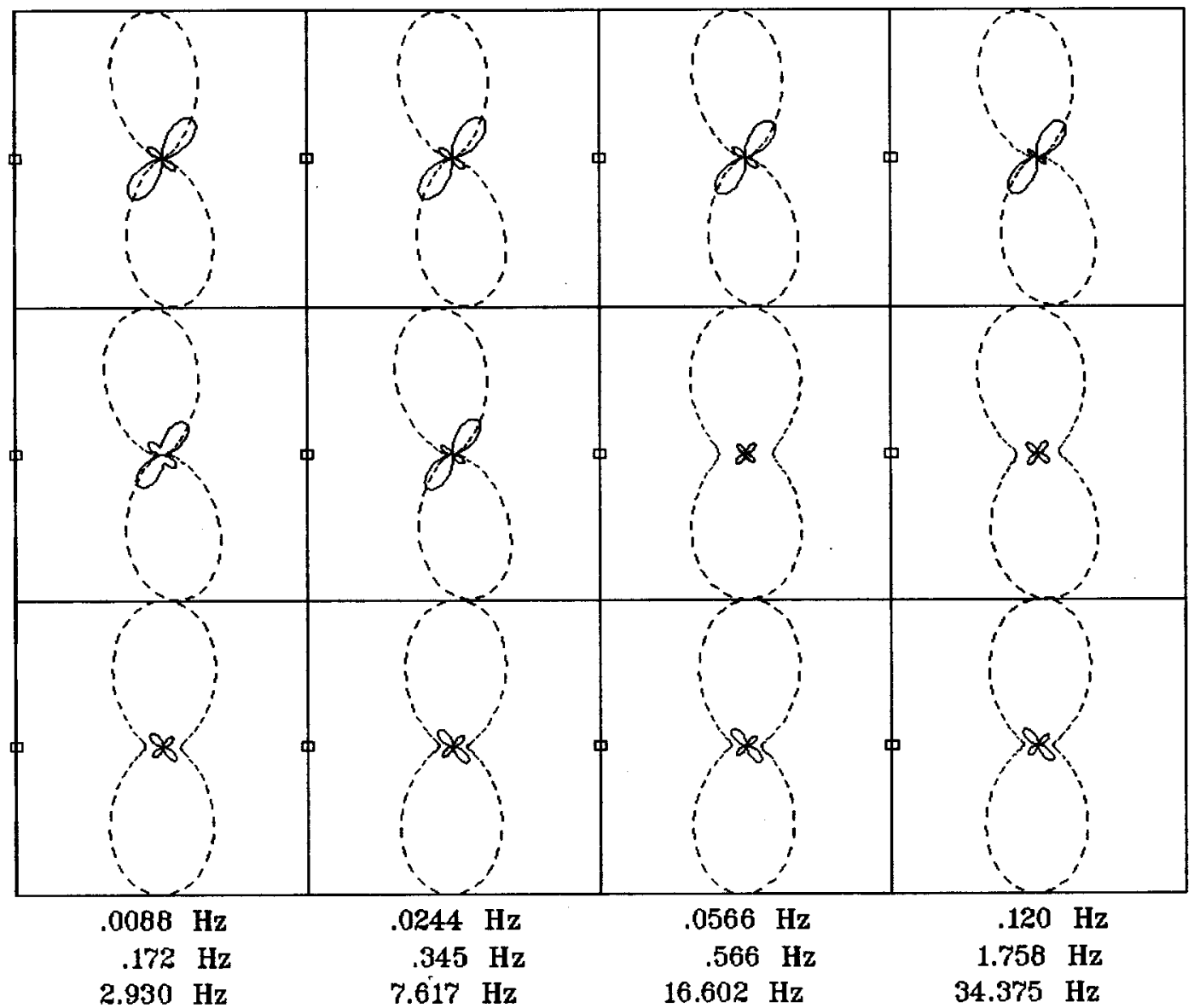

Client:

Remote: none

Acquired: 12:1 Jul 13, 2005 Survey Co:USGS
Rotation:

Filename: ap36n.avg

Channels: Ch1 Ch2 Ch3 Ch4 Ch5 Ch3 Ch4

Plotted: 08:47 Jul 19, 2005

< EMI - ElectroMagnetic Instruments > 
TIPPER MAGNITUDE

Wells, NV 100k

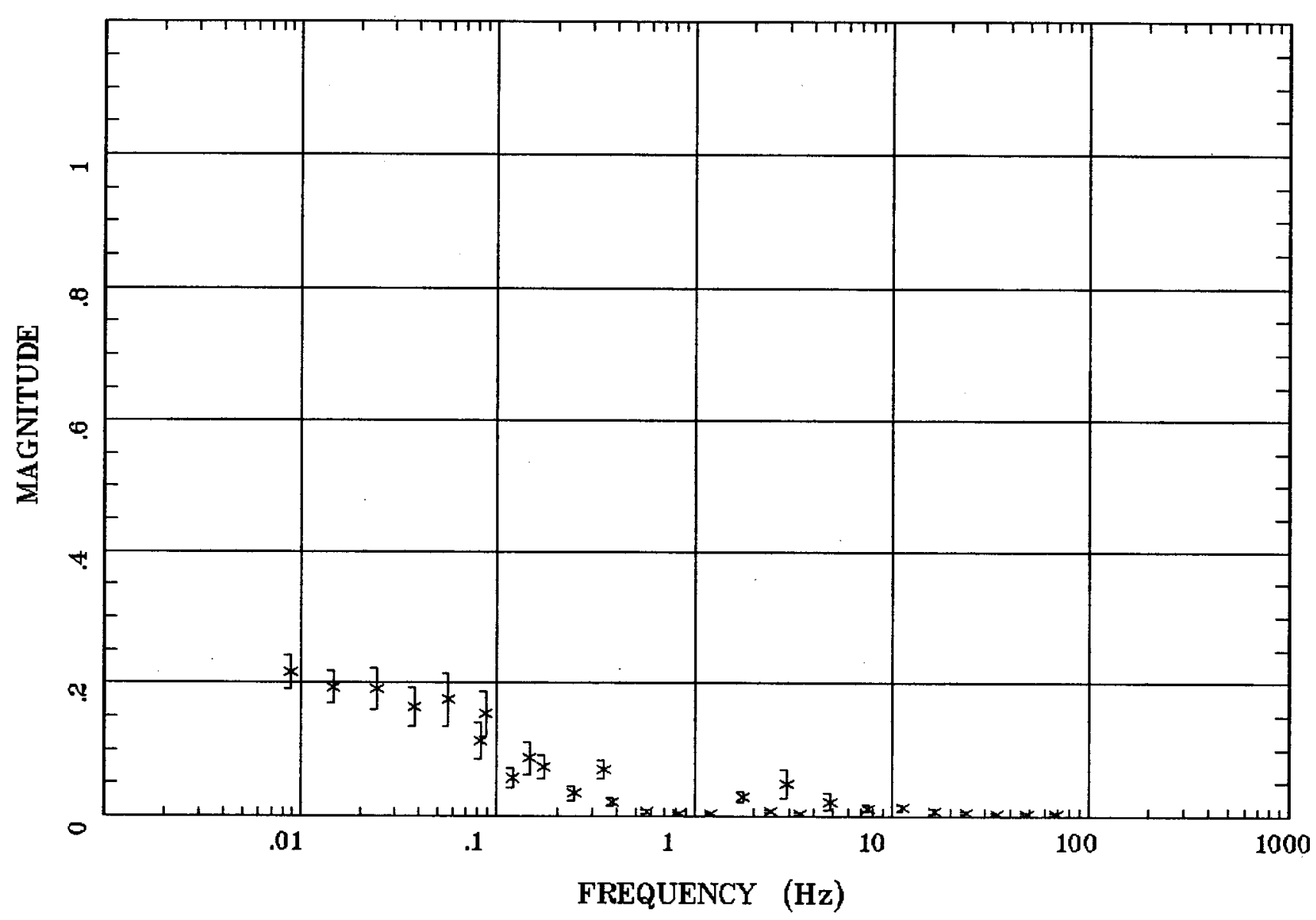

Client:

Remote: none

Acquired: 12:1 Jul 13, 2005

Survey Co:USGS
Rotation:

Filename: ap36n.avg

Channels: Ch1 Ch2 Ch3 Ch4 Ch5 Ch3 Ch4

Plotted: 08:47 Jul 19, 2005

< EMI - ElectroMagnetic Instruments > 


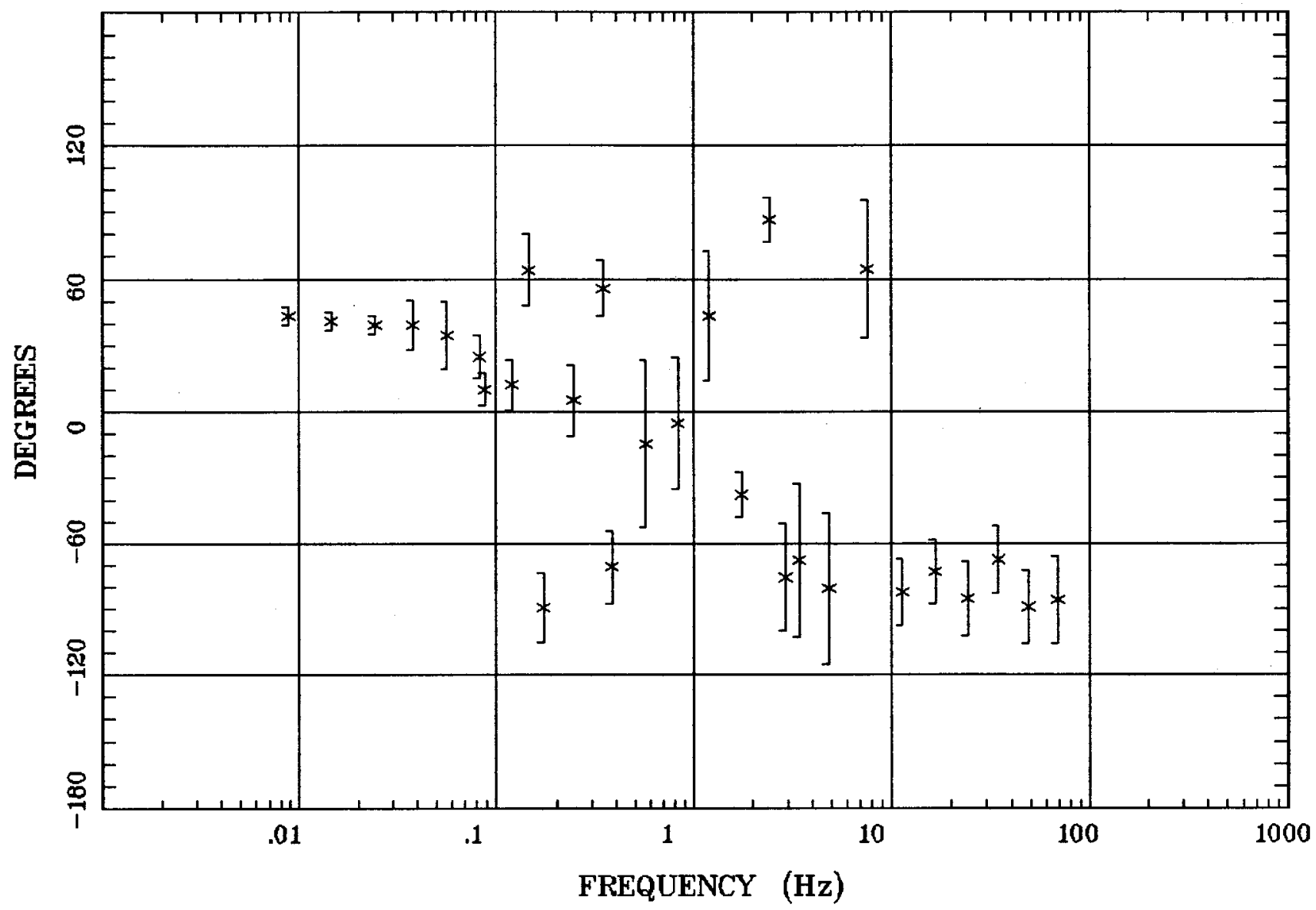

Client:

Remote: none Acquired: 12:1 Jul 13, 2005 Survey Co:USGS
Rotation:

Filename: ap36n.avg Channels: Ch1 Ch2 Ch3 Ch4 Ch5 Ch3 Ch4 Plotted: 08:47 Jul 19, 2005

$<$ EMI - ElectroMagnetic Instruments 
HzHx.x Coh HzHy.o

Wells, NV 100k

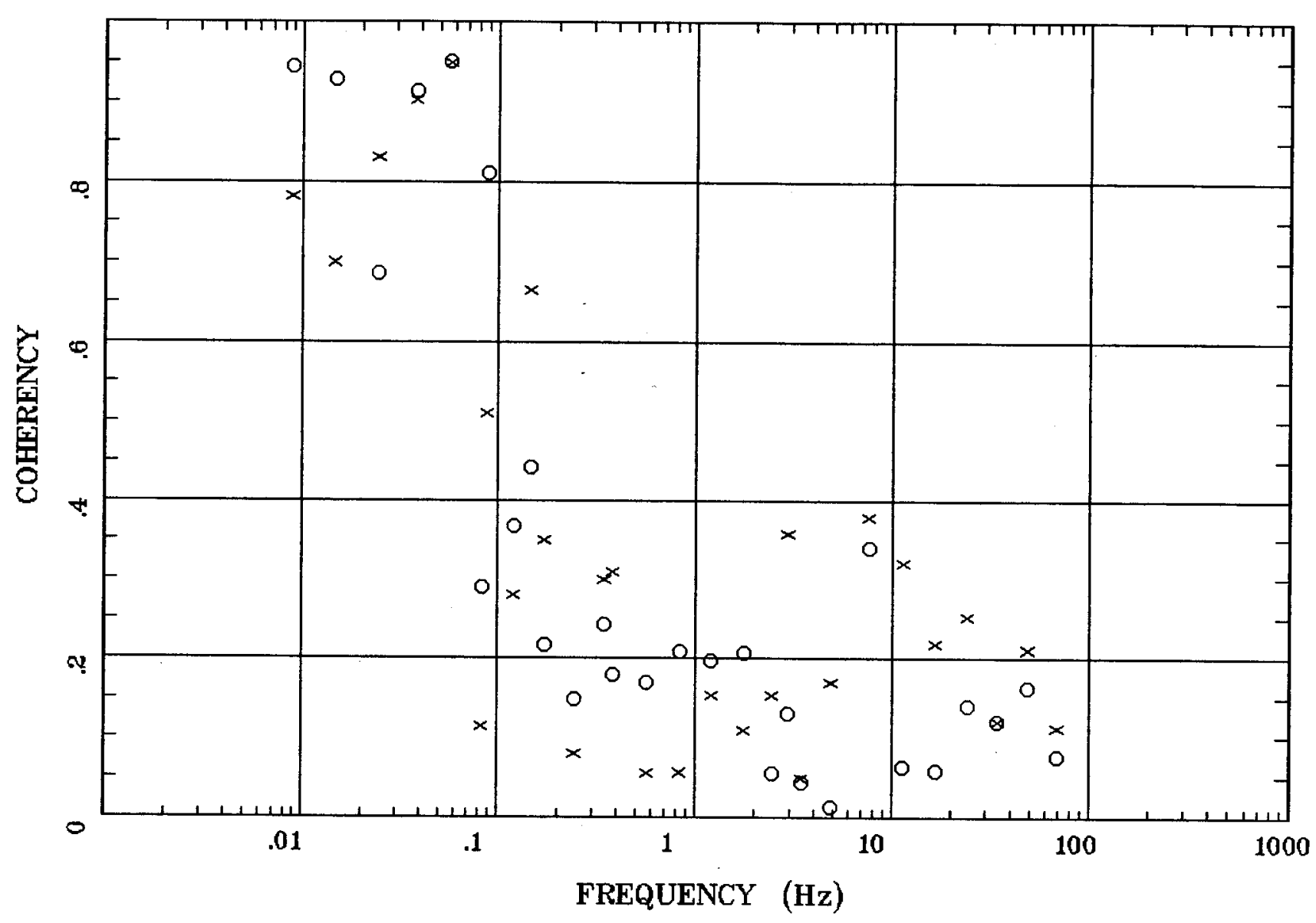

Client:

Remote: none

Acquired: 12:1 Jul 13, 2005 Survey Co:USGS
Rotation:

Filename: ap36n.avg

Channels: Ch1 Ch2 Ch3 Ch4 Ch5 Ch3 Ch4 Plotted: 08:47 Jul 19, 2005

$<$ EMI - ElectroMagnetic Instruments > 